\title{
Recent Progress Concerning the $N$-Arylation of Indoles
}

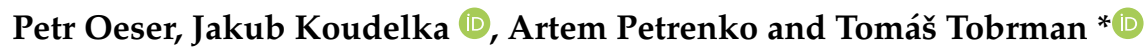 \\ Department of Organic Chemistry, University of Chemistry and Technology, 16628 Prague, Czech Republic; \\ petr.oeser@vscht.cz (P.O.); jakub.koudelka@vscht.cz (J.K.); petrenka@vscht.cz (A.P.) \\ * Correspondence: tomas.tobrman@vscht.cz
}

check for updates

Citation: Oeser, P.; Koudelka, J.; Petrenko, A.; Tobrman, T. Recent Progress Concerning the $N$-Arylation of Indoles. Molecules 2021, 26, 5079. https://doi.org/10.3390/ molecules26165079

Academic Editors: David StC Black and Naresh Kumar

Received: 31 July 2021

Accepted: 18 August 2021

Published: 22 August 2021

Publisher's Note: MDPI stays neutral with regard to jurisdictional claims in published maps and institutional affiliations.

Copyright: (c) 2021 by the authors. Licensee MDPI, Basel, Switzerland. This article is an open access article distributed under the terms and conditions of the Creative Commons Attribution (CC BY) license (https:// creativecommons.org/licenses/by/ $4.0 /)$.

\begin{abstract}
This review summarizes the current state-of-the-art procedures in terms of the preparation of $\mathrm{N}$-arylindoles. After a short introduction, the transition-metal-free procedures available for the $N$-arylation of indoles are briefly discussed. Then, the nickel-catalyzed and palladium-catalyzed $\mathrm{N}$-arylation of indoles are both discussed. In the next section, copper-catalyzed procedures for the $\mathrm{N}$-arylation of indoles are described. The final section focuses on recent findings in the field of biologically active $N$-arylindoles.
\end{abstract}

Keywords: $\mathrm{N}$-arylation; indole; Buchwald-Hartwig amination; Ullmann condensation; ChanLam coupling

\section{Introduction}

Heterocyclic compounds are cyclic compounds that each contain either a heteroatom or a number of heteroatoms. Among the most important groups of heterocyclic compounds are the aromatic heterocyclic compounds. Well-known examples of such compounds include pyridine, pyrrole, thiophene, and furan. Indoles occupy a unique position within the field of heterocyclic compounds. An indole is a condensed compound that is composed of a benzene and pyrrole core. The importance of indoles and their derivatives is illustrated by the examples shown in Figure 1. Tryptophan is an aromatic essential amino acid, and sattazolin [1] and umifenovir [2] are indole derivatives with antiviral effects. $N$ arylated indoles also belong to the group of important indole derivatives. An example of such a compound is sertindole, which is used as an antipsychotic drug [3]. Due to the significant biological activity of the indole derivatives, much attention has been paid to the modification of the indole unit [4-8].

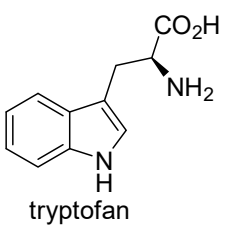

tryptofan

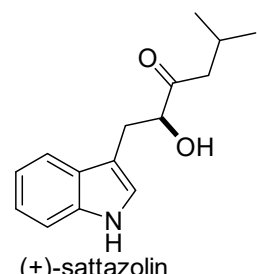

$(+)$-sattazolin

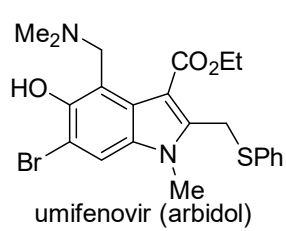

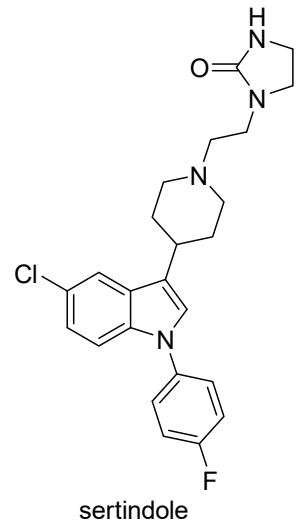

sertindole
Figure 1. Selected examples of important indole derivatives.

The significant biological activity exhibited by sertindole has inspired the search for new procedures for the preparation of $N$-arylindoles. Every indole contains a pyrrole core, so it can be expected that the $N$-arylation of indoles will proceed in a similar manner 
to the $\mathrm{N}$-arylation of pyrroles. Among the group of aromatic heterocyclic compounds with one heteroatom, pyrrole is unique in terms of its reactivity. Unlike pyrrole, modifications of heteroatoms in furan and thiophene to form stable derivatives of the starting compound are not feasible. In some cases, phospholes can be $P$-arylated to form pentasubstituted phospholes [9], although the reactivity of the phosphole is affected by its low aromaticity [10-13]. By contrast, pyrroles can be very easily arylated at position $1[14,15]$ or 2 [16,17]. In addition, the dearomatizations of pyrroles are important [18-22]. Similar reactivity can be expected even in the case of indole arylations. The typical approach for the $\mathrm{N}$-arylation of amines, including nitrogen-containing heteroaromatic compounds, involves the use of transition-metal-catalyzed reactions (Scheme 1). In these cases, Ullman condensation [23-25], Buchwald-Hartwig amination [26-28], and Chan-Lam coupling [29-31] are all frequently used. A common feature of these procedures is the reaction of amines with organohalides or boronic acids in the presence of a transition metal catalyst and a base. A relatively large number of $\mathrm{N}$-arylation reactions of indoles have been reported over the last decade. However, to the best of our knowledge, only a few review articles have addressed the preparation of $N$-arylindoles [32-34]. Thus, we decided to summarize the procedures that have been used for the preparation of $\mathrm{N}$-arylindoles over the past decade. The scope of the present review is limited to works that focused on the $\mathrm{N}$-arylation of indoles or otherwise significantly contributed to this field.

\section{a) Ullmann condensation}

$$
\text { Ar- } \mathrm{X}+\mathrm{HN} \underset{\mathrm{R}}{\mathrm{R} ;} \frac{\mathrm{R}}{\text { base }} \text { Ar }-\mathrm{N}-\frac{\mathrm{R}}{\mathrm{R}-\text {; }}
$$

b) Buchwald-Hartwig amination

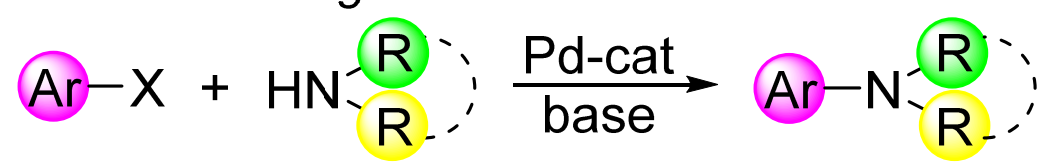

\section{c) Chan-Lam coupling}

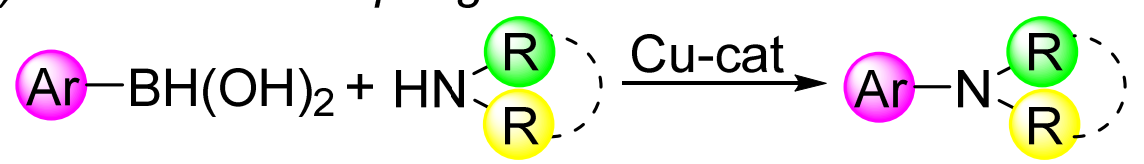

Scheme 1. Transition-metal-catalyzed approaches to $N$-arylamines.

\section{Transition-Metal-Free $\mathrm{N}$-Arylation of Indoles}

The preparation of $N$-arylindoles without transition metal catalysts can be easily carried out using benzynes. This approach was first reported in 2018 (Scheme 2) [35]. In this study, the starting indole S2-1 was treated with 2-bromoacetophenone (S2-2) in the presence of ${ }^{t} \mathrm{BuOK}$ to produce $\mathrm{N}$-phenylindole $\mathbf{S 2 - 3}$ in a $66 \%$ yield. The proposed mechanism accounts for the formation of a benzyne intermediate (S2-6) and ketene (S2-5) from the enolate S2-4. The scope of the reaction is limited to the indole S2-3. However, Chen and Wu published another benzyne-involving route to functionalized indoles, which in contrast, furnishes mainly C3-arylated indole derivatives, along with $\mathrm{N}$-arylated indoles as side-products [36]. 


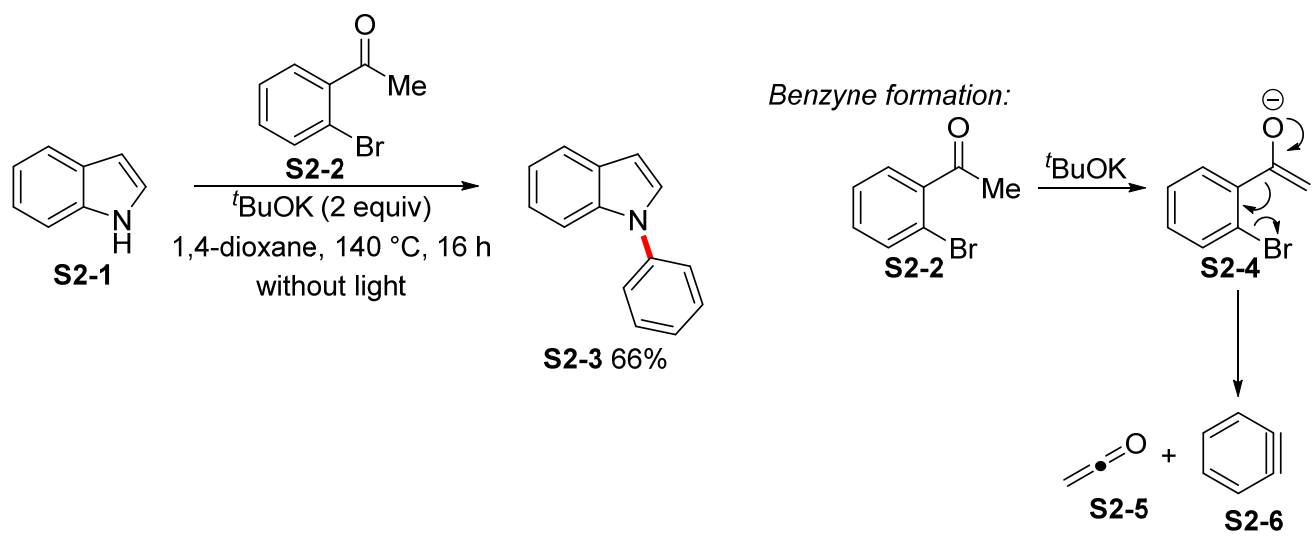

Scheme 2. $N$-arylation of an indole using a benzyne intermediate.

The second and seemingly most frequently used approach is based on nucleophilic aromatic substitution. The intramolecular $N$-arylation of indoles S3-1 was used for the preparation of dibenzo[b,f][1,4]oxazepines S3-3 (Scheme 3) [37]. Based on the general reaction, it appears that the methodology relies on Smiles rearrangement. This assumption has been experimentally confirmed, and the proposed mechanism assumes the formation of diaryl ether S3-4, which is converted into the $N$-arylated indole S3-3 by means of the Smiles rearrangement. Selected examples (S3-3a-S3-3c) show that the described procedure

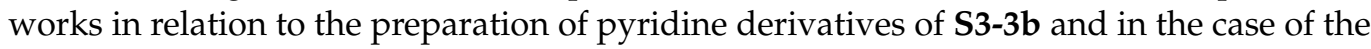
regioisomer S3-3c of the starting materials S3-2.

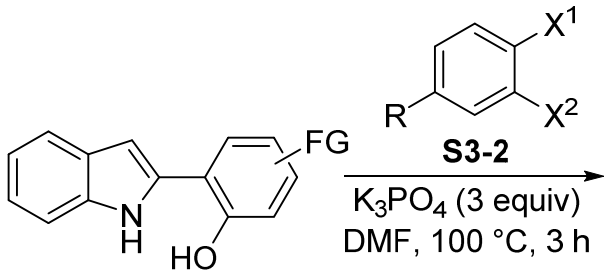

S3-1

$\mathrm{X}^{1,2}=\mathrm{F}, \mathrm{Cl}, \mathrm{NO}_{2}$

Selected examples:<smiles>CC(=O)c1ccc2c(c1)Oc1ccccc1-n1c-2cc2ccccc21</smiles>

S3-3a $66 \%$<smiles>[R]c1ccc2c(c1)Oc1ccccc1-n1c-2cc2ccccc21</smiles>

S3-3 46-99\% 27 examples<smiles>c1ccc2c(c1)Oc1cnccc1-n1c-2cc2ccccc21</smiles>

S3-3b $73 \%$<smiles></smiles>

S3-3c $96 \%$

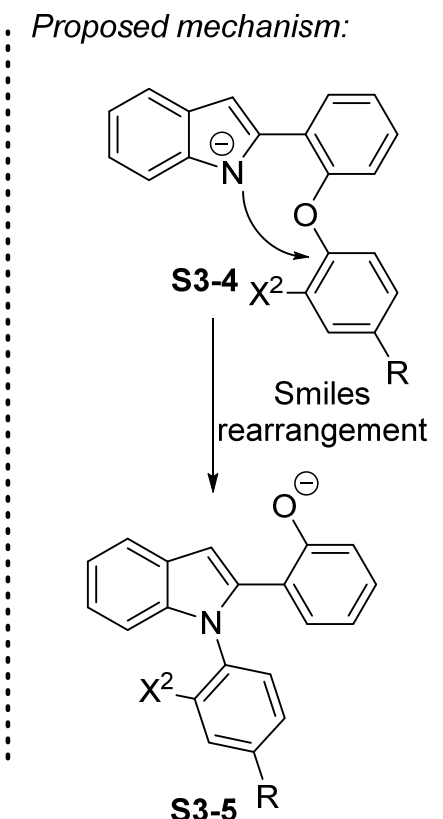

Scheme 3. Preparation of dibenzo[b,f][1,4] oxazepines S3-3 by means of Smiles rearrangement.

A similar concept for the $\mathrm{N}$-arylation of indoles, which is based on intramolecular nucleophilic aromatic substitution, has been described by both Annareddygari [38] and Chen Ma [39] (Scheme 4). The first procedure for the preparation of indolo[1,2-a]quinoxalines S4-3 makes use of the condensation reaction of 2-formylindole S4-1 with substituted anilines S4-2 in N,N-dimethylformamide (DMF) at $120^{\circ} \mathrm{C}$. Similarly, the condensationintramolecular-based transition-metal-free arylation approach was used by Ngernmeesri for the synthesis of indolo[1,2-a]quinolines [40]. Ma's procedure starts with amides S4-4, 
and the $\mathrm{N}$-arylation of the indole is achieved via double intramolecular nucleophilic aromatic substitution. In both cases, the scope of the studied reaction was limited to the preparation of five indole derivatives, S4-6. Intramolecular nucleophilic aromatic substitution has also been used for the preparation of $9 H$-pyrrolo[1,2-a]indol-9-ones and $10 \mathrm{H}$-indolo[1,2-a]indol-10-ones by means of the base-mediated $\mathrm{N}$-arylation of pyrroles and indoles [41].

Annareddygari's synthesis of indolo[1,2-a]quinoxalines:

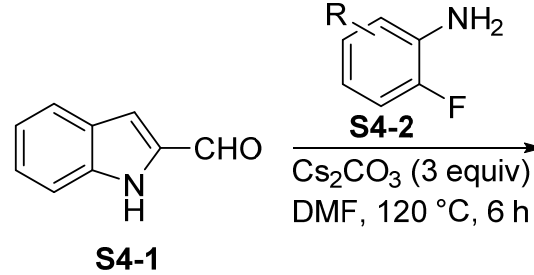

S4-1

Ma's synthesis of indolo[1,2-a]quinoxalines:

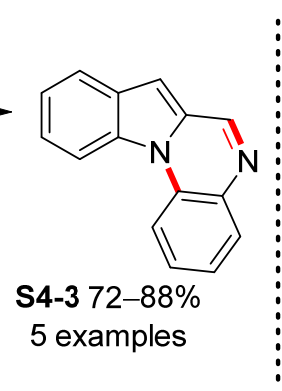<smiles>CC(C)(C)O[Mg]O[Mg]</smiles><smiles>C/C=C\CC1(C(=O)Br)N=Cc2cc3ccccc3n2-c2cc(Br)cc(Br)c21</smiles>

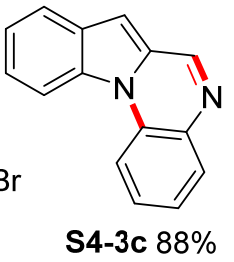

S4-3b $78 \%$

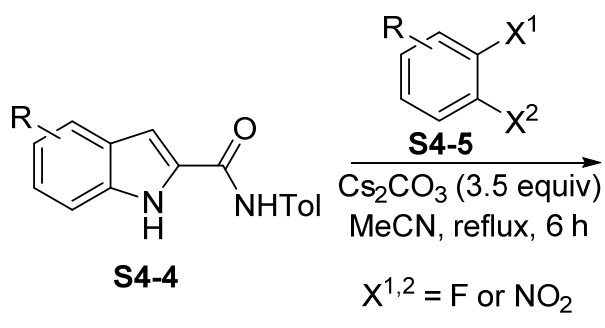<smiles>O=c1c2cc3ccccc3n2c2ccccc2n1[AlH2]</smiles>

S4-6 $73-92 \%$ 5 examples

\section{S4-3a $84 \%$}

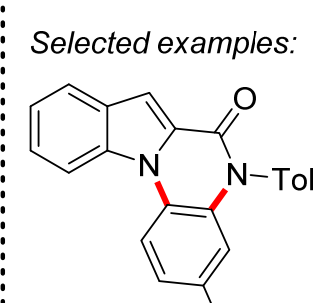

S4-6a $73 \% \mathrm{NO}_{2}$<smiles></smiles>

S4-6b $92 \%$

Scheme 4. Transition-metal-free syntheses of indolo[1,2-a]quinoxalines.

Intermolecular nucleophilic aromatic substitution can also be used to prepare $N$ arylindoles (Scheme 5). This concept for the preparation of $N$-arylindoles is usually based on the reaction of aryl fluorides with indoles under basic conditions. Diness et al. developed two procedures for the preparation of $N$-arylindoles. In the first procedure, the reaction of pentafluorobenzene with an indole in the presence of ${ }^{t} \mathrm{BuONa}$ afforded $N$-arylindole S5-2, which was then used for the preparation of pentasubstituted benzene (Scheme 5, Diness's $N$-arylation of indoles) [42]. The analogous reaction with a halogenated aromate containing only one fluorine atom proceeded under harsh reaction conditions, as illustrated by the selected synthesis of indole S5-3. However, the overall reaction scope was limited to three examples of $N$-arylated indoles [43]. Similar reaction conditions were used for the preparation of bis $\mathrm{N}$-arylindoles with structures represented by the indole S5-5 (Scheme 5, Chang's $N$-arylation of indoles). The prepared $N$-arylindoles were polymerized, and their optical and electrochemical properties and thermal stability were determined [44]. The results summarized in Scheme 5 indicate that the use of nucleophilic aromatic substitution for the preparation of $N$-arylindoles proceeds best in the case of pentafluorobenzenes. This conclusion was confirmed by the work of Zhang [45], who prepared a series of tetrafluorophenylbenzenes through the reaction of indoles with pentafluorobenzenes in the presence of sodium hydroxide under mild reaction conditions (Scheme 5, Zhang's $N$-arylation of indoles). Similar reaction conditions ( $\left.\mathrm{KOH}, \mathrm{DMSO}, 100{ }^{\circ} \mathrm{C}, 24 \mathrm{~h}\right)$ were used by Hua to prepare a series of $N$-arylated indoles ( 23 compounds, $24-87 \%$ isolated yields) [46]. 
Diness's $N$-arylation of indoles by $S_{N}$ Ar of aryl fluorides:

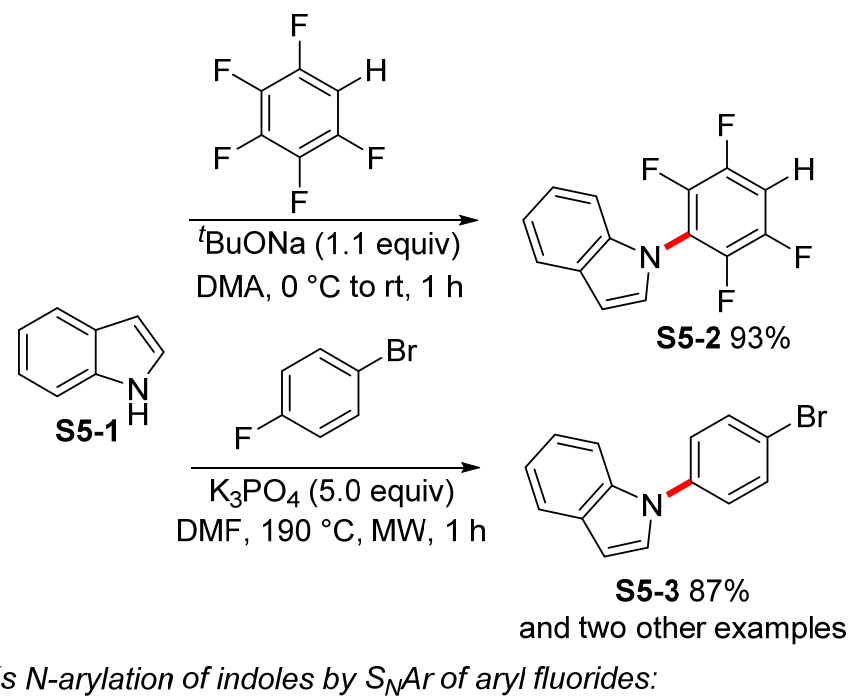

Chang's $N$-arylation of indoles by $S_{N} A r$ of aryl fluorides:

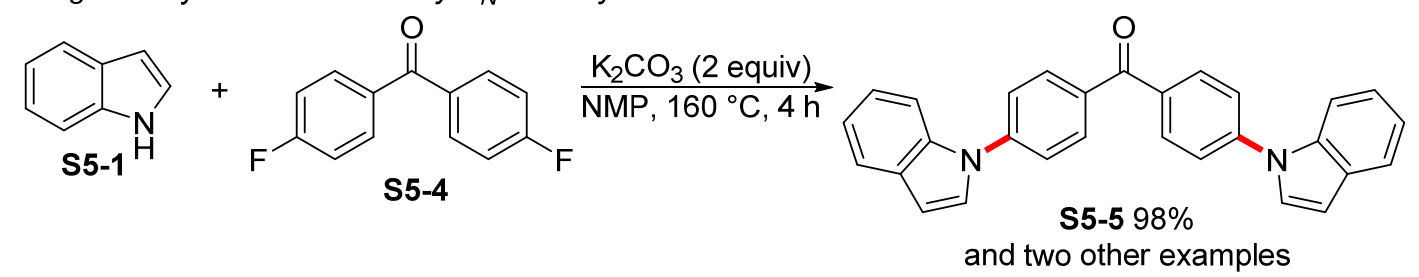

Zhang's $N$-arylation of indoles by $S_{N} A r$ of aryl fluorides:

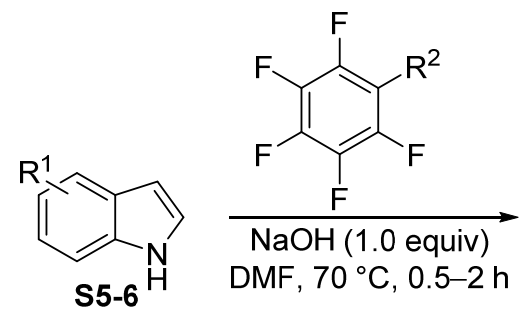<smiles>[R1]c1ccc2c(ccn2-c2c(F)c(F)c([R])c(F)c2F)c1CCCCCCCC</smiles>

S5-7 66-88\% 18 examples :
Selected examples:<smiles>COc1ccc2c(ccn2-c2c(F)c(F)c(C)c(F)c2F)c1</smiles>

Scheme 5. Intermolecular nucleophilic aromatic substitution for the synthesis of $N$-arylindoles.

In addition to the above-mentioned procedures for the transition-metal-free arylation of indoles by means of intermolecular nucleophilic aromatic substitution, other procedures have also been used to achieve limited $N$-arylation of indoles as parts of general procedures for the preparation of $N$-arylated amines. Such works include the preparation of benzimidazole-pyrrolo[1,2-a]quinoxaline [47], arene-metal $\pi$-complexation mediated C-H arylation [48], base-promoted nucleophilic fluoroarene substitution of C-F bonds [49], and the preparation $\mathrm{N}$-arylation of amines via triarylsulfonium triflates [50].

The organocatalytic preparation of $N$-aryl carbazoles and indoles was reported in 2020 (Scheme 6) [51]. The reaction between the azonaphthalene S6-2 and $N$-nucleophiles was catalyzed by chiral phosphoric acid derivatives. Although the majority of reported $N$ arylations have been performed on carbazole (26 examples), the reaction has also been used for the preparation of ten $N$-arylindoles. It was proposed that the formation of the reaction products S6-3 involves the asymmetric nucleophilic addition of indoles S6-1 to the reaction center, and that the final product of the reaction S6-3 is obtained via rearomatization. Unfortunately, the scope of the reaction was limited to azonaphthalene S6-2, and the scope of the indoles was also limited. 


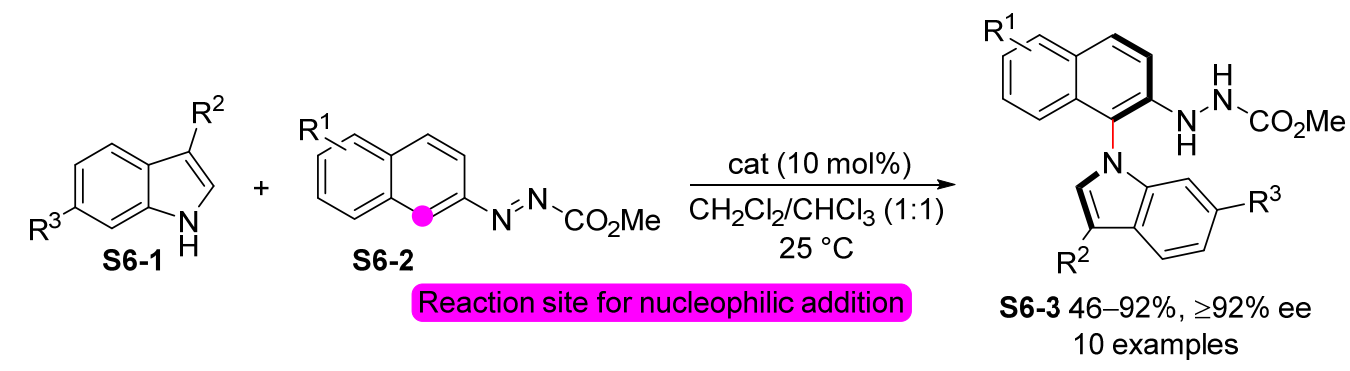

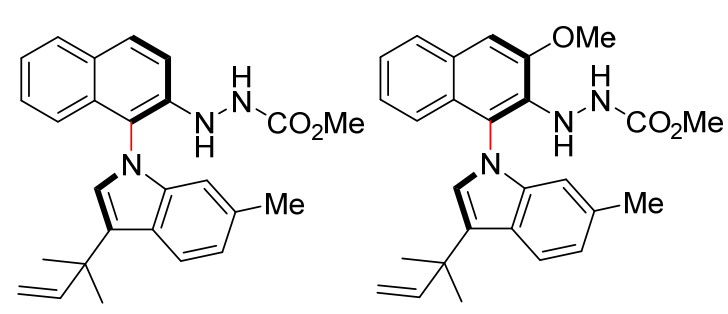

S6-3a $52 \%, 93 \%$ ee

S6-3b $47 \%, 92 \%$ ee

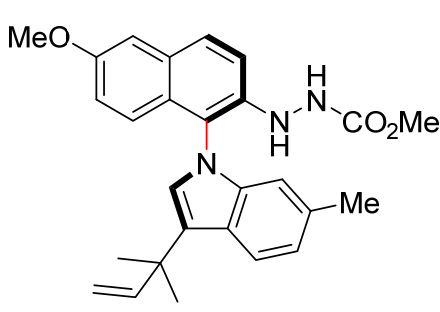

S6-3c $46 \%, 92 \%$ ee

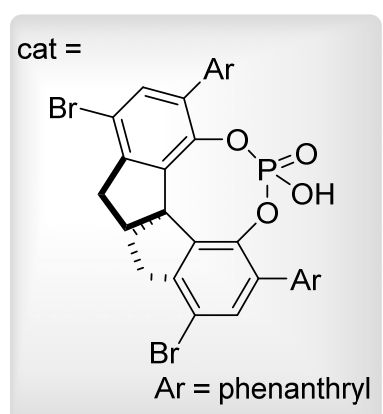

Scheme 6. Atroposelective $\mathrm{N}$-arylation of indoles by arene $\mathrm{C}-\mathrm{H}$ amination.

A different approach to the $\mathrm{N}$-arylation of indoles, which involves aza-Michael addition and aromatization, was reported in 2018 (Scheme 7) [52]. The developed methodology is based on the reaction of azoles with cyclohexa-2,4-dienones in the presence of a catalytic amount of scandium triflate in acetonitrile. The procedure can be used for the regioselective preparation of $N$-aryl pyrazoles, 1,2,4-triazoles, benzimidazoles, and 1,2,3-benzotriazoles in high yields. In the case of substituted indoles, the low selectivity of the arylation reaction was observed. Thus, 3-methylindole S7-1a reacted with the starting dienone to form a mixture of C2- and N-arylated indoles S7-2a and S7-3a. By contrast, 3-ethylindole $\mathbf{S 7 - 1 \mathbf { b }}$ exclusively gave $\mathrm{N}$-arylindole $\mathbf{S 7 - 2} \mathbf{b}$ in a $75 \%$ yield. The observed reactivity was not explained.
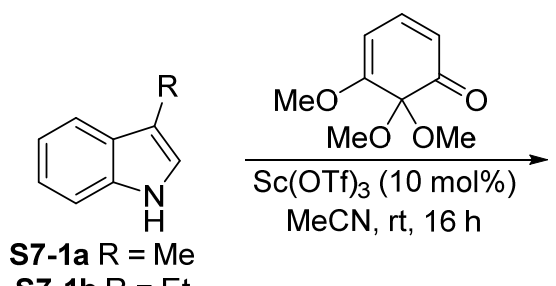

$$
\text { S7-1b R = Et }
$$<smiles>[R]c1c(-c2cc(O)c(OC)c(OC)c2)[nH]c2ccccc12</smiles>

S7-3a $35 \%, R=M e$

S7-2a $35 \%, R=M e$

S7-2b $75 \%, R=E t$

Scheme 7. Synthesis of $N$-arylindoles via an aza-Michael addition and aromatization sequence.

The transition-metal-free synthesis of $N$-arylindoles S8-3 from 1,2-allenic ketones S8-2 and variously substituted indoles S8-1 via a $\mathrm{Cs}_{2} \mathrm{CO}_{3}$-promoted tandem benzannulation reaction has recently been demonstrated by $\mathrm{Li}$ et al. (Scheme 8) [53]. The substrate scope with respect to both indoles S8-1a and S8-1b and allenic ketones S8-2 is quite broad. Interestingly, the C2-substituted indoles were either unreactive or reacted poorly under the reaction conditions, likely due to steric hindrance. A mechanism that involves a series of Michael additions followed by cyclization and benzannulation may be operative, as proposed by the authors. 
<smiles>[R]C=Cc1ccc[nH]1</smiles>

S8-1a $R=M e$ S8-1b $R=E t$

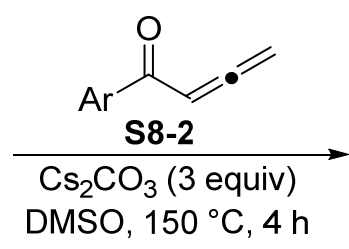

(2)<smiles>[R]c1cccc2ccn(-c3cc([Al])cc(C)c3C(=O)[Al])c12</smiles>

S8-3 22-82\%

Selected examples: 23 examples<smiles>Cc1cccc(C(=O)c2c(C)cc(-c3cccc(C)c3)cc2-n2ccc3ccccc32)c1</smiles>

S8-3a $82 \%$<smiles>Cc1cc(-c2cccs2)cc(-n2ccc3ccccc32)c1C(=O)c1cccs1</smiles>

S8-3b 68\%<smiles>Cc1cc(-c2ccccc2)cc(-n2ccc3c(Br)cccc32)c1C(=O)c1ccccc1</smiles>

S8-3c $34 \%$<smiles>Cc1cc(-c2ccccc2)cc(-n2ccc3ccc([N+](=O)[O-])cc32)c1C(=O)c1ccccc1</smiles>

S8-3d 22\%

Scheme 8. Cascade benzannulation for the synthesis $N$-arylated indoles.

\section{Transition-Metal-Catalyzed $N$-Arylation of Indoles}

\subsection{Nickel-Catalyzed N-Arylation of Indoles}

Nickel(0) complexes are highly reactive toward oxidative addition, and therefore, nickel catalysts are used for the cross-coupling reactions of aryl chlorides. Rull [54] was the first to report the $\mathrm{Ni}(0)$-catalyzed arylation of indole S9-1 using aryl chlorides S9-2 (Scheme 9). The $N$-arylations were carried out using the [(IPr)Ni(styrene) $\left.)_{2}\right]$ complex [IPr=1,3-Bis(2,6-diisopropylphenyl)imidazol-2-ylidene] in the presence of ${ }^{t} \mathrm{BuOLi}$ in $1,4-$ dioxane at $100{ }^{\circ} \mathrm{C}$. As illustrated by selected examples S9-3a-S9-3h, the yields of the $N$-arylindoles were high. No reaction was observed with aryl chlorides bearing trifluoromethyl and benzoyl groups or ortho-substituted chlorobenzenes. Yet, the preparation of indoles with heteroaryl substituents required $10 \mathrm{~mol} \%$ of the catalyst loading to achieve high yields of the corresponding indoles S9-3g and S9-3h. The need to use $10 \mathrm{~mol} \%$ of the catalyst was explained by the competitive coordination of heteroaryl halide during the $N$-arylation reaction.

Different catalytical systems for the $N$-arylation of indoles were studied by Stradiotto [55], who investigated the reactivity of DPPF-based ligands (Scheme 10) during the $\mathrm{Ni}(0)$-catalyzed $\mathrm{N}$-arylation of indoles (Scheme 10). Heteroaryl chlorides were coupled with alkylamines and indole in the presence of ten structurally diverse $1,1^{\prime}$ bis(bis(alkyl/aryl)phosphino)ferrocene ligands $\left(\mathrm{L}^{\mathrm{X}}\right)$ and $\mathrm{Ni}(\mathrm{COD})_{2}$. The electron-poor ligand $\mathrm{L}^{\mathrm{CF} 3}$ proved to be extremely potent. It was the only ligand that gave the $N$-arylated indole S10-3a bearing a naphthyl substituent in a $80 \%$ yield. By contrast, the $N$-arylation of an indole with 4-chlorobenzonitrile proceeded efficiently with several $\mathrm{L}^{\mathrm{X}}$ variants, including $\mathrm{L}^{i \mathrm{Pr}}, \mathrm{L}^{\mathrm{Cy}}, \mathrm{L}^{\mathrm{Ph}}, \mathrm{L}^{\mathrm{CF} 3}, \mathrm{~L}^{\mathrm{OMe}}$, and $\mathrm{L}^{\mathrm{Me}}$. The amination of 4-chloroquinaldine with the ligand $\mathrm{L}^{\mathrm{Ph}}$ represents the first room-temperature $N$-arylation of an indole. In addition, ligands with ortho-substituted phenyl ( $\mathrm{L}^{\text {o-tol }}$ and $\left.\mathrm{L}^{1-n a p}\right)$, a sterically demanding dialkylphosphino group $\left(\mathrm{L}^{t \mathrm{Bu}}\right)$, and difuranylphosphino variants $\left(\mathrm{L}^{\text {fur }}\right)$ proved ineffective under the studied conditions. The comparable catalytic performance of $\mathrm{L}^{\mathrm{Ph}}, \mathrm{L}^{\mathrm{CF} 3}$, and $\mathrm{L}^{\mathrm{OMe}}$ in the studied nickel-catalyzed $N$-arylations suggests that the electronic perturbations arising from arylphosphine substitution do not significantly affect the behavior of nickel in this branch of chemistry. 


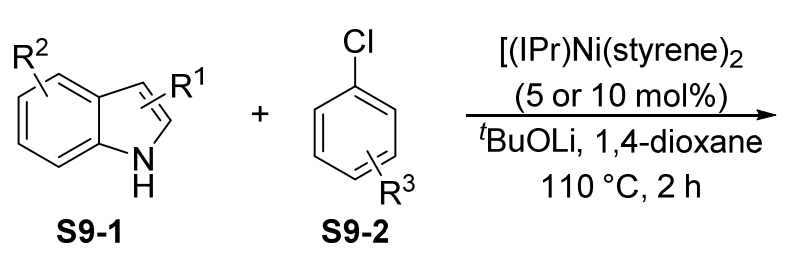

Selected examples ( 5 mol\% of the catalyst):<smiles>c1ccc(-n2ccc3ccccc32)cc1</smiles>

S9-3a $85 \%$<smiles>c1ccc2cc(-n3ccc4ccccc43)ccc2c1</smiles>

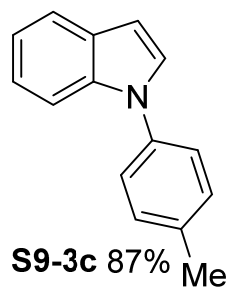

S9-3c $87 \% \mathrm{Me}$<smiles></smiles>

S9-3 51-95\%

30 examples<smiles>Cc1ccc(-n2c(C)cc3ccccc32)cc1</smiles>

Selected examples (10 mol\% of the catalyst):<smiles>c1ccc(-n2ccc3ccccc32)nc1</smiles>

S9-3f $80 \%$<smiles>Cc1cn(-c2ccccn2)c2ccccc12</smiles>

S9-3g $84 \%$<smiles>Cc1cc2ccccc2n1-c1ccc2ccccc2n1</smiles>

Scheme 9. Scope of the $\mathrm{N}$-arylation of indoles with aryl chlorides catalyzed by [(IPr)Ni(styrene $\left.)_{2}\right]$.

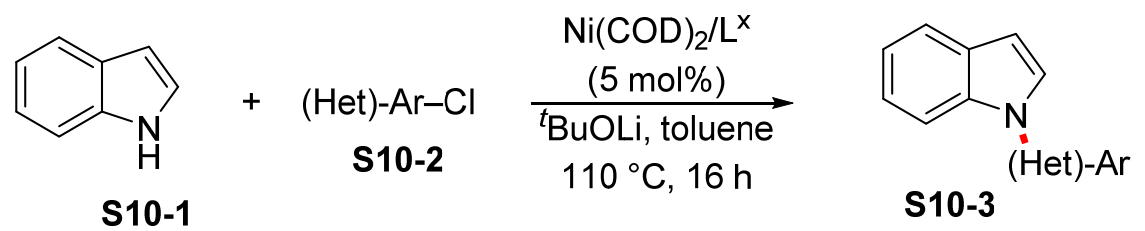


via the reaction with cyanuric chloride (TCT) in 1,4-dioxane in the presence of a base. The conditions for the formation of the cyanuric acid ester S11-4 were obtained through extensive optimization. For example, the $N$-arylation of indole S11-1 with activated phenol S11-4 was performed using the $\mathrm{NiCl}_{2}$ (dppf) catalytic system to give the $\mathrm{N}$-arylated indole S11-3 in a 78\% yield. Morpholine, carbazole, indoline, and pyrazole are examples of the other tested amines.
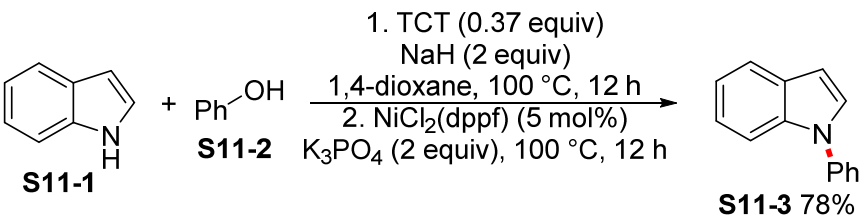

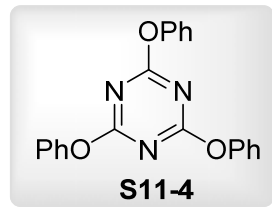

Scheme 11. Ni-catalyzed $\mathrm{N}$-arylation of phenols via $\mathrm{C}-\mathrm{O}$ bond activation by means of a TCT reagent.

The nickel-catalyzed decarbonylation of substituted $N$-acyl indoles S12-1 represents another approach for the preparation of $\mathrm{N}$-arylated indoles (Scheme 12) [57]. Two conditions were optimized for the $\mathrm{Ni}(0)$-catalyzed decarbonylation of the starting indoles. First, stoichiometric amounts of $\mathrm{Ni}(\operatorname{cod})_{2}$ and $\mathrm{PC}_{3}$ preferred quantitative decarbonylation at $80^{\circ} \mathrm{C}$ (Condition A). Second, catalytic decarbonylation was achieved through the use of the 1,2-ethanediylbis[dicyclohexyl]phosphine (dcype) ligand at $180^{\circ} \mathrm{C}$ (Condition B). Condition $\mathrm{B}$ proved to be suitable for $\mathrm{N}$-acylindoles bearing an electron withdrawing group, whereas Condition A was suitable for $\mathrm{N}$-acylindoles bearing an acyl group with electronneutral and electron-rich substituents. Selected examples S12-2a-S12-2f indicate that this method tolerates esters, nitriles, and the ketone functional group. In addition to benzoic acid derivatives, this method has proven suitable for the formation of $\mathrm{N}$-alkenylindoles S12-2e and $N$-heteroarylindoles S12-2f.<smiles>[R]c1ccc(-n2ccc3ccccc32)cc1</smiles>

A: $\mathrm{Ni}(\mathrm{cod}){ }_{2}(100 \mathrm{~mol} \%), \mathrm{PCy}_{3}(100 \mathrm{~mol} \%), 80^{\circ} \mathrm{C}$

B: $\mathrm{Ni}(\mathrm{cod})_{2}(20 \mathrm{~mol} \%)$, dcype $(20 \mathrm{~mol} \%), 180^{\circ} \mathrm{C}$<smiles>N#Cc1ccc(-n2ccc3ccccc32)cc1</smiles>

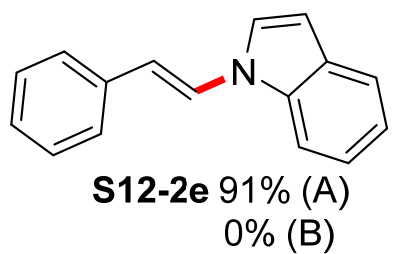<smiles>CC(=O)c1ccc(-n2ccc3ccccc32)cc1</smiles><smiles>[R16]c1ccc2ccc(-n3ccc4ccccc43)cc2n1</smiles>

Scheme 12. Ni-catalyzed decarbonylation of $N$-acylated heteroarenes. 
Recently, the use of $\mathrm{NiO}$ nanoparticles for the $\mathrm{N}$-arylation of indoles by means of the reaction of boronic acids with indoles in the presence of $\mathrm{NiO}$ nanoparticles as a catalyst has been reported [58]. Pure $\mathrm{NiO}$ nanoparticles were prepared using the quercetin-mediated (F2-1, Figure 2) hydrothermal method.<smiles>O=c1c(O)c(-c2ccc(O)c(O)c2)oc2cc(O)cc(O)c12</smiles>

F2-1

Figure 2. The structure of quercetin.

In addition to the above-mentioned nickel-based catalytic systems for the $N$-arylation of indoles, the use of nickel catalysts F3-1 [59], F3-2 [60], F3-3 [61], F3-4 [62], and Ni(COD) 2 with a polymeric triazine-phosphite ligand [63] for the reaction of amines or heterocycles with electrophiles has also been reported (Figure 3). A unique procedure for the preparation of $N$-aryl amines and indoles makes use of the nickel-catalyzed decarbonylative amination of carboxylic acid esters [64]. However, such procedures have mainly been developed for the $N$-arylation of amines, whereas the $N$-arylation of indoles has been achieved for only a limited number of indole derivatives.<smiles>CN1CCN(C)P12(c1ccccc1P)c1ccccc1C#CCc1ccccc12</smiles>

F3-1<smiles>Cc1ccccc1N1C=C2C=CC=C2P(c2ccccc2)P(c2ccccc2)(c2ccccc2)(c2ccccc2)c2cccc(c2)[PH]1(Cl)c1ccccc1</smiles>

F3-2

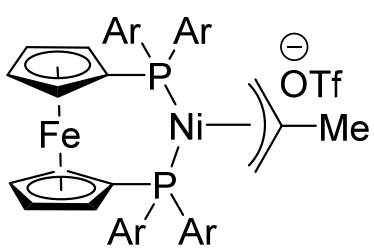

$\mathrm{Ar}=3,5-\left(\mathrm{CF}_{3}\right)_{2} \mathrm{C}_{6} \mathrm{H}_{3}$

F3-3<smiles>Cc1cc(C)c(P(=P)(Br)c2ccccc2P(c2ccccc2)c2ccccc2)c(C)c1</smiles>

F3-4

Figure 3. Examples of nickel catalysts used for the $N$-arylation of amines.

\subsection{Palladium-Catalyzed N-Arylation of Indoles}

Similarly to the palladium-catalyzed arylation of pyrroles, the formation of 1,2 , and 3-arylated indoles can also be observed in the palladium-catalyzed arylation of indoles (Scheme 13) [65-67]. The regioselectivity of palladium-catalyzed indole arylation can be influenced by the detailed optimization of the reaction conditions. This was demonstrated in 2019 by Zhang et al., who reported the palladium-catalyzed cascade decarboxylative arylation of indoles [68]. The authors optimized the course of the reaction of indolyl carboxylic acids S13-1 with diaryliodonium salts S13-2 and determined that N1/C2 or C2/C3 arylations of indoles can be performed with high regioselectivity. The reaction allows the introduction of variously substituted biphenyls. The proposed key intermediates for both C2/C3 and N1/C2 arylation, S13-5 and S13-6, show that the N-arylation of indoles is the first step in N1/C2 arylation. However, the C3 arylation of the starting material occurs first in the case of C2/C3 arylation of the starting indolyl carboxylic acid S13-1. 


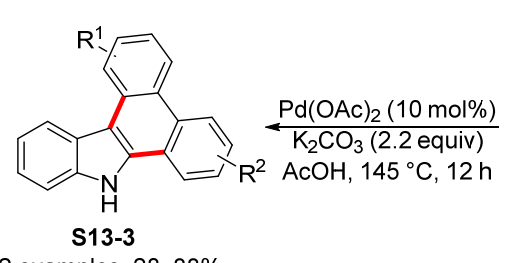

12 examples, $28-88 \%$

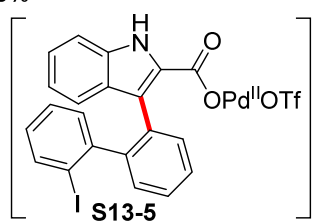

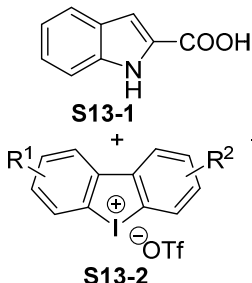

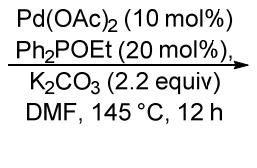

S13-2

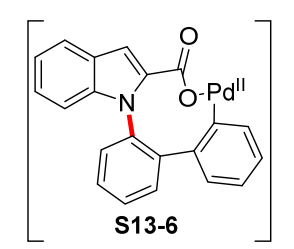

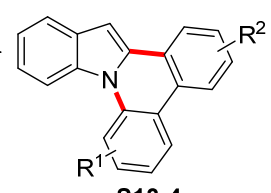

S13-4

20 examples, $46-99 \%$

Scheme 13. Palladium-catalyzed site-selective N1/C2 and C3/C2 arylation of indoles.

A different approach for the preparation of diarylated indoles was reported in 2020 (Scheme 14) [69]. Muller et al. used 5-bromoindole to prepare diarylated indoles via sequential Suzuki reaction and Buchwald-Hartwig amination. The Suzuki reaction was performed first to avoid any side reactions. The subsequent amination reaction uses the same catalytic system as the Suzuki reaction, although potassium carbonate is used instead of CsF. Selected examples S14-2a and S14-2b illustrate how the Suzuki reaction of bromoindole S14-1 with 1-naphthylboronic acid gives worse yields of the indole S14-2b than the Buchwald-Hartwig amination with naphthyl bromide. This approach is also suitable for the preparation of diarylated carbazoles and $10 H$-phenothiazines.

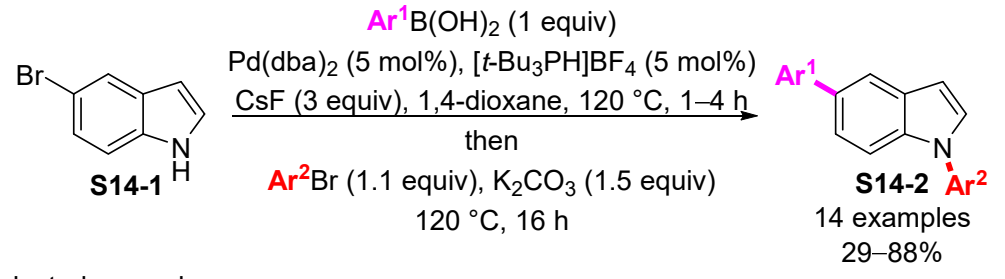

Selected examples:
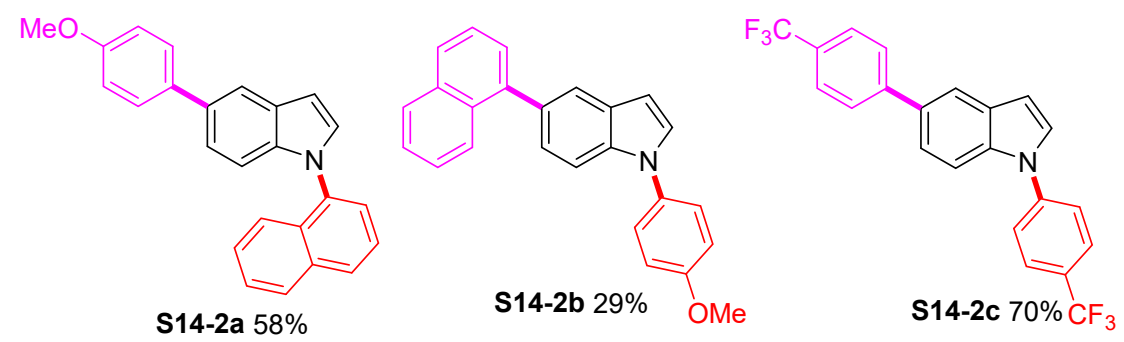

Scheme 14. Sequential Suzuki arylation and Buchwald-Hartwig amination for the synthesis of $N$-arylated indoles.

An alternative approach to $N$-arylated indoles utilizes reactions the substituted indole S15-1 with substrates with activated $\mathrm{C}-\mathrm{O}$ and $\mathrm{C}-\mathrm{N}$ bonds. Selected examples are presented in Scheme 15. In some cases, the palladium-catalyzed reaction of quaternary ammonium salts with indoles in the presence of potassium tert-butoxide can be used to prepare $N$ arylated indoles, although the reported scope of the reaction is limited to the preparation of four simple $N$-arylindoles, S15-4. However, the synthesis of $N$-alkylated indoles by means of this approach is convenient [70]. Additionally, tosylates are sufficiently reactive for the preparation of $N$-arylindoles. In this way, a large group of quinazolines S15-2 were prepared in high isolated yields, although similar nonaflates do not react under the developed reaction conditions [71]. A similar approach for the synthesis of $N$-arylindoles S15-3 was reported in 2018 by Kwong, albeit with a significantly narrower scope [72]. 
<smiles>[R]c1ccc2nc(Br)nc(-n3ccc4cc[R]cc43)c2c1</smiles>

S15-2

24 examples 58-92\%<smiles>[Mg]Cc1nc(Br)c2ccccc2n1</smiles>

$\operatorname{Pd}(\mathrm{TFA})_{2}(5 \mathrm{~mol} \%)$

SPhos (10 mol\%)

$\mathrm{K}_{2} \mathrm{CO}_{3}$ (2 equiv) toluene, $110^{\circ} \mathrm{C}$
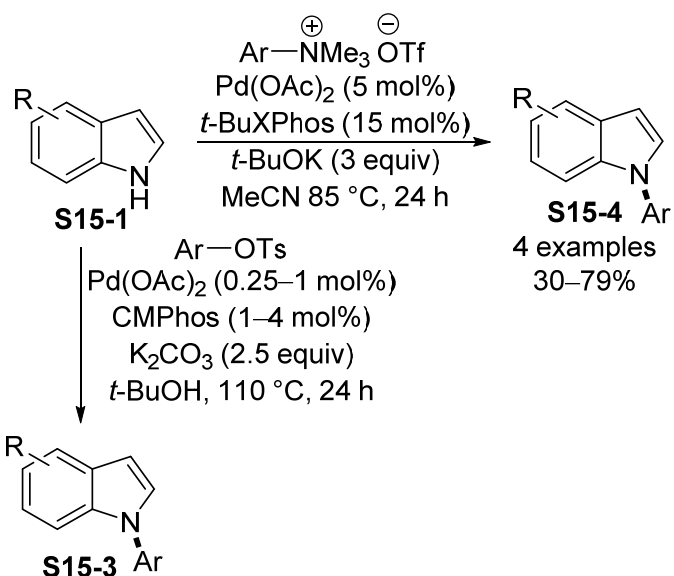

8 examples

72-99\%

Scheme 15. Palladium-catalyzed $N$-arylation of indoles via the reactions with substrates with activated $\mathrm{C}-\mathrm{O}$ and $\mathrm{C}-\mathrm{N}$ bonds.

A hydrogen-transfer-mediated cross-coupling reaction can also be used for the preparation of $N$-arylindoles (Scheme 16) [73]. The starting material, as represented by the structure of substituted indolines S16-1, reacts with 2-naphthols and their derivatives in the presence of $\mathrm{Pd} / \mathrm{C}$ and sodium methoxide. Optimized conditions were applied to prepare 27 indole derivatives S16-2 with a naphthyl group at position 1 . The reaction can tolerate, for example, an ester and a hydroxy functional group. However, 1-naphthols do not react under the optimized reaction conditions, as illustrated in Scheme 16. The proposed mechanism assumes the formation of active catalyst S16-5 by means of the reaction of $\mathrm{Pd}(0)$ with indoline. The resultant palladium catalyst S16-5 subsequently hydrogenates 2-naphthol S16-6 to form the intermediate S16-7. The final reaction product is formed by the condensation of intermediate S16-7 with indoline S16-1a, followed by palladium-mediated dehydrogenation.

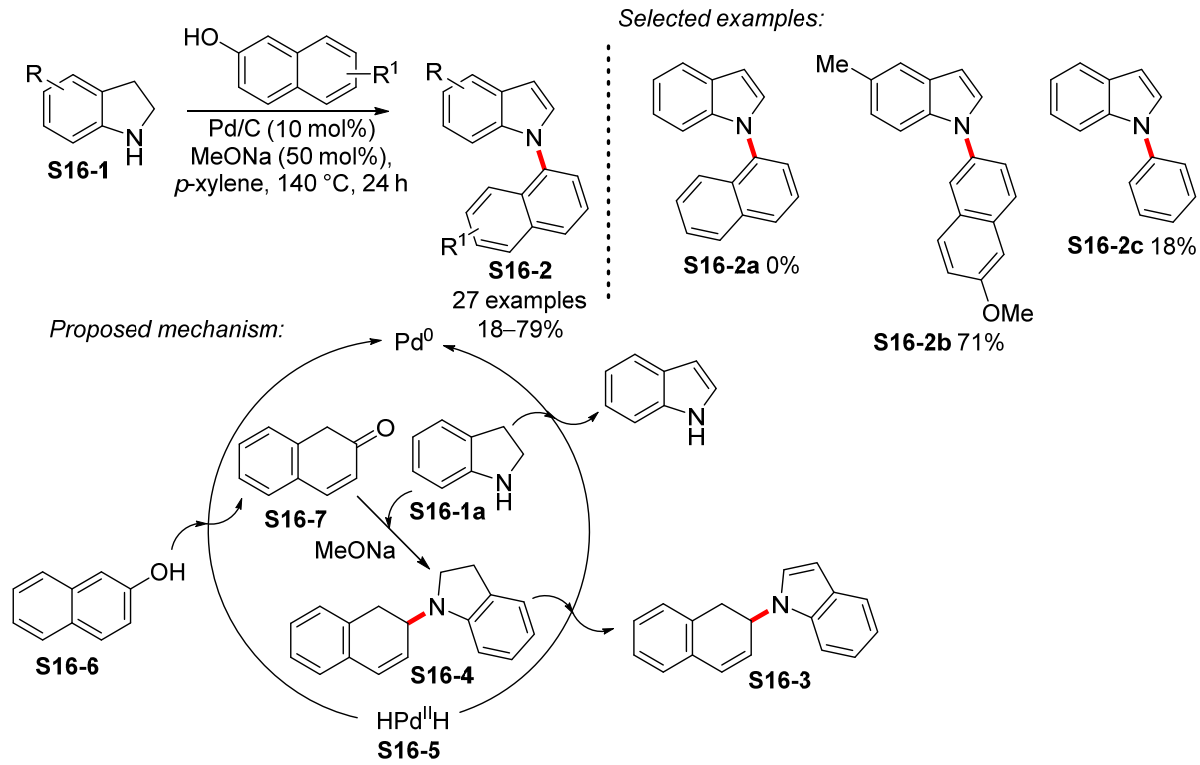

Scheme 16. Hydrogen-transfer-mediated $N$-arylation of indolines en route to $N$-arylated indoles. 
The two-step one-pot procedure for the preparation of $N$-arylindoles relies on the palladium-catalyzed cyclization of 2-bromophenethylamines $\mathbf{S 1 7 - 1}$, which is followed by the palladium-catalyzed $N$-arylation of the resulting indoles S17-2a (Scheme 17) [74]. The optimization of the reaction conditions revealed that the cyclization of amines S17-1 into indoles S17-3 must be carried out at $200{ }^{\circ} \mathrm{C}$. Running the same cyclisation reaction at $140{ }^{\circ} \mathrm{C}$ exclusively produces indoline derivatives S17-2b and intermediates. In the next step, the arylation of the resulting indole S17-2a is performed using the same catalytic system at $180^{\circ} \mathrm{C}$.

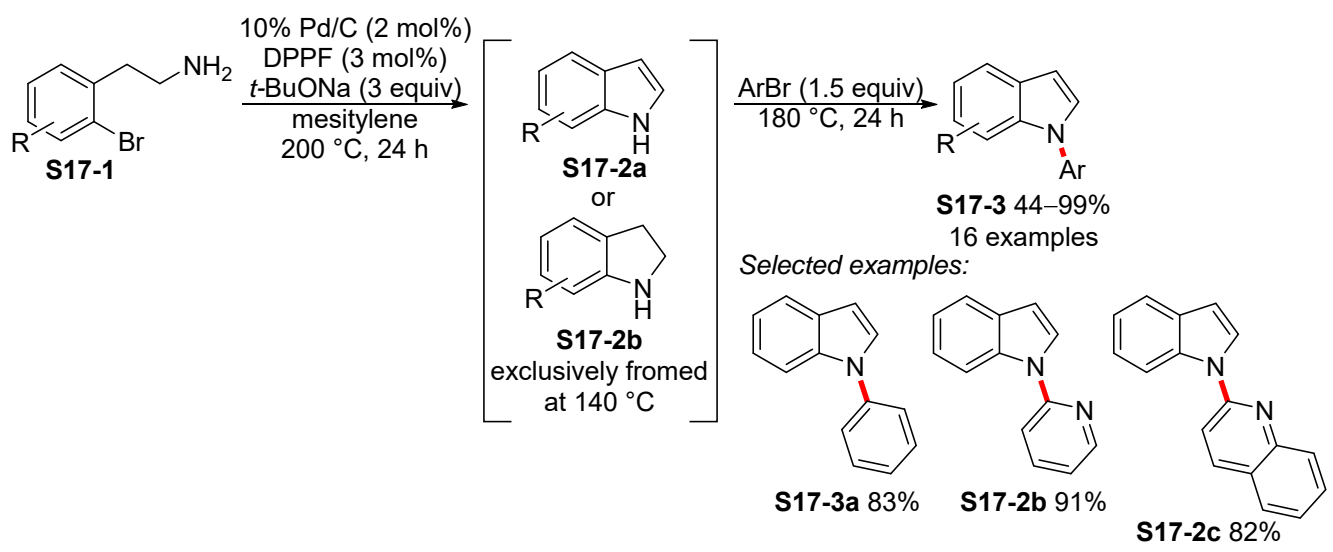

Scheme 17. Palladium-catalyzed one-pot synthesis of $N$-arylated indoles.

A similar approach for the preparation of $N$-arylated indoles was reported by Stradiotto (Scheme 18) [75]. In this case, the starting alkynes S18-1 reacts with ammonia to form indole-based intermediates S18-3. In the next step, the $N$-arylation of the resulting indole is performed using the same catalytic system in the presence of potassium tert-butoxide. This procedure led to the preparation of 13 indole derivatives. From the selected examples S18-2a-S18-2e, it is evident that the $N$-arylation of indoles also tolerates ortho-disubstituted aryl halides. The reaction conditions for the $N$-arylation of indoles developed in relation to the two-step one-pot procedure can also be used for the $N$-arylation of independently prepared indoles.<smiles>[R]C#Cc1[R1]csc1Br</smiles>

$R$ BippyPhos/[Pd(cinnamyl)Cl] 2 (4 mol\%/1 mol\%) $110^{\circ} \mathrm{C}, 3$ then $\operatorname{ArX}^{2}$ (1 equiv)

BippyPhos/[Pd(cinnamyl)Cl] 2 (4 mol\%/1 mol\%) $t$-BuOK (1.4 equiv), toluene, $110^{\circ} \mathrm{C}, 8 \mathrm{~h}$<smiles>[R]c1cc2[R4](F)ccc2n1[Ga]</smiles>

S18-2

13 examples $54-88 \%$<smiles>[R]c1cc2cc(C)ccc2[nH]1</smiles><smiles>Cc1cccc(C)c1-n1c(-c2ccccc2)cc2ccccc21</smiles>

S18-2a $82 \%$ $\left(X^{1,2}=C l\right)$<smiles>CCCc1cc2ccccc2n1-c1c(C)cccc1C</smiles>

S18-2b 69\% $\left(X^{1}=C l, X^{2}=B r\right)$

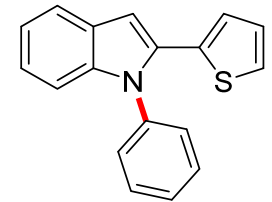

S18-2c $82 \%$ $\left(X^{1}=\mathrm{Cl}, \mathrm{X}^{2}=\mathrm{Br}\right)$<smiles>c1ccc(-c2cc3ccccc3n2-c2ccccc2)cc1</smiles>

S18-2d $71 \%$

$\left(\mathrm{X}^{1,2}=\mathrm{Cl}\right)$

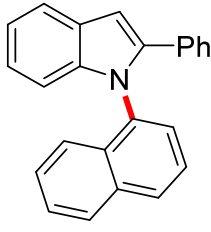

S18-2e $81 \%$ $\left(\mathrm{X}^{1}=\mathrm{Cl}, \mathrm{X}^{2}=\mathrm{Br}\right)$

Scheme 18. Double $N$-arylation for the preparation of $N$-arylated indoles. 
Recently, a series of papers have been published on the $\mathrm{N}$-arylation of indoles using palladium catalysts immobilized on mesoporous silica SBA-15 [76,77], carbon nanotubes [78], or magnetic $\mathrm{Fe}_{3} \mathrm{O}_{4}$ nanoparticles [79]. Scheme 19 illustrates the immobilization of the palladium catalyst on the surface of SBA- 15 through the coordination of palladium to the amidoxime group [76]. The major advantages offered by immobilized catalysts are their recyclability and reusability. This was demonstrated by reusing the immobilized catalyst in five catalytic cycles [76].
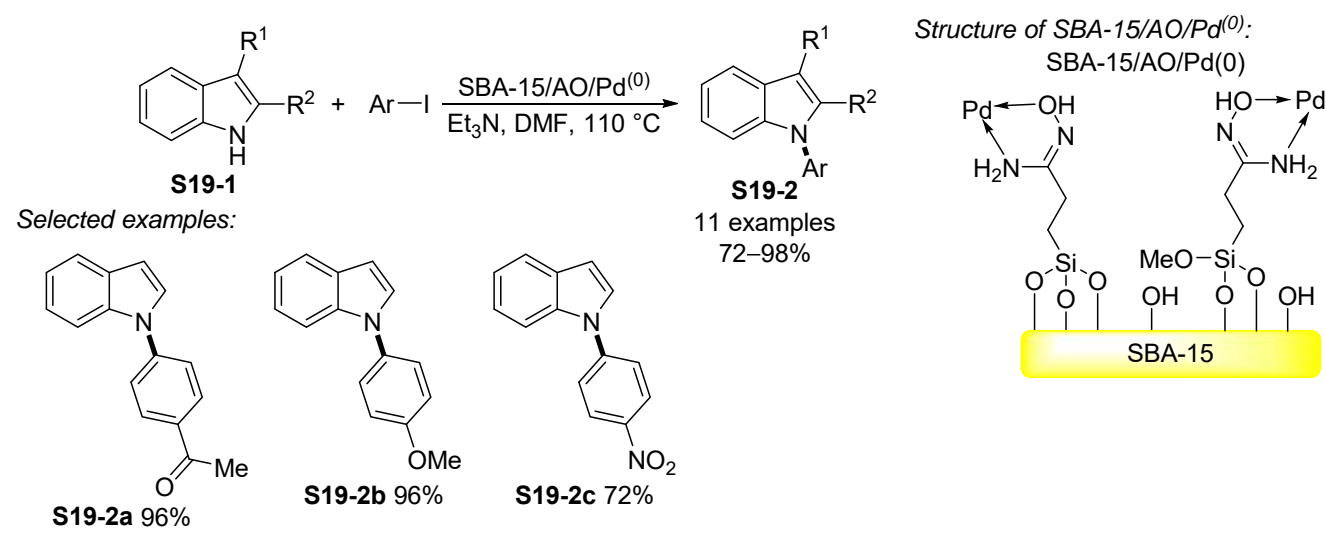

Scheme 19. Amidoxime-functionalized mesoporous SBA-15 as a heterogeneous and recyclable nanocatalyst for indole $N$-arylation.

Palladium-catalyzed $N$-arylation of indoles has been used for the total synthesis of (-)-aspergilazine A (Scheme 20) [80]. In this report, the preparation of (-)-aspergilazine A (S20-3) was achieved by means of a cross-coupling reaction between non-brominated S20-1 and brominated indole S20-2 to form (-)-aspergilazine A (S20-3) at a 9\% yield. When evaluating this approach to (-)-aspergilazine A, it should be noted that the starting substances contained four $\mathrm{N}-\mathrm{H}$ bonds that could be arylated. In addition, $80 \%$ of the unreacted starting material S20-1 was isolated together with the reaction product S20-3.

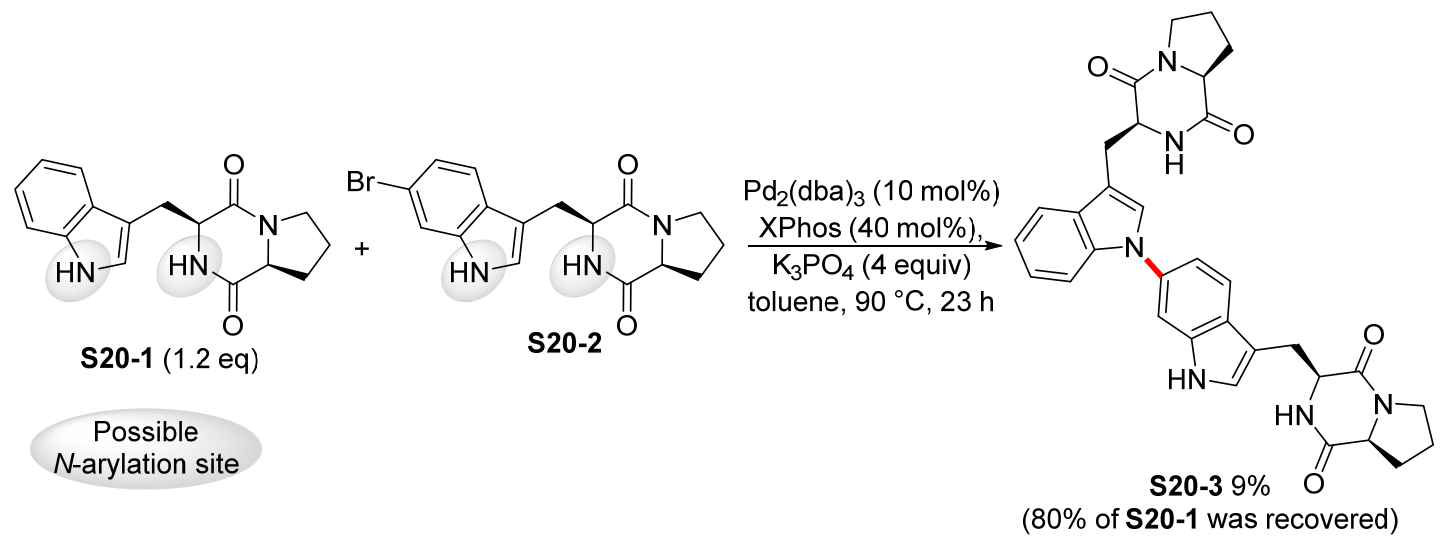

Scheme 20. Use of $\mathrm{N}$-arylation of indoles for the preparation of (-) Aspergilazine A.

Other examples of Buchwald-Hartwig indole $\mathrm{N}$-arylation include the use of the ligands F4-1 [81], F4-2 [82], and $t$ BuXphos (F4-3) [83] (Figure 4). In addition, the palladiumcatalyzed amination of triflates [84,85]; cross-coupling reactions of silylated indoles with aryl halides [86,87]; and reactions that are catalyzed by $\mathrm{Pd} / \mathrm{ZnO}$ nanoparticles [88], palladium immobilized on graphene [89], or silica-starch substrates [90] were used to prepare $\mathrm{N}$-arylindoles. However, these procedures have mainly been developed for the $\mathrm{N}$-arylation of amines, whereas the $\mathrm{N}$-arylation of indoles was given for only a limited number of indole derivatives. 

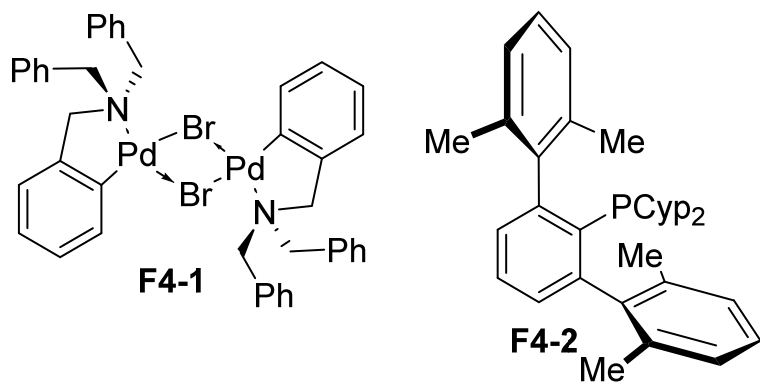

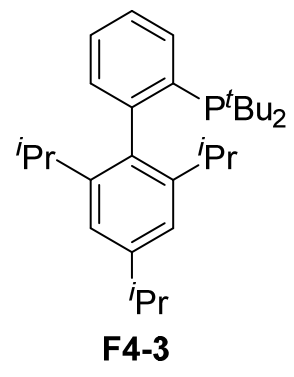

Figure 4. Selected examples of general palladium-catalyzed $N$-arylations used for the preparation of $N$-arylindoles.

\subsection{Copper-Catalyzed N-Arylation of Indoles}

Ligand-free cross-coupling reactions can be considered economical and advantageous due to the cost reductions associated with the designed chemical transformations. In addition, indole $\mathrm{N}$-arylations have been the subjects of ligandless experimental setups. This approach for the preparation of $N$-aryl azoles, including $N$-arylindoles, was reported by Teo in 2011 (Scheme 21) [91]. The reaction of unsubstituted indoles with aryl iodides in the presence of catalytic amounts of copper oxide and tetrabutylammonium bromide (TBAB) as phase-transfer catalysts in water gave $N$-arylindoles S21-2 in high isolated yields. Only aryl iodides can be used for the reaction, because the use of the corresponding bromides leads to significantly lower isolated yields of the target compounds, S20-2. The developed reaction conditions can also be used for the $\mathrm{N}$-arylation of imidazole, pyrrole, 7 -azaindole, and indazole. Alternatively, $5 \mathrm{~mol} \%$ of copper(II) sulphate has been used to catalyze indole and azole $\mathrm{N}$-arylation in the presence of sodium hydroxide at $110{ }^{\circ} \mathrm{C}$ in dimethyl sulfoxide [92].
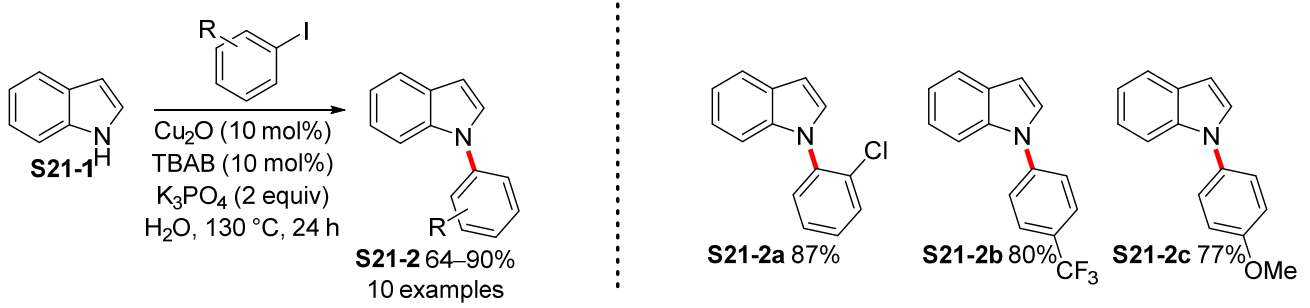

Scheme 21. Ligand-free copper-catalyzed $N$-arylation of indole.

Copper nanocatalysts have become a popular tool for the preparation of $\mathrm{N}$-arylindoles. Recent examples of the use of such nanocatalysts for the synthesis of $\mathrm{N}$-arylindoles are listed in Table 1 . In most cases, nanocatalysts catalyze the $\mathrm{N}$-arylation of indoles under ligandless conditions. An exception to this concerns the preparation of $\mathrm{N}$-arylindoles in the presence of 1,10-phenanthroline as a ligand, which is catalyzed by electrospun copper oxide nanoparticles [93] and ceria-supported copper [94] (Table 1, entries 1 and 2). Other copper-based nanocatalysts include $\mathrm{CuO}$ nanoflakes (CuO NFs@MP) prepared by reducing copper(II) chloride with fruit waste [95] and $\mathrm{CuO}$ nanoparticles, which are easily available by reducing copper(II) acetate by means of water extraction from fresh Rosa canina fruits [96] (Table 1, entries 3 and 4). The structures of both nanocatalysts were determined using physicochemical methods, including X-ray diffraction, Fourier transform infrared spectroscopy, field emission scanning electron microscopy, and others. However, the testing of their ability to catalyze the $N$-arylation of indoles is limited to only a few cases. Substantially better scopes were reported for carbon nanotube-copper oxide (CNT-CuO) [97], copper oxide nanoparticles [98,99], and copper nanoparticles decorated with organically modified montmorillonite (copper-decorated OMMT) [100] (Table 1, entries 5-7). 
Table 1. Nanocatalyzed $N$-arylations of indoles.

\begin{tabular}{|c|c|c|c|c|}
\hline \multirow[b]{2}{*}{ Entry } & \multicolumn{2}{|c|}{$\begin{array}{c}\mathrm{X}-\mathrm{Ar}\left({ }^{\mathrm{Het}} \mathrm{Ar}\right) \\
\mathrm{X}=\mathrm{Br}, \mathrm{I}\end{array}$} & \multirow[t]{2}{*}{$\operatorname{Ar}\left({ }^{\text {het }} \mathrm{Ar}\right)$} & \multirow[b]{2}{*}{ Ar/hetArFG } \\
\hline & Conditions & $\begin{array}{c}\text { No. of } \\
\text { Examples }\end{array}$ & & \\
\hline 1 & $\begin{array}{l}\mathrm{CuO} \text { nano }(5 \mathrm{~mol} \%) \\
1,10-\text { phen }(50 \mathrm{~mol} \%) \\
\mathrm{KOH}(2 \text { equiv), } \mathrm{DMSO}, \\
\text { reflux, } 24 \mathrm{~h}\end{array}$ & $\begin{array}{c}4 \\
56-80 \%\end{array}$ & - & $\mathrm{Cl}$ \\
\hline 2 & $\begin{array}{c}\mathrm{Cu} @ \mathrm{CeO}_{2}(5 \mathrm{~mol} \%), \\
1,10-\text { phen }(50 \mathrm{~mol} \%) \\
\mathrm{KOH}(2 \text { equiv), DMSO, } \\
\text { reflux, } 24 \mathrm{~h}\end{array}$ & $\begin{array}{c}6 \\
82-89 \%\end{array}$ & - & $\mathrm{Cl}$ \\
\hline 3 & $\begin{array}{c}\text { PhI, CuO NFs@MP } \\
(15 \mathrm{mg} / \mathrm{mmol}) \\
\mathrm{K}_{2} \mathrm{CO}_{3}(1.5 \text { equiv }), \mathrm{DMF}, \\
100^{\circ} \mathrm{C}, 6 \mathrm{~h}\end{array}$ & & & \\
\hline 4 & $\begin{array}{c}\mathrm{CuO} \text { NPs }(10 \mathrm{mg} / 1 \mathrm{mmol} \\
\text { of indole), TEA ( } 2 \text { equiv), } \\
\text { DMF, reflux, } 2 \mathrm{~h}\end{array}$ & & $\begin{array}{l}\mathrm{R}=\mathrm{Ph} 96 \\
\mathrm{R}=4-\mathrm{Me}\end{array}$ & $\dashv_{4} 96 \%$ \\
\hline 5 & $\begin{array}{c}\mathrm{CNT}-\mathrm{CuO}(5 \mathrm{~mol} \%), \\
{ }^{t} \mathrm{BuONa}(3 \text { equiv }), \mathrm{DMSO}, \\
120^{\circ} \mathrm{C}, 12 \mathrm{~h}\end{array}$ & $\begin{array}{c}21 \\
42-95 \%\end{array}$ & $\mathrm{Cl}, \mathrm{F}$ & $\begin{array}{c}\mathrm{Cl}, \mathrm{F}, \mathrm{COMe}, \\
\mathrm{CO}_{2} \mathrm{Me}, \mathrm{CN}, \mathrm{CF}_{3}, \\
3,4-\left(\mathrm{CH}_{2} \mathrm{OCH}_{2}\right), \\
\mathrm{NO}_{2}, \mathrm{SMe}\end{array}$ \\
\hline 6 & $\begin{array}{l}\mathrm{CuO} \text { nano }(5 \mathrm{~mol} \%) \\
\mathrm{K}_{2} \mathrm{CO}_{3} \text { (1 equiv), } \mathrm{DMF} \\
\text { reflux, } 8 \mathrm{~h}\end{array}$ & $\begin{array}{c}15 \\
62-98 \%\end{array}$ & $\begin{array}{c}\mathrm{Br}, \mathrm{CN}, \mathrm{NO}_{2} \\
\mathrm{OMe}\end{array}$ & $\mathrm{NO}_{2}$ \\
\hline 7 & $\begin{array}{c}\text { Copper-decorated OMMT } \\
(5 \mathrm{~mol} \%), \mathrm{K}_{2} \mathrm{CO}_{3} \\
(2 \text { equiv }), \\
\text { DMSO }, 130{ }^{\circ} \mathrm{C}, 6 \mathrm{~h}\end{array}$ & $\begin{array}{c}8 \\
73-97 \%\end{array}$ & $\mathrm{CN}$ & $\mathrm{OH}, \mathrm{NH}_{2}$ \\
\hline
\end{tabular}

An alternative route to $\mathrm{N}$-arylindoles is based on the two-step $\mathrm{N}$-arylation of indoles starting from either indolines, S22-1a, or indoline carboxylic acids, S22-1b (Scheme 22) [101]. The reaction of the starting compounds S22-1a and S22-1b with predominantly aryl iodides is catalyzed by a recyclable nano-copper oxide catalyst. Based on the available literature, the authors assume that the preparation of the target compounds S22-2 starts with the aromatization of indolines into indoles, followed by $\mathrm{N}$-arylation. During this study, $27 \mathrm{~N}$-arylated indoles were prepared. Selected examples S22-2a-S22-2d show that the scope of the reaction is mainly limited to unsubstituted indoles and aryl iodides with simple substituents. The authors also confirmed that the nano-copper oxide catalyst can be reused in up to four cycles without a significant loss in activity.

Copper catalysts and nitrogen ligands represent a popular combination for crosscoupling reactions. This is also true for the $N$-arylation of indoles. A first example of the use of $N$-ligands concerns the preparation of $N$-arylindoles, which is catalyzed by copper iodide and ligand L1 (Table 2, entry 1) [102]. The authors succeeded in the preparation of $25 \mathrm{~N}$-arylindoles, although a limited number of functional groups were introduced by this procedure. Significantly greater tolerance on the part of the functional groups was achieved by using the hydroxyquinalidine ligand $\mathbf{L} 2$ (Table 1, entry 2) [103]. In contrast to previous work [102], the $\mathrm{N}$-arylation can be performed at $90{ }^{\circ} \mathrm{C}$, and the reaction can also be used to prepare $\mathrm{N}$-aryl imidazoles, pyrazoles, pyrroles, benzoimidazoles, and carbazoles. Ligands in the form of natural amino acids allow the $\mathrm{N}$-arylation of indoles under similarly mild 
reaction conditions [103]. Unfortunately, the scope of the reaction is almost exclusively limited to the preparation of $N$-arylindoles (Table 2, entries 3 [104] and 4 [105]). The use of metformin as the ligand for $\mathrm{N}$-arylation led to the formation of $\mathrm{N}$-arylindoles, although the reactions were carried out in DMF at $130^{\circ} \mathrm{C}$ (Table 2, entry 5) [106]. The scope of this $\mathrm{N}$-arylation is limited to the preparation of $\mathrm{N}$-arylindoles.

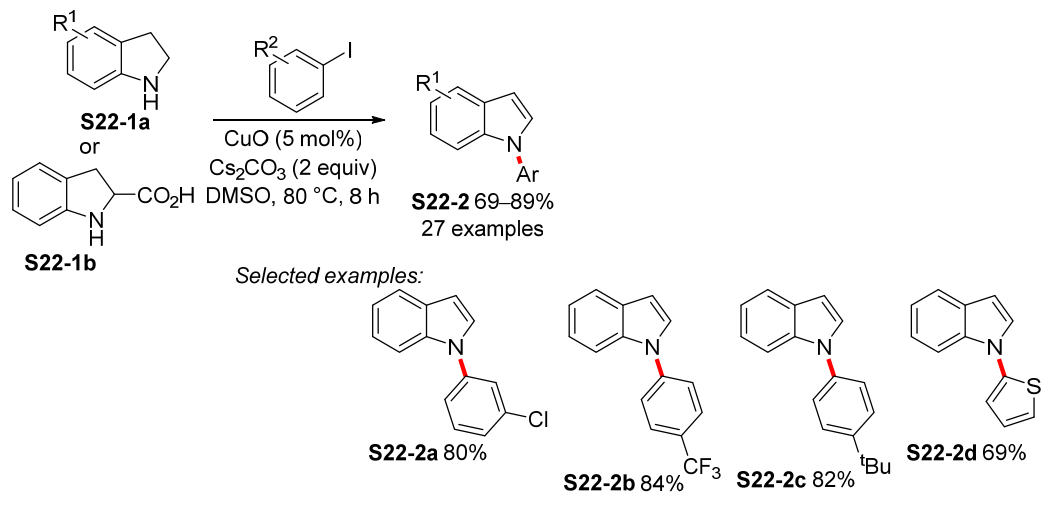

Scheme 22. Synthesis of $N$-arylindoles from indolines or indoline carboxylic acids.

Table 2. Nitrogen-based ligands for the $N$-arylation of indoles.

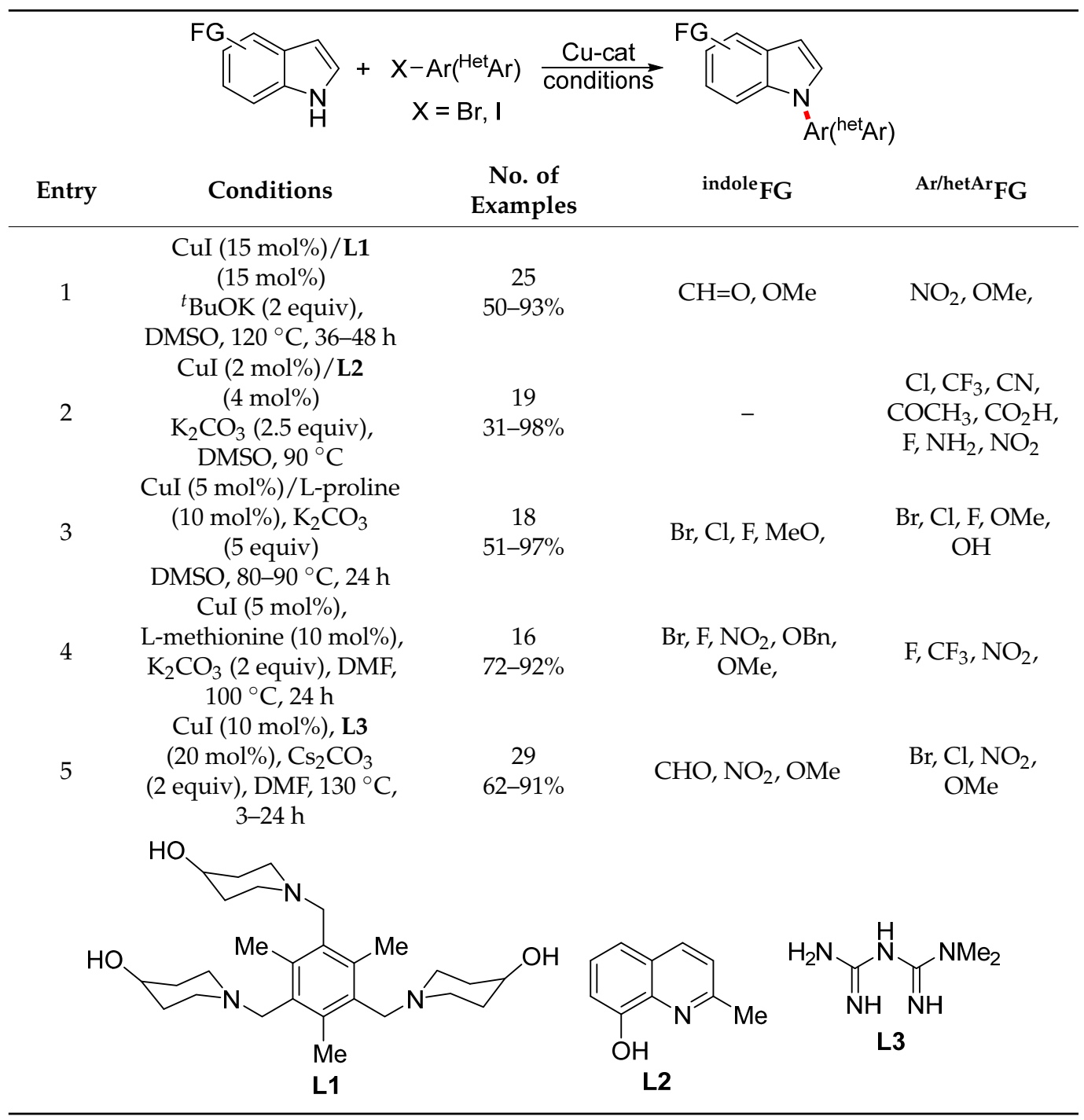


The copper-catalyzed $\mathrm{N}$-arylation of indoles in the presence of an L-proline ligand was used to prepare indolo[1,2-a]quinoxalines (Scheme 23) [107]. The authors used the Ugi multicomponent reaction to prepare 2-substituted indoles S23-2, and the subsequent intramolecular cyclization gave the target compounds S23-3. The Ugi reaction is limited to unsubstituted 2-iodaniline and 2-indolyl carboxylic acid. From the examples of S23-3a

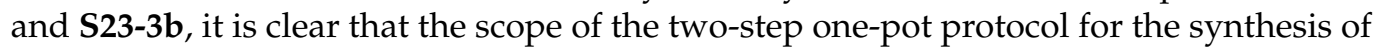
indolo[1,2-a]quinoxalines $\mathbf{S 2 3 - 3}$ is limited to aldehydes and isonitriles without functional groups. It is worth noting that the copper-catalyzed $\mathrm{N}$-arylation gave better yields of $\mathrm{N}$ arylated indoles S23-3 than the palladium-catalyzed cyclization $\left(\mathrm{Pd}(\mathrm{OAc})_{2}\right.$, $\mathrm{BINAP}, \mathrm{K}_{2} \mathrm{CO}_{3}$, toluene, reflux, $24 \mathrm{~h}$ ).
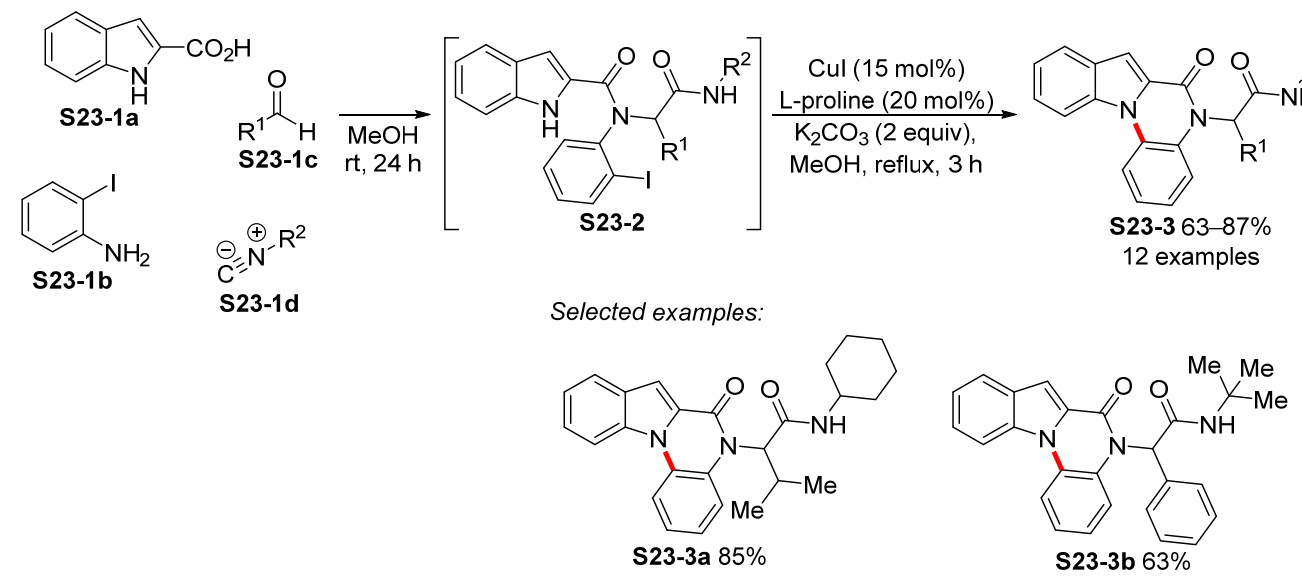

Scheme 23. Ugi four-component reaction and subsequent post-modification for the synthesis of indolo[1,2a]quinoxalines $\mathbf{S} 23-3$.

A similar approach for the intramolecular cyclization of Ugi adducts was reported by Liu in 2013 (Scheme 24) [108]. In this approach, the Ugi reaction is carried out among 2-indolylcarbaldehyde S24-1a, 2-iodobenzoic acid S24-1c, amine S24-1b, and isonitriles S24-1d. The Ugi adduct S24-2 is subsequently cyclized under different conditions. The $\mathrm{N}$-arylation products $\mathbf{S 2 4} \mathbf{4}$ are obtained via a copper-catalyzed reaction in the presence of an L-proline ligand. The products of 2,3-cyclization S24-5 are formed during the palladiumcatalyzed reaction. Cyclization performed without a transition metal produced isoindolin1-ones S24-3. The scope of the discovered transformations is limited to a few examples, although a more extensive scope was reported by the same author in 2014 [109]. 


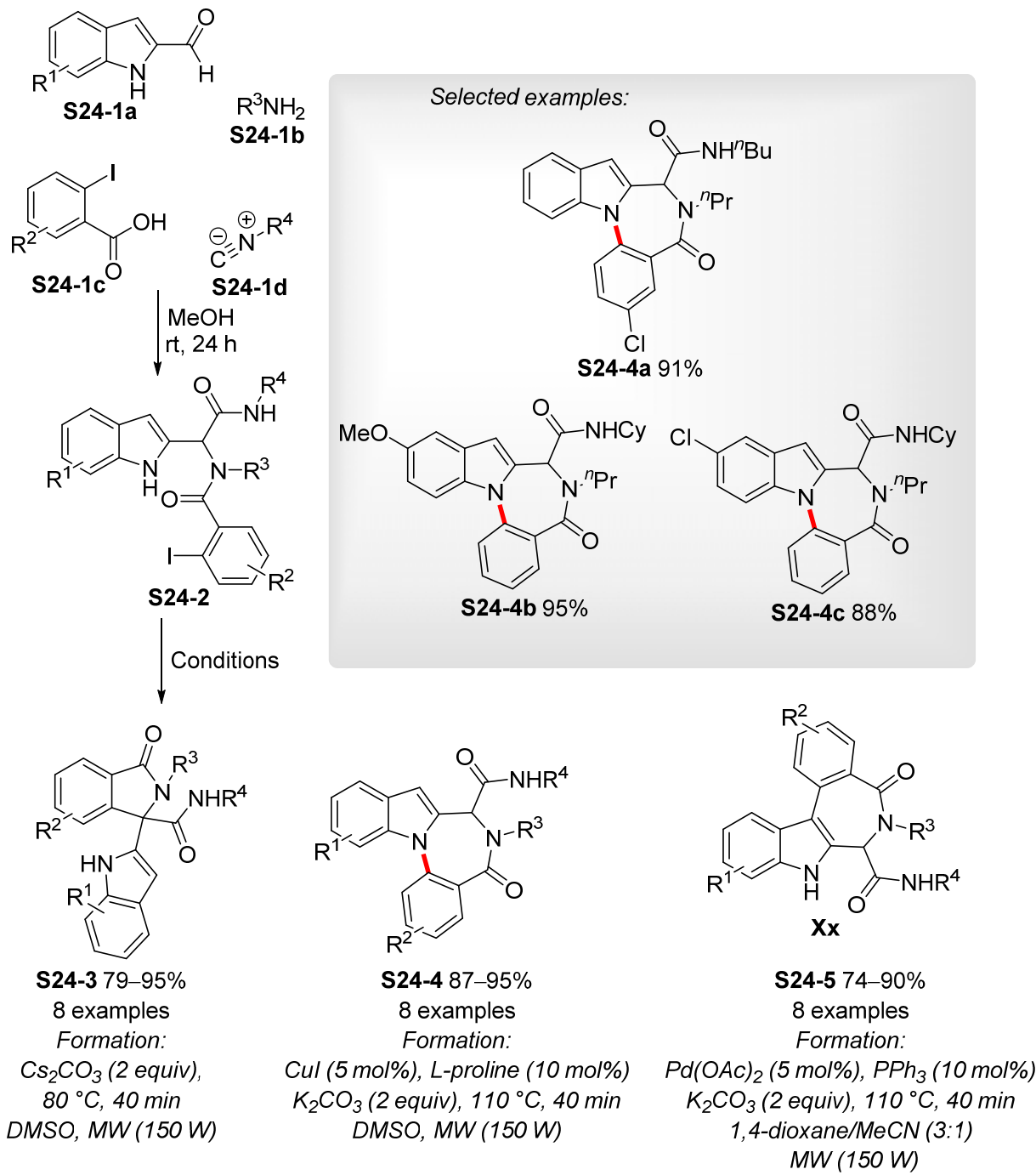

Scheme 24. Diverse synthesis of heterocyclic compounds from the Ugi adducts S24-2.

$N, N^{\prime}$-Dimethylethylenediamine (DMEDA) is a popular ligand for use in the coppercatalyzed $\mathrm{N}$-arylation of indoles. Lim used stoichiometric amounts of copper oxide for the arylation of indoles in pyridine (Table 3, entry 1) [110]. Unfortunately, the reaction scope is limited to the preparation of indoles with an ethoxycarbonyl group at position 2 of the indole moiety. An interesting route for the preparation of functionalized $\mathrm{N}$-arylindoles was reported in 2013 (Table 3, entry 2) [111]. In their study, Ham and Kim developed the chemoselective arylation of halogen aryltrifluoroborates to form functionalized organotrifluoroborates. Only two indole derivatives were prepared by this procedure (in $72 \%$ and $73 \%$ yields, respectively). The presence of a trifluoroborate group in the structure of $\mathrm{N}$-arylindoles can be used in the Suzuki reaction to prepare $\mathrm{N}$-arylindoles with more complex substituents at position 1 [111]. The complementary method for the $N$-arylation of indoles was performed under similar reaction conditions (Table 3, entries 3 and 4) $[112,113]$. 
Table 3. Copper-catalyzed $N$-arylation of indoles in the presence of a DMEDA ligand.

\begin{tabular}{|c|c|c|c|c|}
\hline \multirow[b]{2}{*}{ Entry } & \multirow[t]{2}{*}{ In } & Ar) $\frac{\mathrm{Cu}-\mathrm{C}}{\text { condit }}$ & \multicolumn{2}{|c|}{ Ar $\left({ }^{\text {het }} \mathrm{Ar}\right)$} \\
\hline & & $\begin{array}{c}\text { No. of } \\
\text { Examples }\end{array}$ & ${ }^{\text {indole }} F G$ & Ar/hetAr FG \\
\hline 1 & $\begin{array}{c}\mathrm{CuO}\left(2 \text { equiv), } \mathrm{K}_{2} \mathrm{CO}_{3}(2\right. \\
\text { equiv), pyridine, reflux, } \\
2-3 \mathrm{~d}\end{array}$ & $\begin{array}{c}11 \\
15-96 \%\end{array}$ & $\begin{array}{c}\mathrm{Cl}, \mathrm{F}, \mathrm{CO}_{2} \mathrm{Et} \\
\mathrm{OBn}\end{array}$ & $\mathrm{CF}_{3}, \mathrm{~F}, \mathrm{OMe}$ \\
\hline 2 & $\begin{array}{c}\mathrm{CuI}(10 \mathrm{~mol} \%), \text { DMEDA (20 } \\
\text { mol\%), } \mathrm{Cs}_{2} \mathrm{CO}_{3} \text { (1 equiv) } \\
\text { DMSO, } 120^{\circ} \mathrm{C}, 4 \mathrm{~h}\end{array}$ & & $\begin{array}{l}R=1 \\
R=C\end{array}$ & le $73 \%$ \\
\hline 3 & $\begin{array}{c}\mathrm{CuI}(10 \mathrm{~mol} \%), \text { DMEDA (20 } \\
\text { mol } \%), \mathrm{K}_{3} \mathrm{PO}_{4}(2 \text { equiv) } \\
\text { toluene, } 110^{\circ} \mathrm{C}, 24 \mathrm{~h}\end{array}$ & $\begin{array}{c}13 \\
74-91 \%\end{array}$ & $\mathrm{Ph}$ & $\begin{array}{c}\mathrm{Cl}, \mathrm{CO}_{2} \mathrm{Et}, \mathrm{F}, \\
\mathrm{OMe}\end{array}$ \\
\hline 4 & $\begin{array}{c}\mathrm{CuI}(10 \mathrm{~mol} \%), \mathrm{K}_{3} \mathrm{PO}_{4}(3 \\
\text { equiv), } \mathrm{DMEDA}(20 \mathrm{~mol} \%) \\
\text { toluene, } 110{ }^{\circ} \mathrm{C}, 12 \mathrm{~h}\end{array}$ & & $\begin{array}{l}\mathrm{R} \\
\mathrm{R} \\
\mathrm{R} \\
\mathrm{R}\end{array}$ & $\begin{array}{l}34 \% \\
\mathrm{H}_{3} \mathrm{C}_{6} \mathrm{H}_{4}, 72 \% \\
{ }_{6} \mathrm{H}_{4}, 75 \% \\
{ }_{3} \mathrm{C}_{6} \mathrm{H}_{4}, 80 \% \\
\text { enyl, } 57 \%\end{array}$ \\
\hline
\end{tabular}

Dichotomies during the arylations of 3-substituted indoles S25-1a and S25-1b were reported by Schnürch (Scheme 25) [114]. The starting indole, which featured a Boc-protecting group, reacted with arylboronic acids in the presence of a palladium catalyst and one equivalent of copper acetate to give 2-arylindoles S25-3a-S25-3c in moderate yields. The formation of $\mathrm{N}$-arylindoles was not observed in this case. The low yields of indoles S25-3a, S25-3b, and S25-3c were explained by the inferior steric requirements for substitution at position 2. Changing the catalytic system to ferric chloride with a DMEDA ligand led to the formation of $\mathrm{N}$-arylated indoles S25-4a-S25-4e in high yields. $\mathrm{N}$-arylation can also

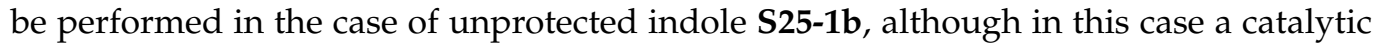
amount of copper iodide with a DMEDA ligand and cesium fluoride as a base had to be used. 


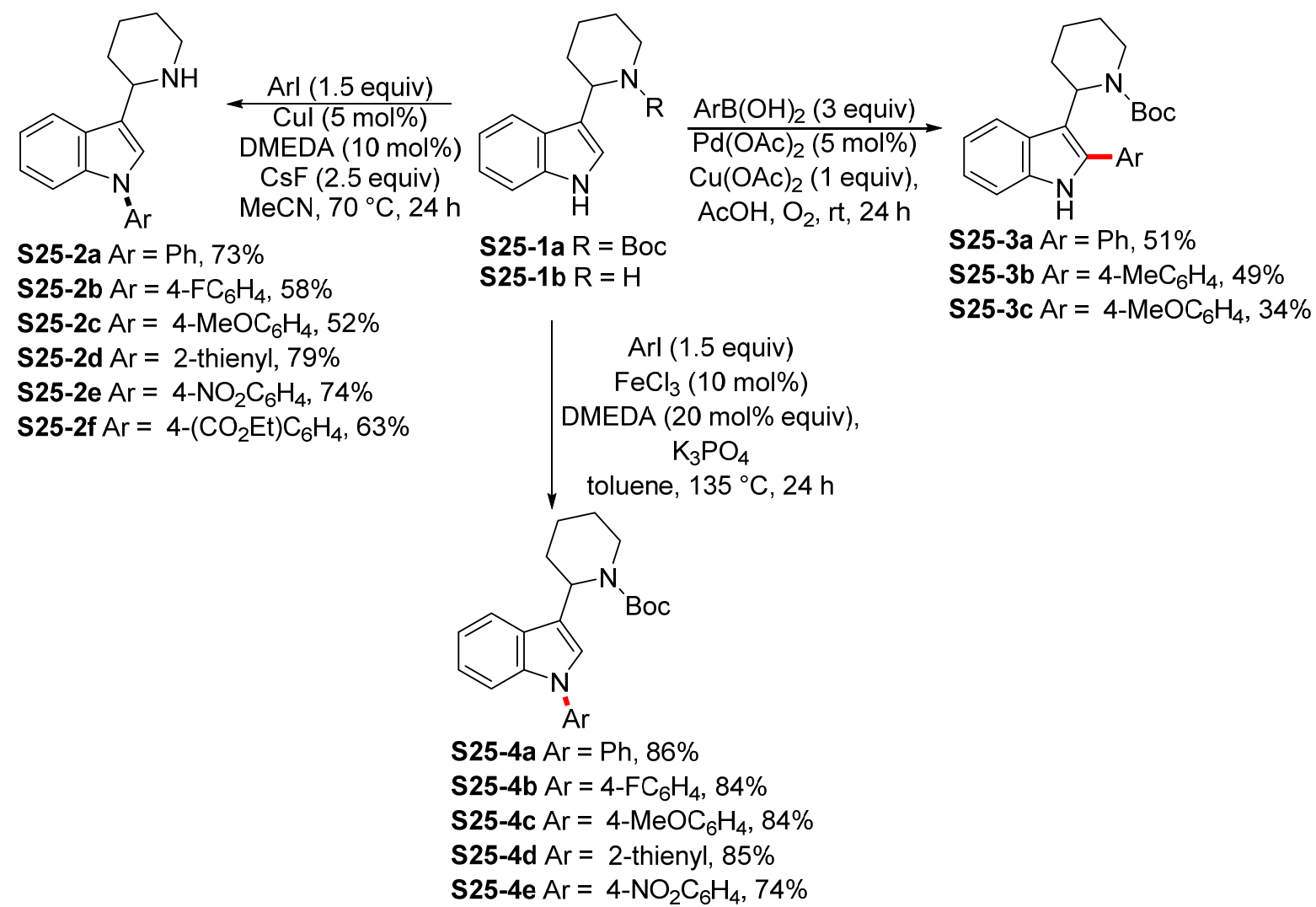

Scheme 25. Dichotomies in the transition-metal-catalyzed arylation of substituted indoles.

A series of $\mathrm{N}$-arylation reactions using ligands or reagents obtained from natural sources included the $\mathrm{N}$-arylation of indoles, which was carried out in glycerol (Table 4, entry 1) [115]. Glycerol is considered a cheap and environmentally-friendly alternative to the commonly used solvents DMF and DMSO. A common feature of $\mathrm{N}$-arylation reactions performed in glycerol, DMF, and DMSO is the high reaction temperature. The authors hypothesize that one equivalent of DMSO acts as a ligand to help the oxidative addition of the copper catalyst to the C-halogen bond. The good solubility of the reaction products in organic ethers allowed the recycling of the catalytic system dissolved in glycerol by extraction of the products and the starting compound to the ether. Such recycled catalysts can be used in three catalytic runs. A different ligand concept for the $\mathrm{N}$-arylation of indoles makes use of methyl- $\alpha$-D-glucopyranoside $\mathbf{L} \mathbf{1}$ and glucosamine $\mathbf{L} \mathbf{2}$ as ligands for coppercatalyzed $N$-arylations, as reported by Xuan [116] and Chen [117] (Table 4, entries 2 and 3). Neither reaction is significantly different from the other procedures available for the $\mathrm{N}$ arylation of indoles. In the case of the glucosamine ligand $\mathbf{L} 2$, the formation of a radical intermediate T4-1 was proposed, although the formation of this intermediate has not been experimentally verified. The use of other natural substances in this regard includes the use of $\mathrm{N}$-alkyl-glucosamine as a sugar-based surfactant [118], alpha-D-galacturonic acid L3 [119], and L-(-)-quebrachitol L4 [120] as ligands for the copper-catalyzed $N$-arylation of indoles and nitrogen-containing substances. 
Table 4. Copper-catalyzed $N$-arylations of indoles.

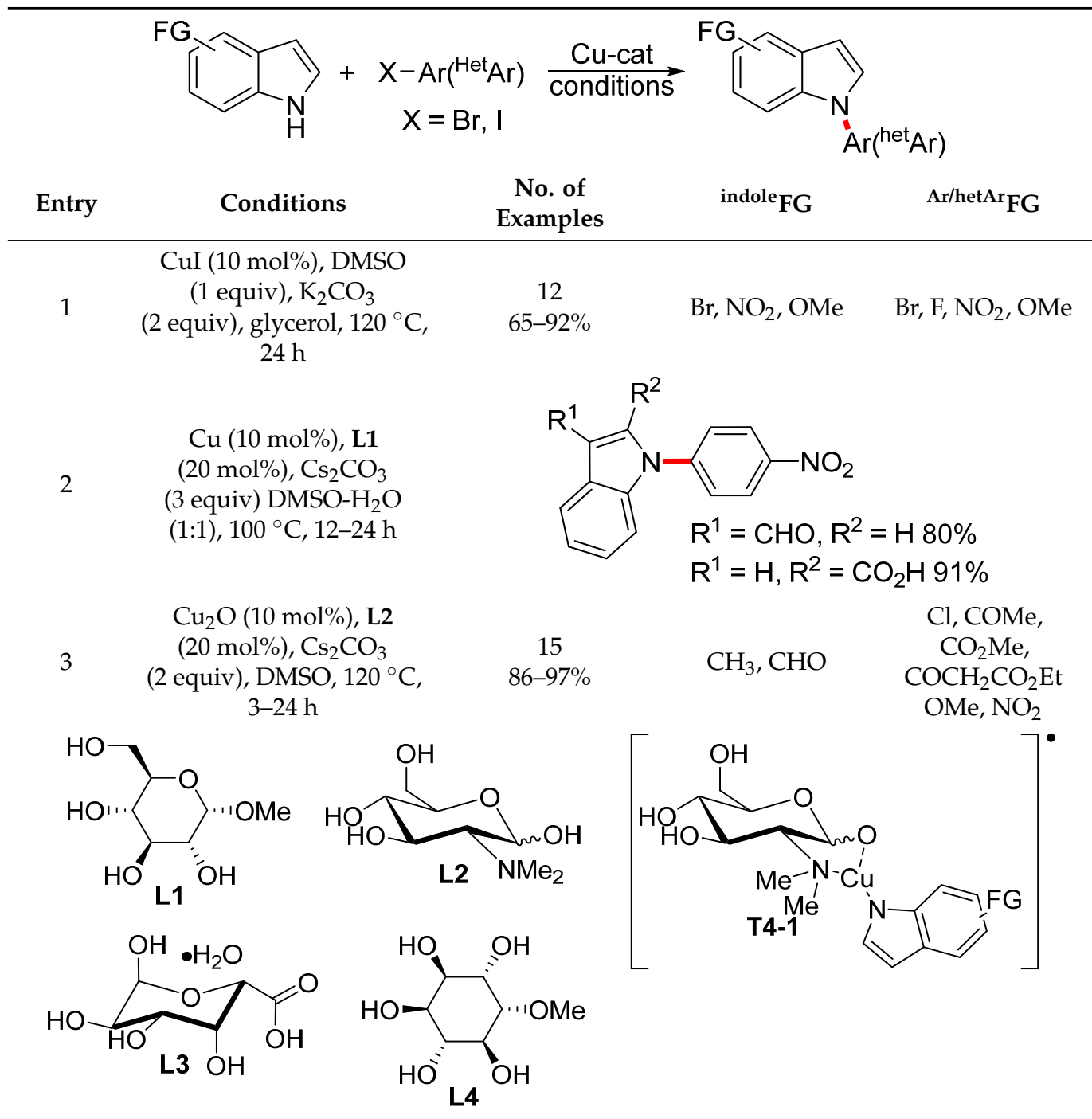

In addition to the above-mentioned examples, other ligands containing a nitrogen atom represent popular choices for the copper-catalyzed arylation of indoles. Nitrogen ligands also form part of the system for the $\mathrm{N}$-arylation of indoles in water (Table 5). Schmitt used copper bromide and the ligand $\mathbf{L 1}$ for the $\mathrm{N}$-arylation of indoles under mild reaction conditions (Table 5, entry 1) [121]. D-Glucose was used as the reducing agent in this case. The reaction was performed in a commercially available DL- $\alpha$-tocopherol methoxypolyethylene glycol succinate solution. It was experimentally verified that the use of a surfactant is necessary to achieve a high yield of $\mathrm{N}$-arylindoles. The developed reaction conditions were used for the synthesis of $11 \mathrm{~N}$-arylindoles, and the tolerance of the functional groups in this case was limited to halogens, nitrile, ethers, and the formyl group. A similar surfactant-based strategy for preparing $N$-arylindoles was reported by Liu in 2013 (Table 5, entry 2) [122]. The reaction conditions for the $N$-arylation of indoles make use of the bipyridine ligand L2, potassium phosphate as the base, and betaine as the surfactant. In contrast to previous work [121], the arylation reaction must be performed at $90{ }^{\circ} \mathrm{C}$. The authors demonstrated the tolerance of the acetyl group during the preparation of ten indole derivatives under optimized reaction conditions. An extensive series of $\mathrm{N}$-arylated indoles was prepared by means of indole arylation catalyzed by copper iodide and the phenanthroline ligand L3 in 30\% aqueous 1,2-dimethoxyethane (DME) (Table 5, entry 3) [123]. The optimum ratio of DME to water was determined using kinetic experiments, which showed that reactions performed in pure water or DME did not achieve 
quantitative conversion. An alternative procedure for the preparation of $\mathrm{N}$-arylindoles relies on the reaction of boronic acids with indoles in aqueous ammonia and potassium tertbutoxide as a base under ligandless conditions [124]. To complete the list of $\mathrm{N}$-arylations of indoles in water, it is necessary to mention the $\mathrm{N}$-arylation procedures associated with heterocyclic compounds and amines, which can be applied for the preparation of a limited number of $N$-arylindoles [125-131].

Table 5. Copper-catalyzed $N$-arylation of indoles in water.

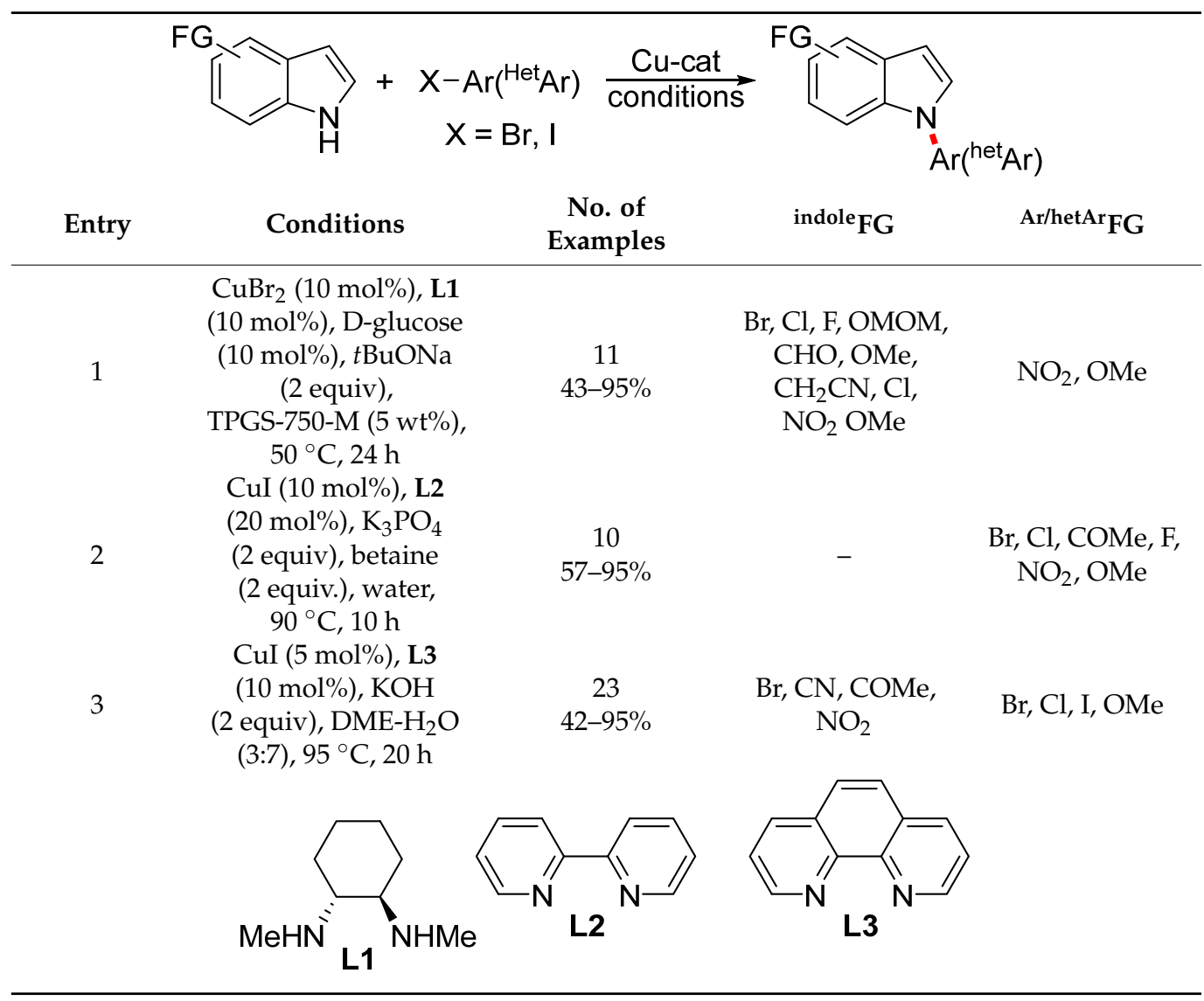

The copper(I)-oxide-catalyzed $\mathrm{N}$-arylation of indoles, as catalyzed using copper oxide and a pyridine $N$-oxide ligand L1, was reported in 2016 (Table 6, entry 1) [132]. By varying the ligands during the optimization of the reaction conditions, it was confirmed that the presence of both pyridine $\mathrm{N}$-oxide and phenyl amide moieties in the structure of the ligand L1 is necessary to achieve maximum yields. The optimized reaction conditions are suitable for the preparation of $\mathrm{N}$-aryl pyrazole, pyrrole, and indazole. The reaction scope for indoles is limited to six examples. The use of a pyridine $\mathrm{N}$-oxide ligand was presumably inspired by prior studies that utilized pyridine $\mathrm{N}$-oxide ligands for general $\mathrm{N}$-arylation [133-135]. The pyridine-based ligand L2, which contains an iminopyridyl moiety, was used for the $\mathrm{N}$-arylation of indoles in DMSO at $120^{\circ} \mathrm{C}$ (Table 6, entry 2) [136]. Another ligand L3 that contains an iminopyridyl moiety in its molecule was reported in 2021 (Table 6, entry 3) [137]. A short communication on the copper-catalyzed $\mathrm{N}$-arylation of indoles was published in 2015 (Table 6, entry 4). Copper(I) chloride with a phosphine ligand L4 in DMSO was found to be the best combination for the $N$-arylation of indoles. The scope of the reaction is limited to aryl halides with electron-donating or electron-neutral substituents. It should be noted that 4-iodobenzonitrile did not react under the optimized reaction conditions. 
Table 6. Pyridine- and phosphorous-based ligands for the $N$-arylation of indoles.

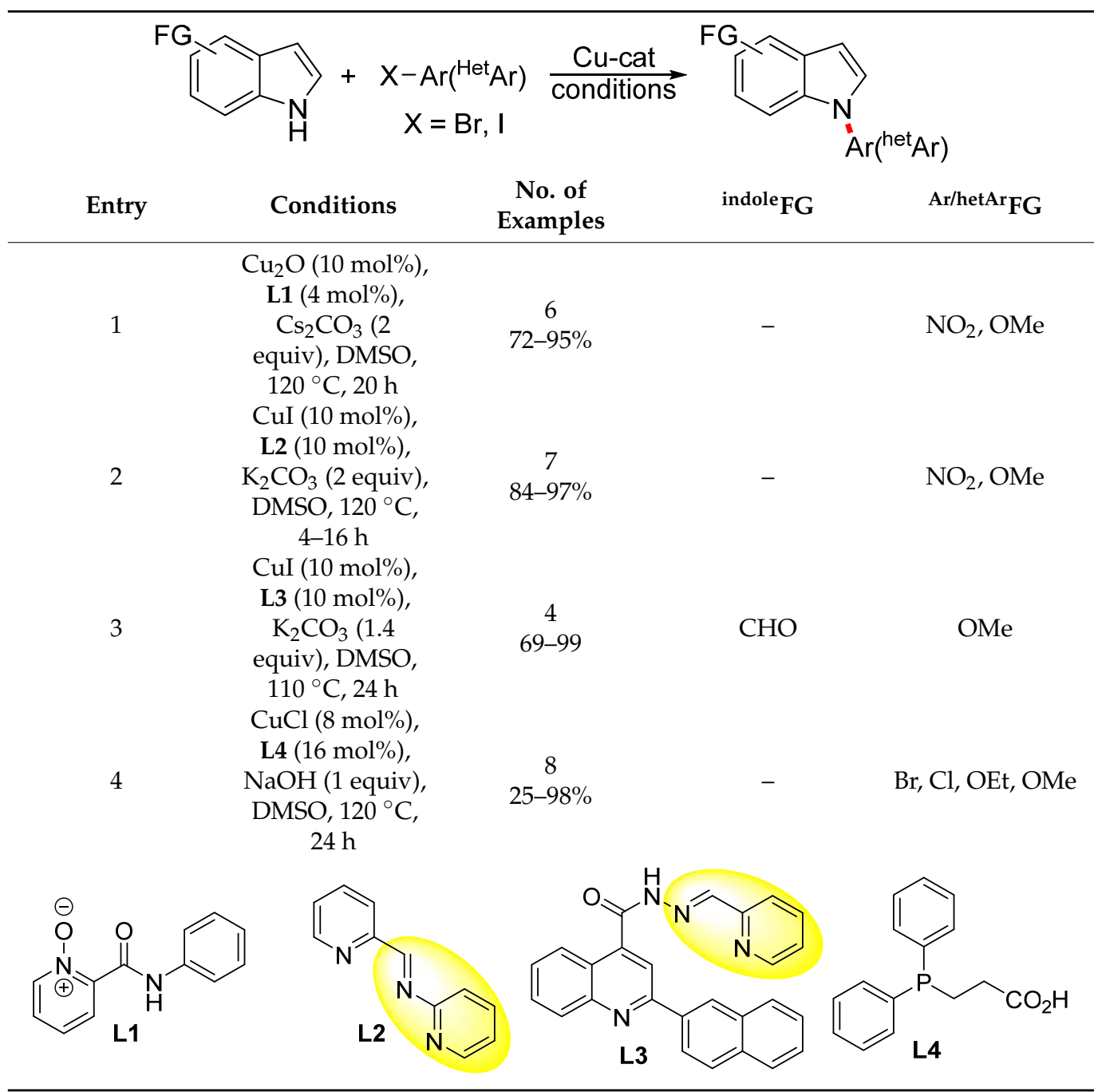

Recently, a self-relaying copper(I)-catalyzed sequence was used for the preparation of indolo[1,2-a]quinazolinones S26-3 by means of the reaction of the methyl esters of 3-indolylcarboxylic acid S26-1 with 2-bromobenzamides S26-2 (Scheme 26) [138]. This reaction is sensitive to the structure of the starting indole derivative, as the use of the 3methylindole led to the formation of the $\mathrm{N}$-arylated indole S26-4 and indoloquinazolinone S26-5. Fifteen indolo[1,2-a]quinazolinone S26-3 derivatives were prepared using this procedure. It is worth noting that despite the harsh reaction conditions, the presence of a chlorine atom was tolerated. It was also verified that the $N$-arylation of indoles to form the intermediate S26-6 is the first step in the formation of the target compounds S26-3. 


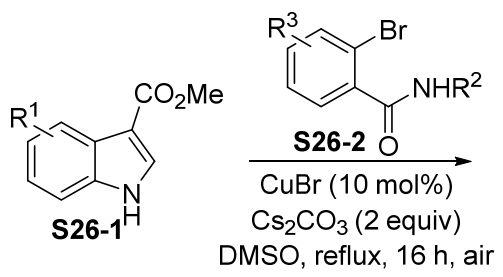

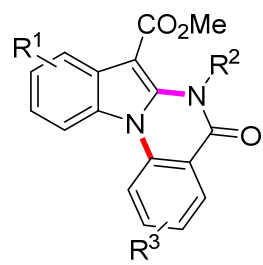

S26-3 52-93\% 15 examples<smiles>CC(=O)c1c2cc(Cl)ccc2n2c1[nH]c(=O)c1ccccc12</smiles>

S26-3a $79 \%$<smiles>CC(=O)c1cc2n(C)c(=O)c3ccccc3n2c1C</smiles>

S26-3b $85 \%$<smiles>COC(=O)c1c2ccccc2n2c3ccc(C)cc3c(=O)n(Cc3ccccc3)c12</smiles><smiles>Cc1cn(-c2cc(C(=O)O)ccc2C(N)=O)c2ccccc12</smiles><smiles>[R]NC(=O)c1cc[R3](S(C)(=O)=O)cc1-n1cc(C(C)=O)c2ccccc21</smiles>

Scheme 26. Formal double $N$-arylation synthesis of indolo[1,2-a]quinazolinones S26-3 via self-relay copper catalysis.

The cobalt-copper-cocatalyzed $N$-arylation and alkenylation of $N$-heterocycles was reported by Ran (Scheme 27) [139]. The reaction conditions were optimized for the alkenylation of amides, although it was determined that these conditions could also be used for the preparation of $N$-arylindoles $\mathbf{S 2 7 - 2} \mathbf{a}$ and $\mathbf{S 2 7 - 2} \mathbf{b}$ in high yields. The authors assume that in the first step, the $\mathrm{Co}^{(\mathrm{II})}$ is reduced to $\mathrm{Co}^{(\mathrm{I})}$ by means of acetylacetone. The oxidative addition is followed by the substitution of the halide ligand, which is facilitated by the formation of the $\mathrm{Cu}(\mathrm{I})-\mathrm{N}$ complex S27-6. The product of the reaction is then obtained by reductive elimination. The proposed mechanism was partially confirmed experimentally. A somewhat different approach to the $N$-arylation of nitrogen-containing heterocycles makes use of the iron-catalyzed bromination of aromatics, followed by copper-catalyzed $N$-arylation [140]. This approach was used for the synthesis of 1-(4-methoxyphenyl)indole in a $78 \%$ yield.

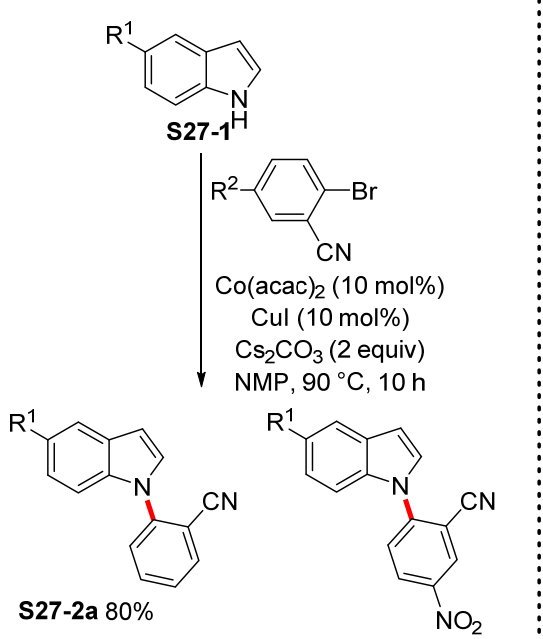

S27-2b $82 \%$

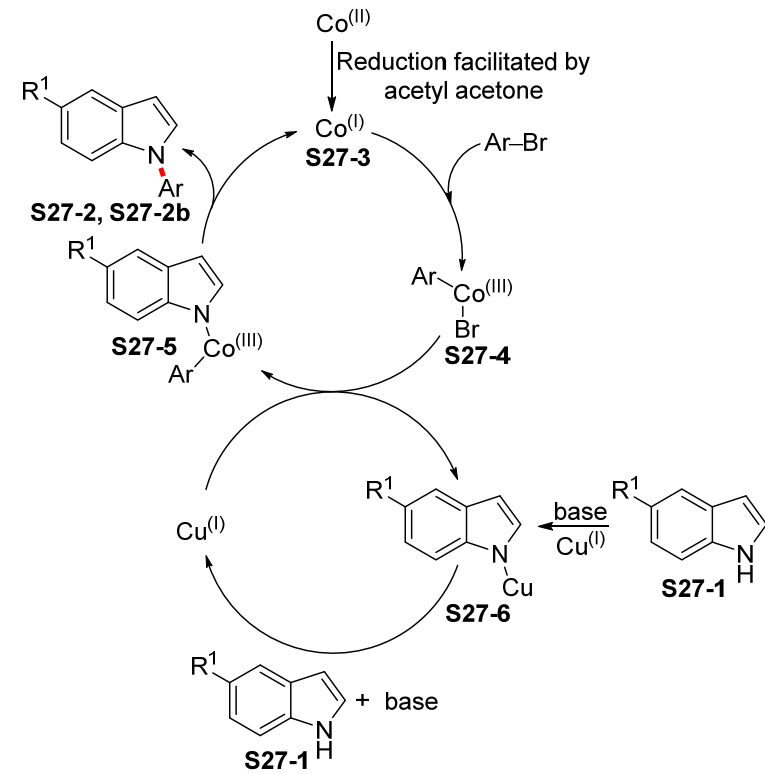

Scheme 27. Cobalt-copper-cocatalyzed $N$-arylation of indoles. 
The general copper-catalyzed $\mathrm{N}$-arylation of indoles and other azoles based on $\mathrm{C}-\mathrm{H}$ bond activation was reported in 2016 (Scheme 28) [141]. The developed methodology is based on $N$-(quinolin-8-yl)benzamides S28-1, which react with azoles and indoles to give ortho-substituted benzamides S28-2. The methodology was used for the preparation of $N$-aryl pyrroles, indoles, carbazoles, and pyrazoles. The presence of a quinolin-8-yl group facilitates the formation of the complex S28-3 by means of copper coordination to the quinolin-8-yl moiety. The oxidation of $\mathrm{Cu}^{\mathrm{II}}$ to $\mathrm{Cu}^{\mathrm{III}}$ forms complex S28-4, which undergoes intramolecular $\mathrm{C}-\mathrm{H}$ cupration. Eight $\mathrm{N}$-arylated indoles were prepared using this procedure. It was shown that benzamide with a pyrrolyl unit can be hydrolyzed into ortho-substituted benzoic acid. The same research group showed that the methodology developed for $\mathrm{C}-\mathrm{H}$ functionalization reactions can be extended to picolinamides, rather than benzamides [142].
S28-1<smiles>Cc1ccc(C(=O)Nc2cccc3cccnc23)cc1</smiles>$$
\text { Me }
$$

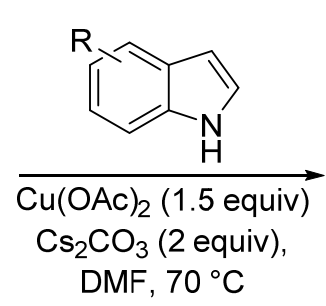

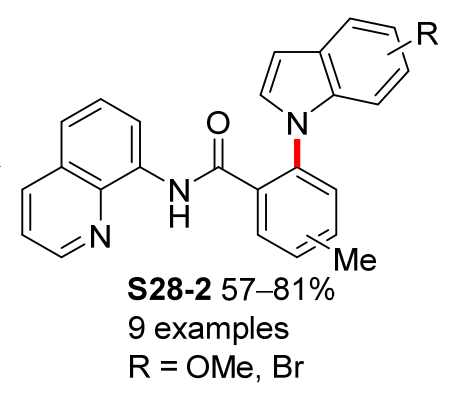

Proposed intermediates:

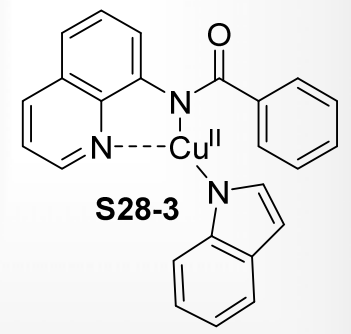

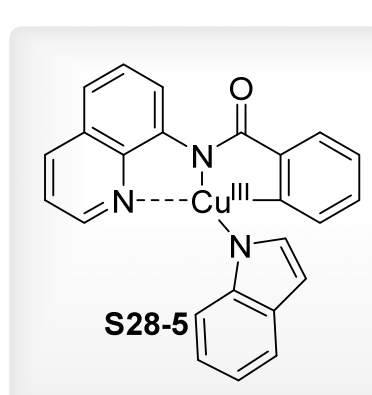

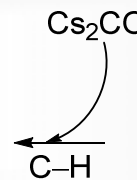
activation<smiles>CC(C)OCCO</smiles>

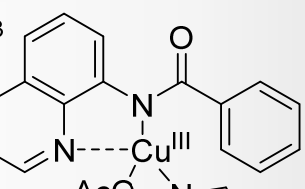

S28-4<smiles>Cn1ccc2ccccc21</smiles>

Scheme 28. C-H activation for the $\mathrm{N}$-arylation of indoles.

An alternative approach to the $N$-arylation of indoles makes use of 2-indolylboronic acids (Scheme 29) [143]. The starting carboxylic acids S29-1 react with aryl bromides or aryl iodides in the presence of catalytic amounts of copper oxide and potassium phosphate as a base. The reported scope of the reaction is limited to substituted phenyl iodides and bromides. Other aromatic and heteroaromatic halides were not tested. In terms of the proposed mechanism, the authors assume the formation of copper carboxylate S29-4 and the subsequent decarboxylation into the 2-indolyl copper reagent $\mathbf{S 2 9 - 5}$. The final products S29-2 are formed via anion exchange, oxidative addition, and reductive elimination steps. 

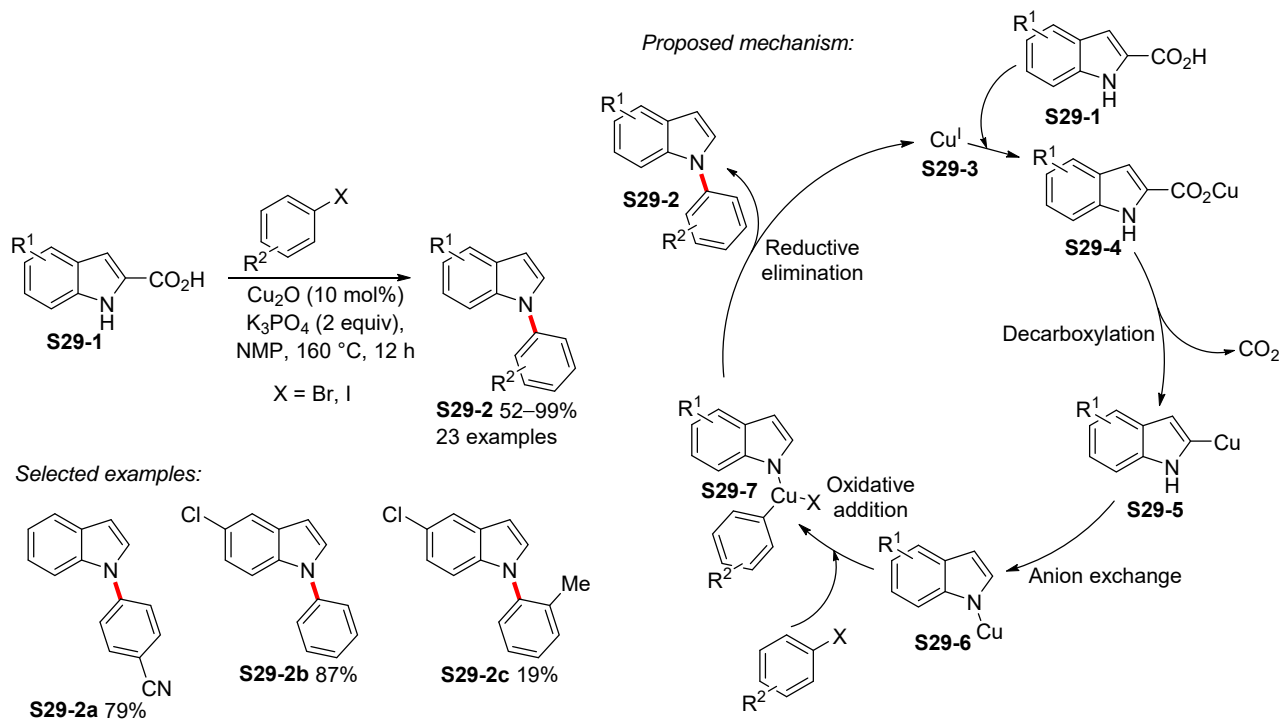

S29-2a $79 \%$
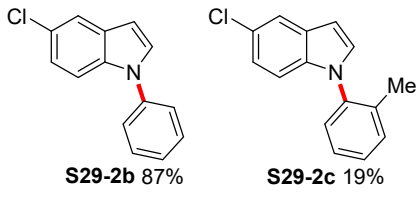

Scheme 29. Decarboxylative $N$-arylation of 2-indolylcarboxylic acids.

Arguably the most extensive procedure for the preparation of $\mathrm{N}$-arylindoles is based on the reaction of indoles with triarylbismuth reagents (Scheme 30) [144]. The reaction is catalyzed by copper acetate in the presence of oxygen and one equivalent of base. The triarylbismuth reagents can be prepared using the reaction of bismuth(III) trichloride with Grignard reagents or by the chemical transformation of the ester or formyl group of the corresponding triarylbismuth reagents. The procedure is suitable for the preparation of highly functionalized indoles because the methodology can tolerate a variety of functional groups, including a formyl or ester group, as illustrated by selected examples $\mathbf{S 3 0 - 2 b - S 3 0 -}$ 2e. The tryptophan derivative $\mathbf{S 3 0 - 2 a}$ was also prepared using this procedure. In addition, a series of heteroatom arylations by organobismuth reagents has been reported [145-148].
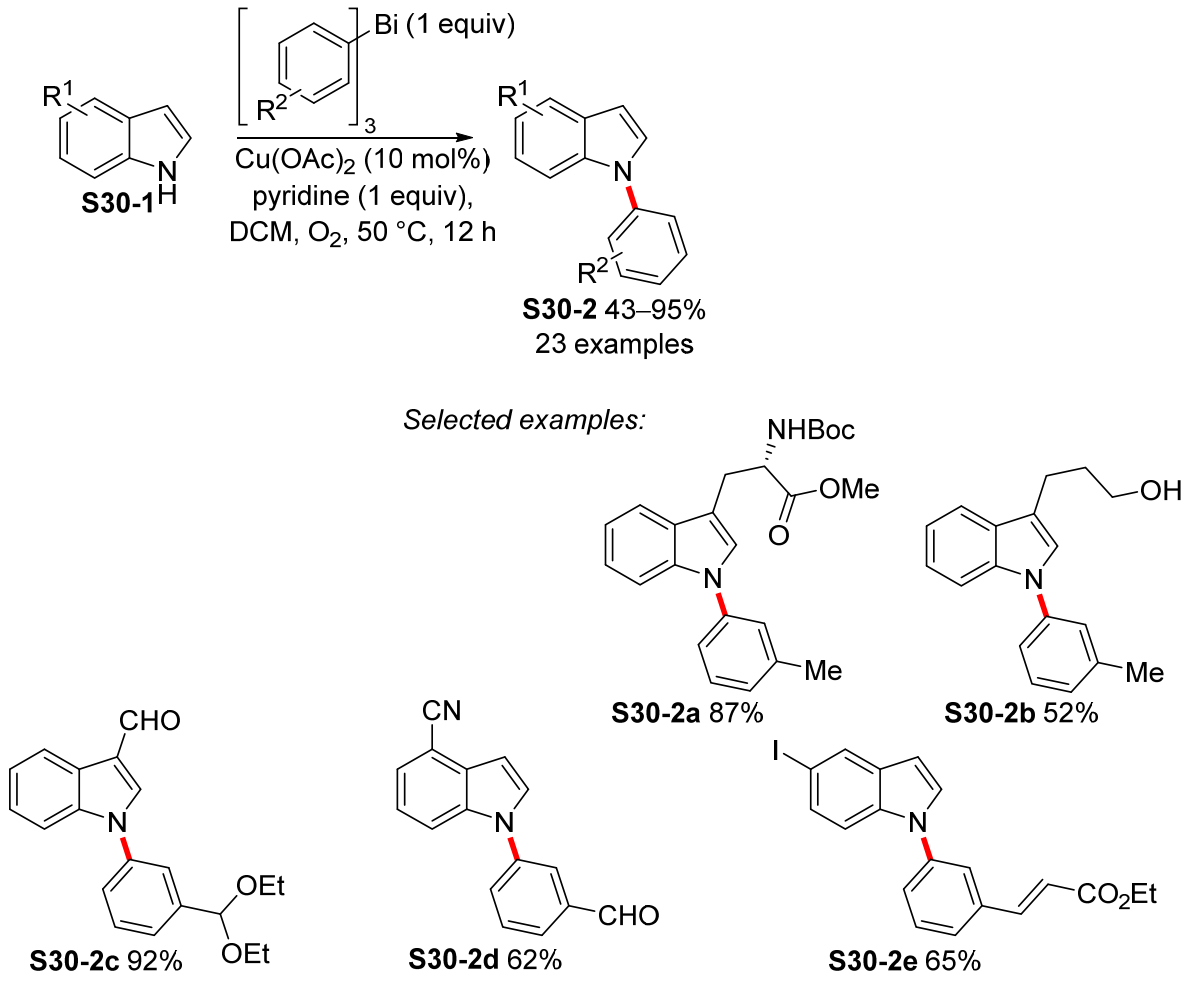

Scheme 30. $N$-arylation of indoles by means of triarylbismuth reagents. 
An alternative approach for the preparation of (-)-aspergilazine A that uses coppercatalyzed indole $N$-arylation was reported in 2017 (Scheme 31) [149]. A direct approach to (-)-aspergilazine A starting from the tryptophan derivative S31-4 proved inefficient because the expected product of the reaction S31-5 was obtained in only a $66 \%$ yield. Thus, the preparation of the target compound from indole S31-1 and 2-bromoindole or 2-iodoindole S31-2 was accomplished in nine steps in a total isolated yield of $36 \%$.

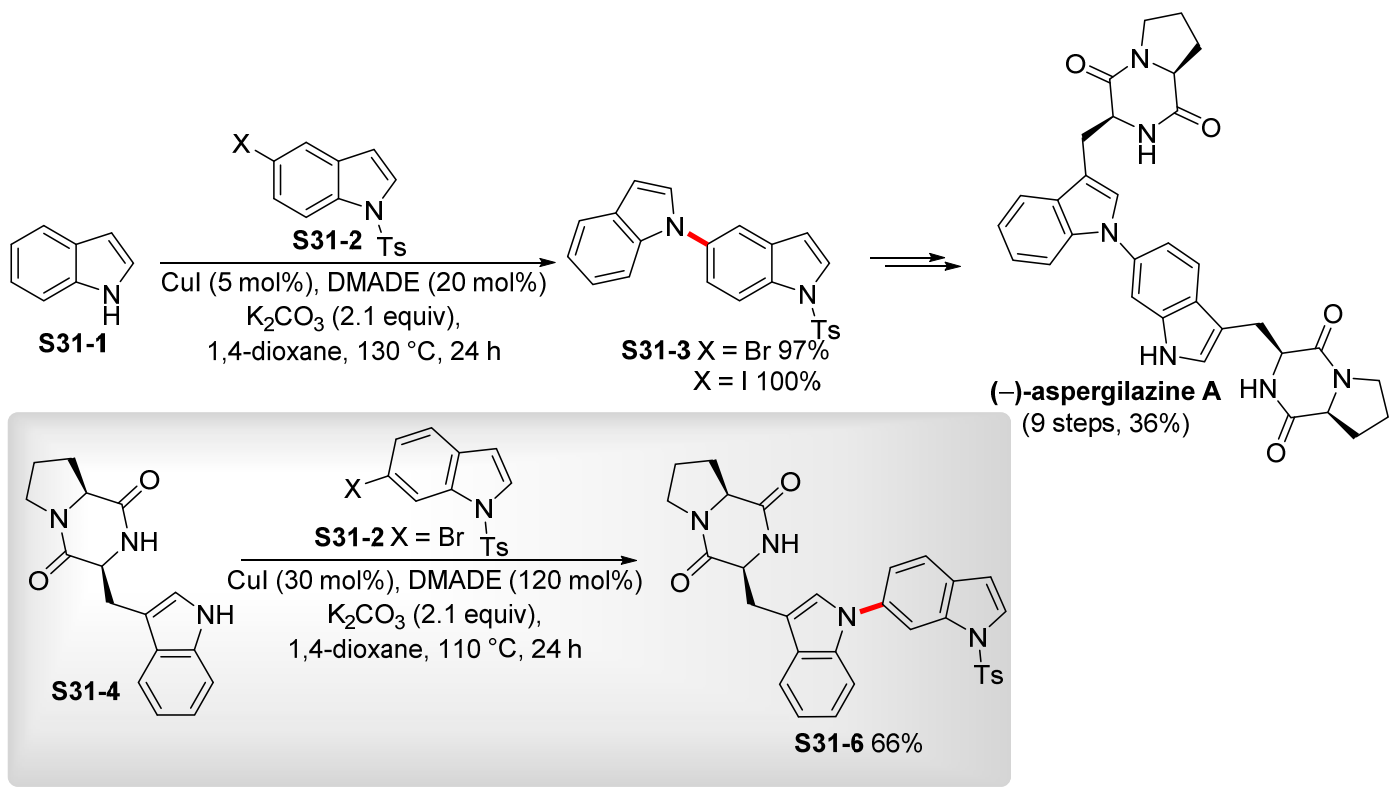

Scheme 31. Total synthesis of (-)-aspergilazine A via the copper-catalyzed $N$-arylation of indoles.

Atom-economic arylation of indoles was described in 2015 (Scheme 32) [150]. N1Unsubstituted indoles react with diaryliodonium salts in the presence of a catalytic amount of copper iodide to give N1- and C3-arylated indoles in average isolated yields. High selectivity was observed for aryl-uracil iodonium triflates S32-3, affording the 3-aryl-1indoles-uracil conjugates S32-4.
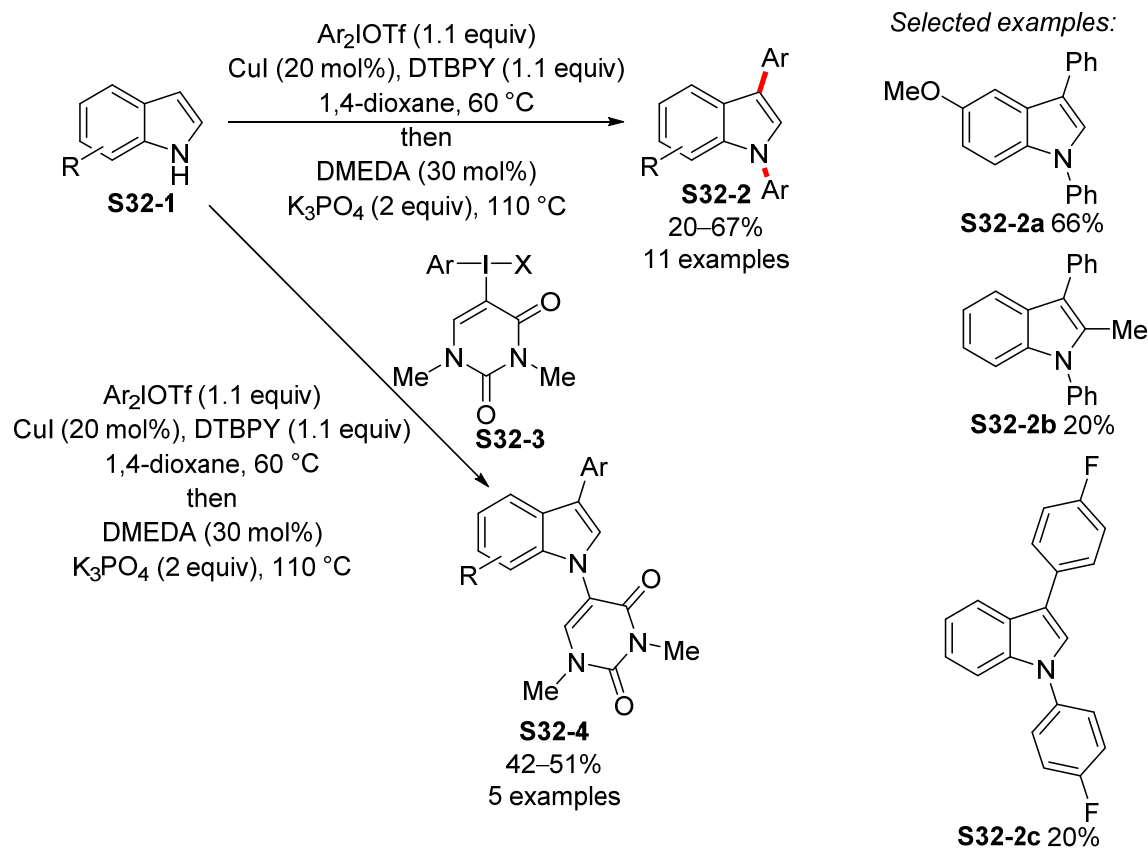

Scheme 32. Atom-economical $N$-arylation of indoles by diaryliodonium salts. 
The combination of photocatalysis and copper-catalyzed $N$-arylation enabled the $N$ arylation of indoles at room temperature (Scheme 33) [151]. The key step in this conversion is the photoexcitation of a copper complex S33-3. The reaction is also suitable for the preparation of $\mathrm{N}$-aryl benzimidazoles, imidazoles, and carbazoles.

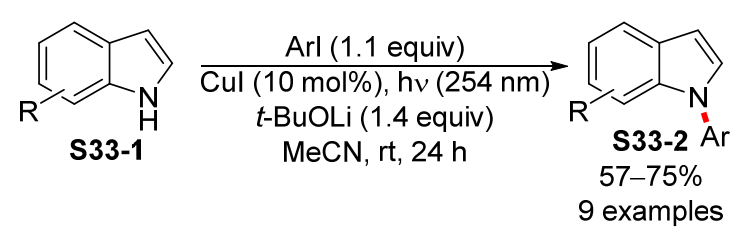

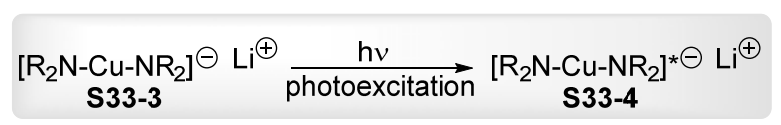

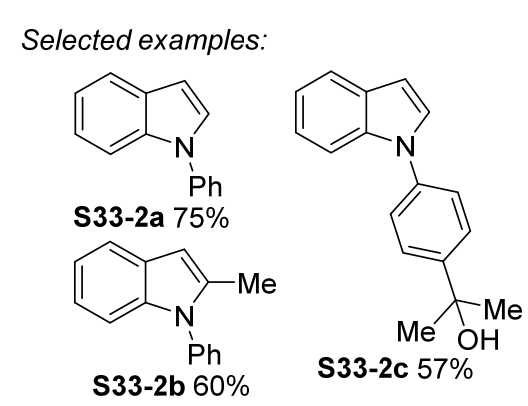

Scheme 33. N-Arylation of indoles under mild conditions.

\subsection{Miscellaneous Transition-Metal-Catalyzed N-Arylation of Indoles}

A straightforward approach to the preparation of indolo[1,2-f]phenanthridine derivatives S34-3 based on the N-arylation of 2-aryl-3-substituted indoles S34-1 using an iridiumcatalyzed oxidative [4 +2] annulation reaction with quinones S34-2 was reported by Guo and Fan (Scheme 34) [152]. A series of $20 \mathrm{~N}$-arylated indoles was prepared, all in satisfactory yields, under optimized reaction conditions. The indoles substituted at positions 2 and 3 smoothly reacted under optimized reaction conditions. However, the reaction is limited for benzoquinone and 2-methylbenzoquinone. Other quinone derivatives, such as 2-chlorobenzoquinone, 2,5-dimethylbenzoquinone, and naphthoquinone, did not furnish the corresponding products. The authors posited a plausible reaction mechanism on the basis of mechanistic studies. Initially, the iridium-catalyzed dual N-H/C-H bond activation of S34-5 is responsible for the formation of five-membered iridacycle S34-6. The subsequent coordination of benzoquinone to the iridium complex S34-6 affords the new iridacycle S34-7, which then undergoes a migratory insertion to deliver a seven-membered intermediate S34-8. Next, the protonolysis of the complex S34-8 with HOAc leads to both intermediate S34-9 and the active Ir(III) catalyst S34-4. Finally, a $\mathrm{Zn}(\mathrm{OAc})_{2}$-promoted intramolecular indolyl N1-attack on the carbonyl group affords the key intermediate S34-10, which undergoes a dehydration reaction to deliver the final product S34-11.

An alternative approach to the $\mathrm{N}$-arylation of indole-2-carboxamides was developed by Kong (Scheme 35) [153]. In this reaction, zinc(II) iodide is used as a catalyst and $\mathrm{Ag}_{2} \mathrm{CO}_{3}$ as an oxidant en route to indolo[1,2-a]quinoxalin-6-on S35-2. The scope of the reaction is limited to substrates with a methoxy group or halogens. The presence of the $\mathrm{N}-\mathrm{CH}_{3}$ amide moiety in the starting compound is crucial for the success of this reaction, as no reaction occurred in the case of a substrate bearing an $\mathrm{N}-\mathrm{H}$ amide group or a $-\mathrm{CO}_{2}(4-\mathrm{MePh})$ group. It was proposed that this behavior is caused by the steric effect of the $\mathrm{N}-\mathrm{CH}_{3}$ group, which can bring the two reaction sites closer, thereby facilitating the intramolecular cyclization reaction. A plausible mechanism can be identified on the basis of controlled experiments. The reaction is initiated by the generation of the indolylzinc(II) intermediate A. The oxidation of $\mathbf{A}$ by $\mathrm{Ag}_{2} \mathrm{CO}_{3}$ delivers the resonance-stabilized radical intermediate $\mathbf{B}$ or $\mathbf{C}$. The intermediate $\mathbf{D}$ is obtained via the intramolecular addition of an indole radical onto the $\mathrm{N}$-aryl moiety, which is followed by oxidation and deprotonation to give the desired product S33-2a. 
<smiles>[R12]c1ccc2[nH]c(-c3cccc(-[Z17]4ccc(O[Si])cc4)c3)c([R])c2c1</smiles>

Selected examples<smiles>Oc1ccc2c(c1)c1ccc(Br)cc1c1c(-c3ccccc3)c3ccccc3n21</smiles>

S34-3a $69 \%$

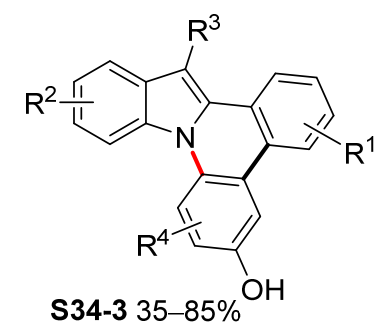

20 examples

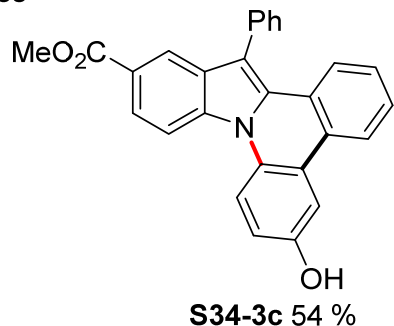

S34-3c $54 \%$

Proposed mechanism:

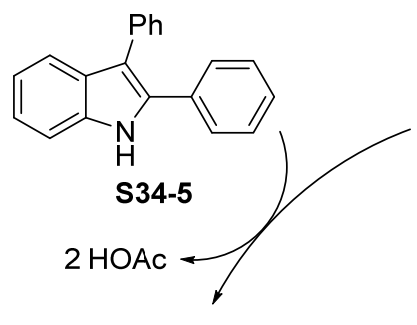<smiles>c1ccc(-c2c3n(c4ccccc24)[I-]c2ccccc2-3)cc1</smiles>

$\mathrm{Cp} * \mathrm{Ir}(\mathrm{OAc})_{2}$

S34-4

S34-3b $63 \%$

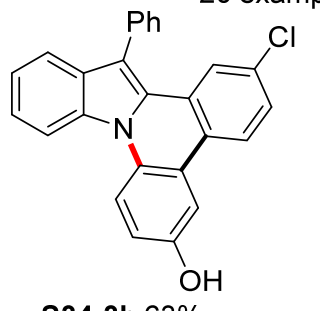

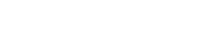
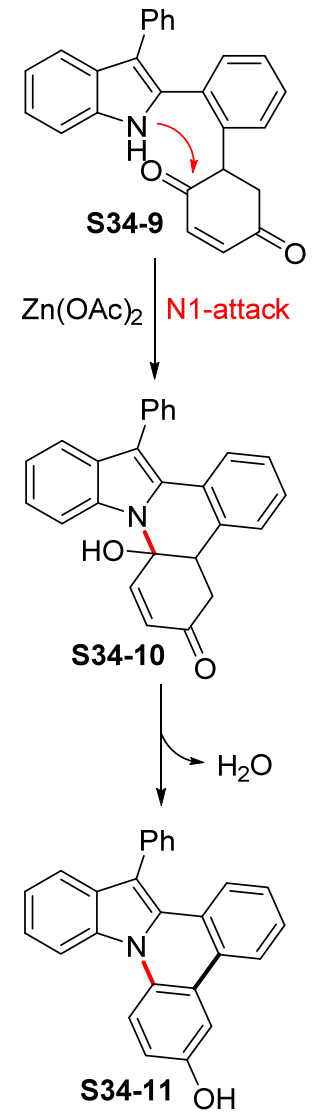

Scheme 34. Iridium-catalyzed oxidative annulation of 2-arylindoles S34-1. 

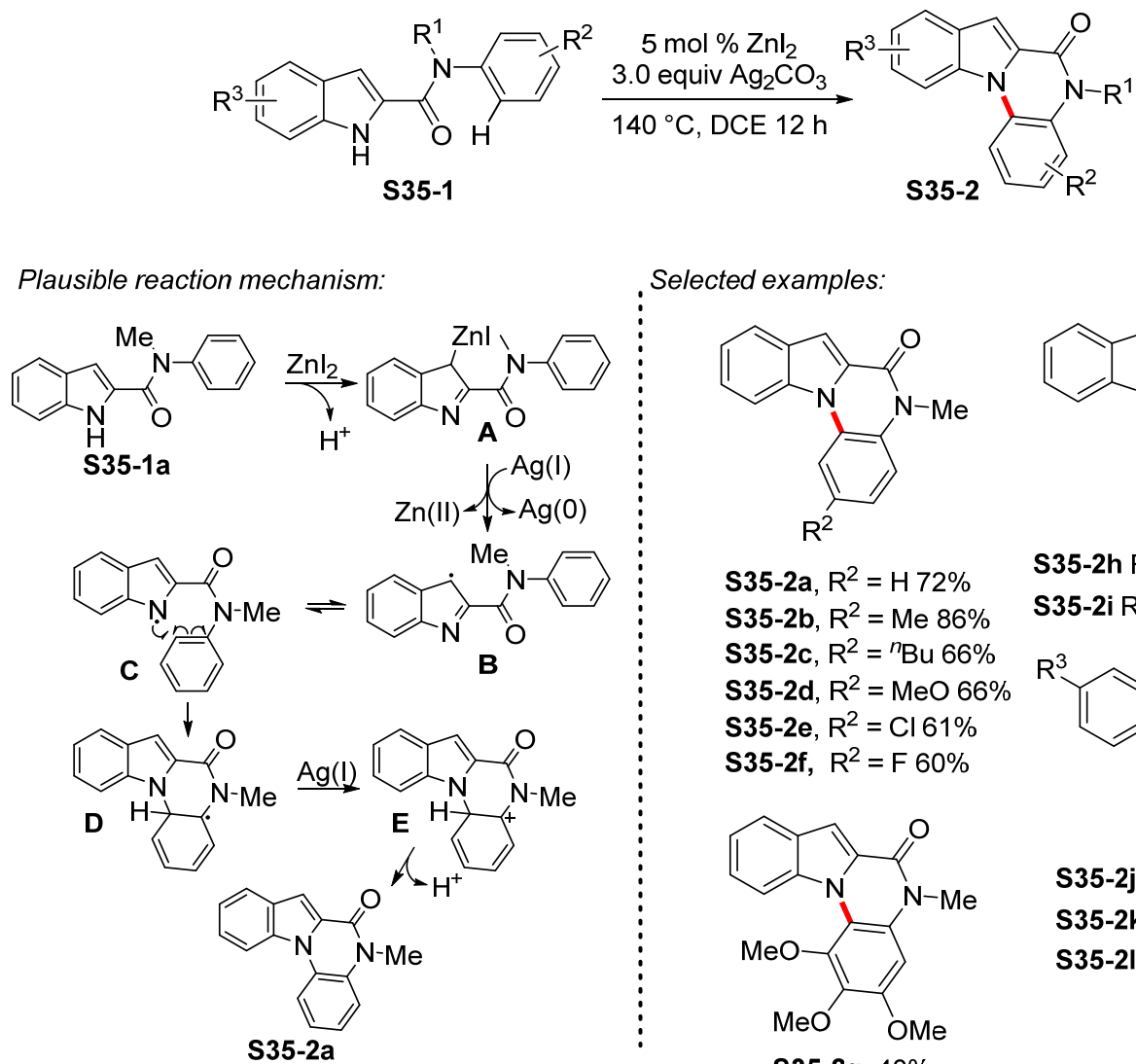

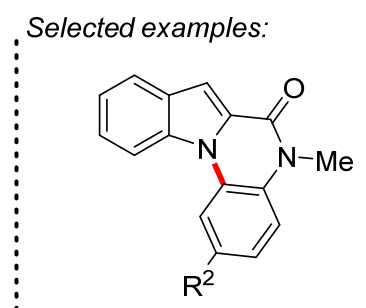

S35-2a, $R^{2}=H 72 \%$ S35-2b, $R^{2}=$ Me $86 \%$ S35-2c, $R^{2}={ }^{n} \mathrm{Bu} 66 \%$ S35-2d, $R^{2}=\mathrm{MeO} 66 \%$ S35-2e, $R^{2}=\mathrm{Cl} 61 \%$ S35-2f, $R^{2}=F 60 \%$<smiles>COc1cc2c(c(OC)c1OC)n1c(cc3ccccc31)c(=O)n2C</smiles>

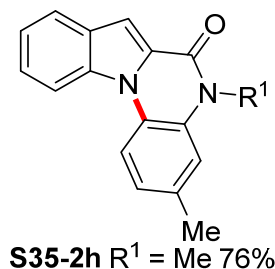

S35-2i R ${ }^{1}=$ Et $79 \%$<smiles>[R]c1ccc2c(c1)cc1c(=O)n(C)c3ccccc3n12</smiles>

S35-2j $R^{3}=\mathrm{MeO} 67 \%$

S35-2k R $\mathrm{R}^{3}=\mathrm{Cl}, 82 \%$

S35-2I R R $^{3}=$ F 77\%

Scheme 35. Novel method for the N-H arylation of indole-2-carboxamides S35-1 developed.

\section{N-Arylated Indoles as Biologically Active Substances}

In the preceding sections, we have discussed a wide variety of procedures that can be used for the preparation of $\mathrm{N}$-indoles. Such a large number of different procedures have been developed due to the near endless number of applications of $\mathrm{N}$-arylindoles. Among them, $\mathrm{N}$-arylindoles have found applications in the field of materials chemistry. For example, $N$-arylindoles have been proposed as novel dye-sensitized solar cells [154], electrophosphorescent diodes [155], oxygen sensors [156], and other things [157-160]. Procedures for the $\mathrm{N}$-arylation of indoles have also been used for the preparation of indoles with biological activity. A number of $\mathrm{N}$-arylindoles have been prepared in structureactivity relationship (SAR) studies in an effort to verify the mechanisms of the biological activity of the substituted indoles; and the determination of the biological activities of $\mathrm{N}$-arylindoles has also been part of a large-scope synthetic study concerning the preparation of $\mathrm{N}$-arylindoles. Examples of such works include inhibitors of human neutrophil elastase (HNE) [161], centromere-associated protein-E (CENP-E) inhibitors [162], CRTh2 antagonists [163], and determinations of cytotoxic activity [164,165]. Ultimately, a large group of $\mathrm{N}$-arylindoles was prepared to study their biological activity. Selected examples are given in Figures 5-9. 
<smiles>[R]C1=NC2(CCCC2)C(=O)N1Cc1cccc2c1ccn2-c1ccccc1-c1nnn[nH]1</smiles>

F5-1a $\mathrm{R}={ }^{n} \mathrm{Pr}$

F5-1b R $={ }^{n} \mathrm{Bu}$

F5-1c $R={ }^{n}$ Pentyl<smiles>[R]C1=NC2(CCCC2)C(=O)N1Cc1ccc2c(ccn2-c2ccccc2-c2nnn[nH]2)c1</smiles>

F5-2a $R={ }^{n} \operatorname{Pr}$

F5-2b R $={ }^{n} \mathrm{Bu}$

F5-2c R $={ }^{n}$ Pentyl

F5-2d R = ${ }^{n}$ hexyl

$\mathrm{N}$-arylation conditions:

2-fluorobenzonitrile, $\mathrm{K}_{2} \mathrm{CO}_{3}$ (2.1 equiv),

DMF, reflux

Biological activity:

Angiotensin II receptor 1 antagonists

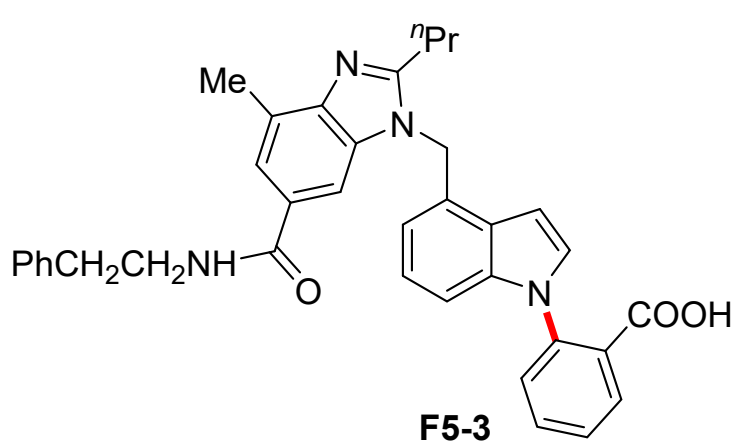<smiles>CCCCc1nc(Cl)c(C(=O)O)n1Cc1cccc2c1ccn2-c1ccccc1-c1noc(=O)[nH]1</smiles>

Figure 5. Selected examples of bioactive $N$-arylindoles-part 1.<smiles>Cc1ccc2c(c1)N=Cc1cc3c(-n4ccc5cc(C)c(F)cc54)cccc3nc1O2</smiles>

F6-1

$\mathrm{N}$-arylation conditions:

${ }^{\text {het }} \mathrm{ArBr}$

XPhos $\mathrm{Pd} \mathrm{G}_{2}$ (3 mol\%)

$t$-BuONa (1.5 equiv), 1,4-dioxane

$90{ }^{\circ} \mathrm{C}, 45 \mathrm{~min}$

Biological activity:

Inhibition of alpha-amylase

and alpha-glucosidase<smiles>Clc1ccc2c(c1)cc1n2c2ccccc2c2nc3ccccc3n21</smiles>

F6-2

$\mathrm{N}$-arylation conditions:

$\mathrm{Ar}-\mathrm{Br}$

Cul (20 mol\%)

$\mathrm{K}_{2} \mathrm{CO}_{3}$ (2 equiv), DMF, $150^{\circ} \mathrm{C}, 2 \mathrm{~h}$

Biological activity:

Antimicrobial activity

Figure 6. Selected examples of bioactive $N$-arylindoles-part 2. 
12<smiles>Cc1c(Sc2c(C)n(-c3cnn(C)c3)c3cc(Cl)ccc23)cccc1C(=O)O</smiles>

$$
\begin{aligned}
& \text { F7-1a X }=\mathrm{N} \\
& \text { F7-1b } X=\mathrm{CH}
\end{aligned}
$$

$\mathrm{N}$-arylation conditions:

4-iodo-1-methylpyrazole $\mathrm{CuO}(50 \mathrm{~mol} \%)$

1,10-phenanthroline (1 equiv)

$\mathrm{Cs}_{2} \mathrm{CO}_{3}$ (2 equiv), pyridine, $110^{\circ} \mathrm{C}, \mathrm{MW}, 2 \mathrm{~h}$

Biological activity: Autotaxin (ATX) inhibitors<smiles>COc1ccc2c(c1)c(CC(=O)NC(Cc1ccccc1)C(=O)NS(=O)(=O)c1ccc(Cl)c([N+](=O)[O-])c1)c(C)n2-c1ccc(-c2ccccc2)cc1</smiles>

F7-2

$N$-arylation conditions:

Ar-I

$\mathrm{CuO}(43 \mathrm{~mol} \%)$

$\mathrm{KOH}$ (2.2 equiv),

DMF, reflux, $5 \mathrm{~h}$

Biological activity:

Inhibitory activities on Bcl-2/Mcl-1 and anti-proliferative activity

39<smiles>O=c1cc(CN2CCOc3c(Cl)cc(-n4ccc5cc(F)ccc54)cc3C2)cc[nH]1</smiles>

$N$-arylation conditions:

$\mathrm{ArBr}$

Cul (10 mol\%)

$N, N^{\prime}$-dimethyl-1,2-cyclohexandiamine (20 mol\%)

$\mathrm{K}_{3} \mathrm{PO}_{4}$ (2.2 equiv)

1,4-dioxane, $110^{\circ} \mathrm{C}$

Biological activity:

Binding afinity for the EP2

Figure 7. Selected examples of bioactive $N$-arylindoles-part 3. 
<smiles>Cc1ccc(-n2cc(CO)c3ccccc32)cc1</smiles>

F8-1

$\mathrm{N}$-arylation conditions: Cul (20 mol\%) L-proline (40 mol\%) $\mathrm{K}_{2} \mathrm{CO}_{3}$ (2 equiv) DMSO, $130^{\circ} \mathrm{C}, 3 \mathrm{~h}$ Biological activity:<smiles>NC(=O)c1cc2ccc(OC(F)(F)F)cc2n1-c1cccc(CCC(=O)O)c1</smiles>

F8-2

$\mathrm{N}$-arylation conditions:

Cul (20 mol\%)

piperidine-2-carboxylic acid (40 mol\%)

$\mathrm{K}_{2} \mathrm{CO}_{3}$ (3 equiv)

DMF, $110^{\circ} \mathrm{C}$

Biological activity:

sPLA $_{2}$ inhibitors

Inhibititors of NEDD4-1 ubiquitin ligase activity

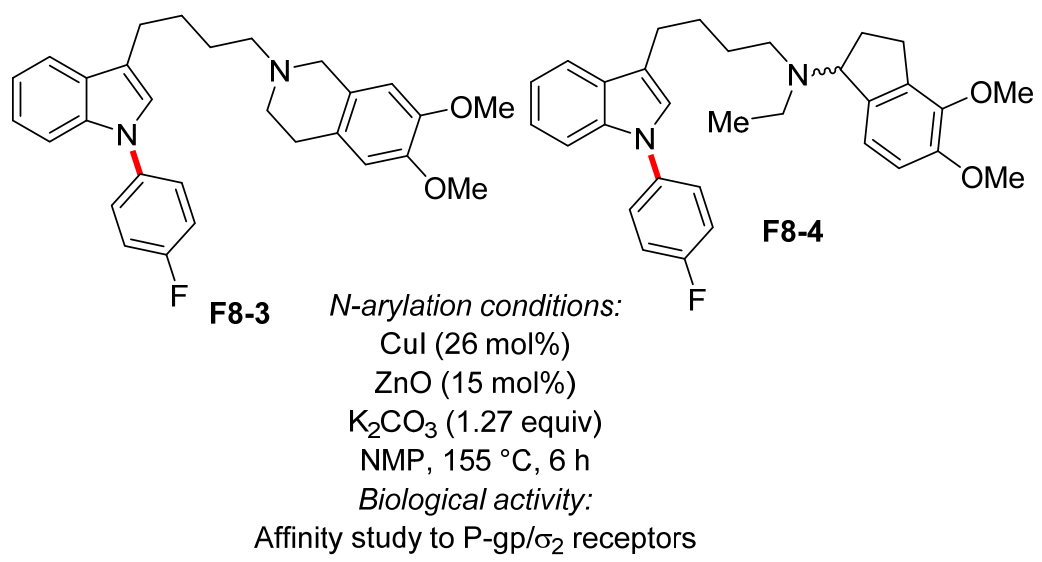

Figure 8. Selected examples of bioactive $N$-arylindoles-part 4.

19<smiles>O=C(O)CCc1ccc2c(c1)c(CCc1ccccc1)cn2-c1ccccc1</smiles>

F9-1

$N$-arylation conditions:

$\mathrm{Ph}-\mathrm{I}$

$\mathrm{CuBr}(10 \mathrm{~mol} \%)$

$\mathrm{K}_{2} \mathrm{CO}_{3}$ (4 equiv), $85 \% \mathrm{KOH}$ (1 equiv)

$\mathrm{Cu}(\mathrm{OAc})_{2}(10 \mathrm{~mol} \%)$

$140{ }^{\circ} \mathrm{C}$, on

Biological activity:

Cytosolic phospholipase $A_{2} \alpha$ inhibitors

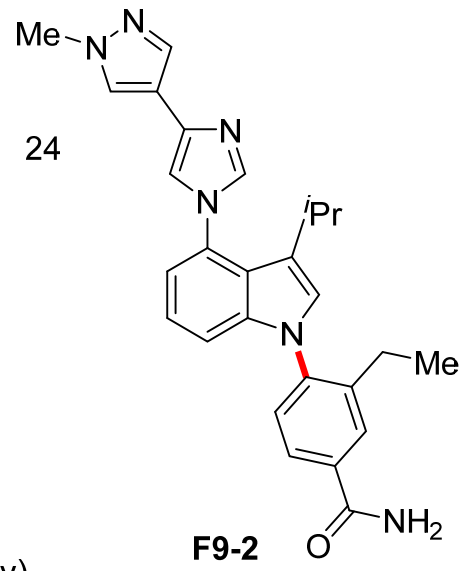

$\mathrm{N}$-arylation conditions:

Ar-I

Cul (10 mol\%), DMEDA (20 mol\%)

$\mathrm{Cs}_{2} \mathrm{CO}_{3}$ (2 equiv),

1,4-dioxane, $110^{\circ} \mathrm{C}, 14 \mathrm{~h}$

Biological activity:

Inhibitors

of the molecular chaperone heat protein 90 (HSP90)

Figure 9. Selected examples of bioactive $N$-arylindoles-part 5. 


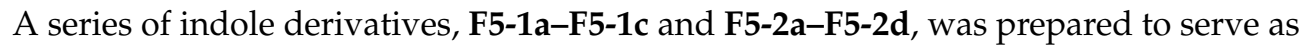
angiotensin II (Ang II) receptor 1 antagonists (Figure 5) [166]. The introduction of the aryl substituent was accomplished through nucleophilic aromatic substitution by means of the reaction of substituted indoles with 2-fluorobenzonitrile in the presence of potassium carbonate in refluxing DMF. Among the prepared $N$-arylindoles, the compound $\mathbf{F 5 - 2 \mathbf { b }}$ showed binding affinity to the angiotensin $\mathrm{AT}_{1}$ receptor, with an $\mathrm{IC}_{50}$ value of $1.26 \pm 0.08 \mathrm{nM}$ in radioligand binding assays. The same compound also showed the strongest antihypertensive effect, with a maximum reducing response of lower than $40.62 \pm 4.08 \mathrm{mmHg} \mathrm{MBP}$ at $15 \mathrm{mg} / \mathrm{kg} 4 \mathrm{~h}$ after oral administration in SHRs. The acute toxicity of compound F5-2b was determined by $\mathrm{LD}_{50}$ as $1551.71 \mathrm{mg} / \mathrm{kg}$. Other indole derivatives have been prepared by the same group and studied as angiotensin II receptor 1 antagonists [167-170]. The examples given in Figure 5 show that a common feature of these compounds is the presence of an ortho-substituted phenyl ring with a carboxylic acid F5-3 $[167,168,170]$ or 1,2,4-oxadiazole F5-4 [169] scaffold at position 1 of the indole unit. Similarly, the introduction of phenyl substituents was accomplished via nucleophilic aromatic substitution in refluxing DMF.

The new quinoline derivatives were prepared by means of a Buchwald-Hartwig reaction, which was catalyzed using a XPhos Pd G2 catalyst and ${ }^{t} \mathrm{BuONa}$ as the base (Figure 6) [171]. A number of compounds, including the indole derivative F6-1, were prepared using this procedure. It was determined that the substance $\mathbf{F 6 - 1}$ inhibited 70\% of the $\alpha$-amylase at a concentration of $50 \mu \mathrm{g} / \mathrm{mL}$, and it also inhibited $\alpha$-glucosidase at a concentration of $50 \mu \mathrm{g} / \mathrm{mL}$. Benzimidazole and indole conjugates were prepared via double copper-catalyzed C-N bond formation [172]. The selected compound F6-2 demonstrated the formation of a $\mathrm{N}^{\text {indole }} \mathrm{C}^{\text {phenyl }}$ bond by a copper(I)-iodide-catalyzed reaction in DMF at $150{ }^{\circ} \mathrm{C}$. The substance $\mathbf{F 6 - 2}$ showed the best minimum inhibitory concentration (MIC) of $4 \mu \mathrm{g} / \mathrm{mL}$ against Gram-negative (E. coli, P. putida, and S. typhi) and Gram-positive (B. subtilis and $S$. aureus) bacteria. The antifungal activity against $C$. albicans and $A$. niger of F6-2 is represented by an MIC value of $16 \mu \mathrm{g} / \mathrm{mL}$.

A number of indole derivatives with a 1-methylpyrazol-4-yl substituent at position 1 were investigated with respect to their inhibitory activity in relation to the autotaxin (ATX) enzyme, which is responsible for the hydrolysis of lysophosphatidylcholine (LPC) (Figure 7) [173]. The introduction of the pyrazole skeleton was performed by means of Ullman condensation with copper oxide and 1,10-phenanthroline ligand in pyridine at $110{ }^{\circ} \mathrm{C}$ under microwave conditions. A detailed SAR study showed that the indole derivative F7-1a is a potent compound with an $\mathrm{IC}_{50}$ value of $22 \pm 6.9 \mathrm{nM}$ in the Bis-pNPP assay and $4 \pm 0.5 \mathrm{nM} \mathrm{IC}_{50}$ in the LPC assay. Similar results were observed for the benzoic derivative F7-1b. The crystal structure of the studied compounds indicated that the active compounds bind within the tunnel, which was described as an allosteric binding site. Both B-cell lymphoma (Bcl-2) and myeloid cell leukemia sequence 1 (Mcl-1) are proteins that help with the development and survival of multiple tumor types. Therefore, Fang [174] focused on studying the properties of indole derivatives with a phenyl substituent at position 1 as compounds that exhibit potent inhibitory activity against Bcl-2. The introduction of the aryl substituents was again catalyzed by cuprous oxide, although the reactions were performed in refluxing DMF. Compound F7-2 showed the best activity against Bcl-2, with a Ki value of $0.35 \pm 0.03 \mu \mathrm{M}$. Docking studies revealed that the active compound F7-2 binds to the active pocket of the Bcl-2 protein through a hydrogen bond with Arg143 and the $\pi-\pi$ interaction with Ph109 and Phe101. A number of 2,3-dihydrobenzo[f][1,4]oxazepine derivatives were prepared as antagonists of the prostaglandin E2 receptor subtype 2 (EP2) [175]. The oxazepine derivative with a 4-fluoroindole substituent F7-3 showed a binding affinity of $8 \mathrm{nM}$ for the hEP2 receptor and an $\mathrm{IC}_{50}$ value of $50 \mathrm{nM}$ in the hEP2 cAMP assay. In addition, the compound lacked CYP inhibition at $3 \mu \mathrm{M}$ and had a 4000-fold higher binding affinity for the hEP2 receptor when compared with hEP1, hEP3, and hEP4. The formation of a N-C ${ }^{\text {aryl }}$ bond was accomplished via a CuI-catalyzed reaction in the presence of a $N, N^{\prime}$-dimethyl-1,2-cyclohexandiamine ligand and potassium phosphate as the base in 1,4-dioxane at $110^{\circ} \mathrm{C}$. 
New substituted indole-3-carbinoles, as potent anti-cancer compounds derived from indole-3-carbinol (I3C), were designed and prepared as new inhibitors of NEDD4-1 ubiquitin ligase activity (Figure 8) [176]. In this case, the $\mathrm{N}$-arylation of indoles was accomplished by means of an L-proline ligand and a copper catalyst. The parent carbinol I3C reached an $\mathrm{IC}_{50}$ value of $284 \mu \mathrm{M}$. The introduction of a benzyl group into position 1 decreased the $\mathrm{IC}_{50}$ value to $12.3 \mu \mathrm{M}$, whereas the introduction of the 4-tolyl group F8-1 substantially improved the $\mathrm{IC}_{50}$ value to $2.71 \mu \mathrm{M}$. Protein thermal shift assays in combination with in-silico binding simulation revealed that the tested derivatives bind to the purified catalytic HECT domain of NEDD4-1. In 2018, Knerr published two papers that evaluated $N$-arylindoles with trifluoromethoxy and carboxamide groups as selective inhibitors of secreted phospholipase $\mathrm{A}_{2}$ type $\mathrm{X}[177,178]$. The formation of an $\mathrm{N}-\mathrm{C}^{\text {aryl }}$ bond was achieved by means of coppercatalyzed Ullman condensation in the presence of piperidine-2-carboxylic acid as a ligand. The indole F8-2 exhibited the best $\mathrm{IC}_{50}$ value $(0.022 \mu \mathrm{M})$ against sPLA $2-\mathrm{X}$. The presence of a trifluoromethoxy group is the key to achieving high inhibitory activity. The substitution of $\mathrm{CF}_{3} \mathrm{O}$ for the methoxy group led to the $\mathrm{IC}_{50}$ value being reduced to $0.62 \mu \mathrm{M}$. In another two papers $[179,180]$, the selective activity of $N$-arylindoles toward P-glycoprotein (P-gp) or $\sigma_{2}$ receptor agents was studied. The indole derivative F8-3 was chosen as a good ligand for both P-glycoprotein (P-gp) and the $\sigma_{2}$ receptor. The starting compound F8-3 was subject to SAR studies wherein the $\mathrm{N}$-arylation of indoles was performed by a copper-catalyzed reaction in the presence of zinc oxide. On the basis of these studies, the compound F8-4 as a (+)-(S)-enantiomer displayed notable nanomolar $\sigma_{2}$ affinity [180].

Another set of indole derivatives with a similar substitution at position 1 of the indole skeleton was reported by Tamoo [181] and Uno (Figure 9) [182]. On the basis of extensive SAR studies, it was found that F9-1 is an inhibitor of $\mathrm{CPLA}_{2 \alpha}$ (with an $\mathrm{IC}_{50}$ value of $0.075 \mu \mathrm{M})[181]$, and indole F9-2 is a selective inhibitor of both HSP90 $\left(\mathrm{IC}_{50}=0.069 \mu \mathrm{M}\right)$ and SK-Br-3 $\left(\mathrm{IC}_{50}=0.33 \mu \mathrm{M}\right)$ [182]. The introduction of the aryl substituents was accomplished via copper-catalyzed Ullman condensation at reaction temperatures above $100{ }^{\circ} \mathrm{C}$.

\section{Conclusions}

This review article has summarized the current state-of-the-art procedures for the preparation of $\mathrm{N}$-arylindoles. The syntheses of the target compounds can be accomplished in several ways. The simplest procedures are based on transition-metal-free reactions. The second approach makes use of transition-metal-catalyzed aminations of organohalogenides or organometallic compounds. The metal most commonly used for the $\mathrm{N}$-arylation of indoles is arguably copper, although a number of processes use palladium and nickel catalysts. The $\mathrm{N}$-arylation of indoles can be performed in an inter- or intramolecular manner in high isolated yields. Despite considerable efforts having been made to successfully accomplish $\mathrm{N}$-arylation experiments, two major limitations persist. The first limitation is associated with the low tolerance of the functional groups. Only the $\mathrm{N}$-arylation of indoles, which is accomplished by the effect of triorganobismuth reagents, avoids this trend. The second limitation concerns the reaction temperatures at which the $N$-arylations take place. In the vast majority of cases, the $\mathrm{N}$-arylations are performed at high temperatures, which commonly exceed $100{ }^{\circ} \mathrm{C}$. In some cases, the arylation reactions are also performed in refluxing DMF. However, $\mathrm{N}$-arylations of indoles at room temperature are rare. Thus, the development of new catalytic systems for the $N$-arylation of indoles represents a new direction of development in this field. Such efforts will result in higher tolerance of the functional groups, which should streamline the development of new biologically active compounds based on substituted indoles. At the same time, efforts to lower the reaction temperature required for the $N$-arylation of indoles will greatly benefit the overall economic aspects of the process. 
Author Contributions: Conceptualization-T.T.; writing original draft and editing-P.O., J.K., A.P., T.T. All authors have read and agreed to the published version of the manuscript.

Funding: This work was supported from the grant of Specific university research grant No A2_FCHT_2021_074 and the APC was funded by University of Chemistry and Technology Prague.

Institutional Review Board Statement: Not applicable.

Informed Consent Statement: Not applicable.

Data Availability Statement: Not applicable.

Conflicts of Interest: The authors declare no conflict of interest.

\section{References}

1. Lampis, G.; Deidda, D.; Maullu, C.; Madeddu, M.A.; Pompei, R.; Delle Monachie, F.; Satta, G. Sattabacins and Sattazolins: New Biologically Active Compounds with Antiviral Properties Extracted from a Bacillus sp. J. Antibiot. 1995, 48, 967-972. [CrossRef]

2. Haviernik, J.; Stefanik, M.; Fojtikova, M.; Kali, S.; Tordo, N.; Rudolf, I.; Hubalek, Z.; Eyer, L.; Ruzek, D. Arbidol (Umifenovir): A Broad-Spectrum Antiviral Drug That Inhibits Medically Important Arthropod-Borne Flaviviruses. Viruses 2018, $10,184$. [CrossRef] [PubMed]

3. Lewis, R.; Bagnall, A.M.; Leitner, M. Sertindole for schizophrenia. Cochrane Database Syst. Rev. 2005, 3. [CrossRef] [PubMed]

4. Bhattacharjee, P.; Bora, U. Organocatalytic Dimensions to the C-H Functionalization of the Carbocyclic Core in Indoles: A Review Update. Org. Chem. Front. 2021, 8, 2343-2365. [CrossRef]

5. Čubiňák, M.; Edlová, T.; Polák, P.; Tobrman, T. Indolylboronic Acids: Preparation and Applications. Molecules 2019, 24, 3523. [CrossRef] [PubMed]

6. Trubitsõn, D.; Kanger, T. Enantioselective Catalytic Synthesis of N-Alkylated Indoles. Symmetry 2020, 12, 1184. [CrossRef]

7. Urbina, K.; Tresp, D.; Sipps, K.; Szostak, M. Recent Advances in Metal-Catalyzed Functionalization of Indoles. Adv. Synth. Catal. 2021, 363, 2723-2739. [CrossRef]

8. Wen, J.; Shi, Z. From C4 to C7: Innovative Strategies for Site-Selective Functionalization of Indole C-H Bonds. Acc. Chem Res. 2021, 54, 1723-1736. [CrossRef]

9. Polák, P.; Čejka, J.; Tobrman, T. Formal Transition-Metal-Catalyzed Phosphole C-H Activation for the Synthesis of Pentasubstituted Phospholes. Org. Lett. 2020, 22, 2187-2190. [CrossRef]

10. Keglevich, G. 1-(2,4,6-Trialkylphenyl)-1H-Phospholes with a Flattened P-Pyramid: Synthesis and Reactivity. In Phosphorus Heterocycles II; Topics in Heterocyclic Chemistry; Bansal, R., Ed.; Springer: Berlin/Heidelberg, Germany, 2010; Volume 21, pp. 149-173.

11. Quin, L.D. The Continuing Development of the Chemistry of Phospholes. Curr. Org. Chem. 2006, 10, 43-78. [CrossRef]

12. Romero-Nieto, C.; Baumgartner, T. Dithieno[3,2-b:2',3'-d]phospholes: A Look Back at the First Decade. Synlett 2013, $24,920-937$. [CrossRef]

13. Zagidullin, A.A.; Bezkishko, I.A.; Miluykov, V.A.; Sinyashin, O.G. Phospholes-Development and Recent Advances. Mendeleev Commun. 2013, 23, 117-130. [CrossRef]

14. Ding, Z.; Nie, N.; Chen, T.; Meng, L.; Wang, G.; Chen, Z.; Hu, J. L-Proline N-Oxide Dihydrazides as an Efficient Ligand for Cross-Coupling Reactions of Aryl Iodides and Bromides with Amines and Phenols. Tetrahedron 2021, 79, 131826. [CrossRef]

15. Antilla, J.C.; Baskin, J.M.; Barder, T.E.; Buchwald, S.L. Copper-Diamine-Catalyzed N-Arylation of Pyrroles, Pyrazoles, Indazoles, Imidazoles, and Triazoles. J. Org. Chem. 2004, 69, 5578-5587. [CrossRef] [PubMed]

16. Chen, W.; Li, H.J.; Cheng, Y.F.; Wu, Y.C. Direct C2-Arylation of N-Acyl Pyrroles with Aryl Halides under Palladium Catalysis. Org. Biomol. Chem. 2021, 19, 1555-1564. [CrossRef] [PubMed]

17. Kaloğlu, M.; Düşünceli, S.D.; Özdemir, İ. The First Used Butylene Linked bis(N-Heterocyclic Carbene)-Palladium-PEPPSI Complexes in the Direct Arylation of Furan and Pyrrole. J. Organomet. Chem. 2020, 915, 121236. [CrossRef]

18. Chen, D.; Li, J.; Shan, Y.; Cui, P.; Zhao, Y.; Tian, L.; Qiu, G. Halogen-Radical-Promoted Dearomative Aza-Spirocyclization of Alkynylimines: An Efficient Approach to 3-Halo-Spirocyclohexadienones. Synthesis 2020, 52, 609-618. [CrossRef]

19. Polák, P.; Tobrman, T. Dearomatization Strategy for the Synthesis of Arylated $2 H$-Pyrroles and 2,3,5-Trisubstituted $1 H$-Pyrroles. Org. Lett. 2017, 19, 4608-4611. [CrossRef]

20. Zhuo, C.-X.; Cheng, Q.; Liu, W.-B.; Zhao, Q.; You, S.-L. Enantioselective Synthesis of Pyrrole-Based Spiro- and Polycyclic Derivatives by Iridium-Catalyzed Asymmetric Allylic Dearomatization and Controllable Migration Reactions. Angew. Chem. Int. Ed. 2015, 54, 8475-8479. [CrossRef]

21. Zhuo, C.-X.; Liu, W.-B.; Wu, Q.-F.; You, S.-L. Asymmetric dearomatization of pyrroles via Ir-catalyzed allylic substitution reaction: Enantioselective synthesis of spiro-2H-pyrroles. Chem. Sci. 2012, 3, 205-208. [CrossRef]

22. Zhuo, C.-X.; Zhou, Y.; You, S.-L. Highly Regio- and Enantioselective Synthesis of Polysubstituted $2 H$-Pyrroles via Pd-Catalyzed Intermolecular Asymmetric Allylic Dearomatization of Pyrroles. J. Am. Chem. Soc. 2014, 136, 6590-6593. [CrossRef]

23. Kunz, K.; Scholz, U.; Ganzer, D. Renaissance of Ullmann and Goldberg Reactions-Progress in Copper Catalyzed C-N-, C-Oand C-S-Coupling. Synlett 2003, 2428-2439. [CrossRef] 
24. Sambiagio, C.; Marsden, S.P.; Blacker, A.J.; McGowan, P.C. Copper Catalysed Ullmann Type Chemistry: From Mechanistic Aspects to Modern Development. Chem. Soc. Rev. 2014, 43, 3525-3550. [CrossRef]

25. Sperotto, E.; van Klink, G.P.M.; van Koten, G.; de Vries, J.G. The Mechanism of the Modified Ullmann Reaction. Dalton Trans. 2010, 39, 10338-10351. [CrossRef] [PubMed]

26. Dorel, R.; Grugel, C.P.; Haydl, A.M. The Buchwald-Hartwig Amination after 25 Years. Angew. Chem. Int. Ed. 2019, 58, 17118-17129. [CrossRef] [PubMed]

27. Forero-Cortés, P.A.; Haydl, A.M. The 25th Anniversary of the Buchwald-Hartwig Amination: Development, Applications, and Outlook. Org. Proc. Res. Develop. 2019, 23, 1478-1483. [CrossRef]

28. Heravi, M.M.; Kheilkordi, Z.; Zadsirjan, V.; Heydari, M.; Malmir, M. Buchwald-Hartwig reaction: An overview. J. Organomet. Chem. 2018, 861, 17-104. [CrossRef]

29. Chen, J.-Q.; Li, J.-H.; Dong, Z.-B. A Review on the Latest Progress of Chan-Lam Coupling Reaction. Adv. Synth. Catal. 2020, 362, 3311-3331. [CrossRef]

30. Munir, I.; Zahoor, A.F.; Rasool, N.; Naqvi, S.A.R.; Zia, K.M.; Ahmad, R. Synthetic Applications and Methodology Development of Chan-Lam Coupling: A Review. Mol. Divers. 2019, 23, 215-259. [CrossRef] [PubMed]

31. West, M.J.; Fyfe, J.W.B.; Vantourout, J.C.; Watson, A.J.B. Mechanistic Development and Recent Applications of the Chan-Lam Amination. Chem. Rev. 2019, 119, 12491-12523. [CrossRef]

32. Joucla, L.; Djakovitch, L. Transition Metal-Catalysed Direct and Site-Selective N1-, C2- or C3-Arylation of the Indole Nucleus: 20 Years of Improvements. Adv. Synth. Catal. 2009, 351, 673-714. [CrossRef]

33. $\mathrm{Xu}, \mathrm{H}$. Advances on $\mathrm{N}$-Arylation of Indoles by Cross-Coupling Reactions. Mini-Rev. Org. Chem. 2009, 6, 367-377. [CrossRef]

34. Halder, P.; Roy, T.; Das, P. Recent developments in selective N-arylation of azoles. Chem. Commun. 2021, 57, 5235-5249. [CrossRef] [PubMed]

35. Chang, D.; Gao, F.; Shi, L. Potassium tert-butoxide-mediated generation of arynes from o-bromoacetophenone derivatives. Tetrahedron 2018, 74, 2428-2434. [CrossRef]

36. Chen, J.; Wu, J. Transition-Metal-Free C3 Arylation of Indoles with Aryl Halides. Angew. Chem. Int. Ed. 2017, 56, 3951-3955. [CrossRef] [PubMed]

37. Hu, F.; Liu, H.; Jia, J.; Ma, C. Transition-metal-free synthesis of indole-fused dibenzo[b,f][1,4]oxazepines via Smiles rearrangement. Org. Biomol. Chem. 2016, 14, 11076-11079. [CrossRef]

38. Annareddygari, S.; Kasireddy, V.R.; Reddy, J. Transition-Metal-Free N-Arylation: A General Approach to Aza-Fused Polyheteroaromatics. J. Heterocycl. Chem. 2019, 56, 3267-3276. [CrossRef]

39. Huang, A.; Liu, F.; Zhan, C.; Liu, Y.; Ma, C. One-Pot Synthesis of Pyrrolo[1,2-a]quinoxalines. Org. Biomol. Chem. 2011, 9, 7351-7357. [CrossRef]

40. Thanetchaiyakup, A.; Rattanarat, H.; Chuanopparat, N.; Ngernmeesri, P. One-Pot Synthesis of Substituted Indolo[1,2-a]quinolines under Transition-Metal-Free Conditions. Tetrahedron Lett. 2018, 59, 1014-1018. [CrossRef]

41. Xu, H.; Sun, L.; Song, C. Base-Mediated N-Arylation for the Synthesis of 9H-Pyrrolo[1,2-a]indol-9-ones and 10H-Indolo[1,2a]indol-10-ones. Helv. Chim. Acta 2019, 102, e1800195. [CrossRef]

42. Diness, F.; Begtrup, M. Sequential Direct $S_{N} A r$ Reactions of Pentafluorobenzenes with Azole or Indole Derivatives. Org. Lett. 2014, 16, 3130-3133. [CrossRef]

43. Diness, F.; Fairlie, D.P. Catalyst-Free N-Arylation Using Unactivated Fluorobenzenes. Angew. Chem. Int. Ed. 2012, 51, 8012-8016. [CrossRef] [PubMed]

44. Chang, G.; Yang, L.; Liu, S.; Luo, X.; Lin, R.; Zhang, L. Synthesis of indole-based functional polymers with well-defined structures via a catalyst-free $\mathrm{C}-\mathrm{N}$ coupling reaction. RSC Adv. 2014, 4, 30630-30637. [CrossRef]

45. Liu, C.; Wang, H.; Xing, X.; Xu, Y.; Ma, J.-A.; Zhang, B. Selective C4-F bond cleavage of pentafluorobenzene: Synthesis of $\mathrm{N}$-tetrafluoroarylated heterocyclic compounds. Tetrahedron Lett. 2013, 54, 4649-4652. [CrossRef]

46. Iqbal, M.A.; Mehmood, H.; Lv, J.; Hua, R. Base-Promoted $\mathrm{S}_{\mathrm{N}}$ Ar Reactions of Fluoro- and Chloroarenes as a Route to N-Aryl Indoles and Carbazoles. Molecules 2019, 24, 1145. [CrossRef]

47. Maiti, B.; Sun, C.-M. Novel Approach Towards the Synthesis of Skeletally Diverse Benzimidazole-pyrrolo[1,2-a]quinoxaline by $\mathrm{S}_{\mathrm{N}} \mathrm{Ar} /$ Pictet-Spengler Reaction under Focused Microwave Irradiation. New J. Chem. 2011, 35, 1385-1396. [CrossRef]

48. Ricci, P.; Krämer, K.; Cambeiro, X.C.; Larrosa, I. Arene-Metal $\pi$-Complexation as a Traceless Reactivity Enhancer for C-H Arylation. J. Am. Chem. Soc. 2013, 135, 13258-13261. [CrossRef]

49. Su, J.; Chen, Q.; Lu, L.; Ma, Y.; Auyoung, G.H.L.; Hua, R. Base-Promoted Nucleophilic Fluoroarenes Substitution of CF Bonds. Tetrahedron 2018, 74, 303-307. [CrossRef]

50. Tian, Z.-Y.; Ming, X.-X.; Teng, H.-B.; Hu, Y.-T.; Zhang, C.-P. Transition-Metal-Free N-Arylation of Amines by Triarylsulfonium Triflates. Chem. Eur. J. 2018, 24, 13744-13748. [CrossRef]

51. Xia, W.; An, Q.-J.; Xiang, S.-H.; Li, S.; Wang, Y.-B.; Tan, B. Chiral Phosphoric Acid Catalyzed Atroposelective C-H Amination of Arenes. Angew. Chem. Int. Ed. 2020, 59, 6775-6779. [CrossRef] [PubMed]

52. Chittimalla, S.K.; Nakka, S.; Koodalingam, M.; Bandi, C. N-Arylation of Heterocycles by a Tandem Aza-Michael Addition Reaction and Aromatization Sequence. Synlett 2018, 29, 57-64. [CrossRef]

53. Li, S.; Wu, X.-X.; Chen, S. Base-Promoted Direct Synthesis of Functionalized N-Arylindoles via the Cascade Reactions of Allenic Ketones with Indoles. Org. Biomol. Chem. 2019, 17, 789-793. [CrossRef] [PubMed] 
54. Rull, S.G.; Blandez, J.F.; Fructos, M.R.; Belderrain, T.R.; Nicasio, M.C. C-N Coupling of Indoles and Carbazoles with Aromatic Chlorides Catalyzed by a Single-Component NHC-Nickel(0) Precursor. Adv. Synth. Catal. 2015, 357, 907-911. [CrossRef]

55. Clark, J.S.K.; Voth, C.N.; Ferguson, M.J.; Stradiotto, M. Evaluating 1,1'-Bis(phosphino)ferrocene Ancillary Ligand Variants in the Nickel-Catalyzed C-N Cross-Coupling of (Hetero)aryl Chlorides. Organometallics 2017, 36, 679-686. [CrossRef]

56. Iranpoor, N.; Panahi, F. Direct Nickel-Catalyzed Amination of Phenols via C-O Bond Activation using 2,4,6-Trichloro-1,3,5-triazine (TCT) as Reagent. Adv. Synth. Catal. 2014, 356, 3067-3073. [CrossRef]

57. Morioka, T.; Nakatani, S.; Sakamoto, Y.; Kodama, T.; Ogoshi, S.; Chatani, N.; Tobisu, M. Nickel-Catalyzed Decarbonylation of N-Acylated N-Heteroarenes. Chem. Sci. 2019, 10, 6666-6671. [CrossRef]

58. Krishnaveni, T.; Lakshmi, K.; Kadirvelu, K.; Kaveri, M.V. Exploration of Catalytic Activity of Quercetin Mediated Hydrothermally Synthesized NiO Nanoparticles Towards C-N Coupling of Nitrogen Heterocycles. Catal. Lett. 2020, 150, 1628-1640. [CrossRef]

59. Gatien, A.V.; Lavoie, C.M.; Bennett, R.N.; Ferguson, M.J.; McDonald, R.; Johnson, E.R.; Speed, A.W.H.; Stradiotto, M. Application of Diazaphospholidine/Diazaphospholene-Based Bisphosphines in Room-Temperature Nickel-Catalyzed C(sp2)-N CrossCouplings of Primary Alkylamines with (Hetero)aryl Chlorides and Bromides. ACS Catal. 2018, 8, 5328-5339. [CrossRef]

60. Park, N.H.; Teverovskiy, G.; Buchwald, S.L. Development of an Air-Stable Nickel Precatalyst for the Amination of Aryl Chlorides, Sulfamates, Mesylates, and Triflates. Org. Lett. 2014, 16, 220-223. [CrossRef]

61. Liu, R.Y.; Dennis, J.M.; Buchwald, S.L. The Quest for the Ideal Base: Rational Design of a Nickel Precatalyst Enables Mild, Homogeneous C-N Cross-Coupling. J. Am. Chem. Soc. 2020, 142, 4500-4507. [CrossRef]

62. Sawatzky, R.S.; Ferguson, M.J.; Stradiotto, M. Thieme Chemistry Journals Awardees-Where Are They Now? Efficient CrossCoupling of Secondary Amines/Azoles and Activated (Hetero)Aryl Chlorides Using an Air-Stable DPEPhos/Nickel Pre-Catalyst. Synlett 2017, 28, 1586-1591.

63. Panahi, F.; Roozbin, F.; Rahimi, S.; Moayyed, M.; Valaei, A.; Iranpoor, N. A Triazine-Phosphite Polymeric Ligand Bearing Cage-Like $P, N$-Ligation Sites: An Efficient Ligand in the Nickel-Catalyzed Amination of Aryl Chlorides and Phenols. RSC Adv. 2016, 6, 80670-80678. [CrossRef]

64. Malapit, C.A.; Borrell, M.; Milbauer, M.W.; Brigham, C.E.; Sanford, M.S. Nickel-Catalyzed Decarbonylative Amination of Carboxylic Acid Esters. J. Am. Chem. Soc. 2020, 142, 5918-5923. [CrossRef]

65. Lokhandet, S.K.; Vaidyat, G.N.; Satpute, D.P.; Venkatesh, A.; Kumar, S.; Kumar, D. Structure Ligation Relationship of Amino Acids for the Selective Indole $\mathrm{C}-\mathrm{H}$ Arylation Reaction: L-Aspartic acid as Sustainable Alternative of Phosphine Ligands. Adv. Synth. Catal. 2020, 362, 2857-2863. [CrossRef]

66. Mohr, Y.; Renom-Carrasco, M.; Demarcy, C.; Quadrelli, E.A.; Camp, C.; Wisser, F.M.; Clot, E.; Thieuleux, C.; Canivet, J. Regiospecificity in Ligand-Free Pd-Catalyzed C-H Arylation of Indoles: LiHMDS as Base and Transient Directing Group. ACS Catal. 2020, 10, 2713-2719. [CrossRef]

67. Yamaguchi, M.; Suzuki, K.; Sato, Y.; Manabe, K. Palladium-Catalyzed Direct C3-Selective Arylation of N-Unsubstituted Indoles with Aryl Chlorides and Triflates. Org. Lett. 2017, 19, 5388-5391. [CrossRef] [PubMed]

68. Ye, Z.; Li, Y.; Xu, K.; Chen, N.; Zhang, F. Cascade $\pi$-Extended Decarboxylative Annulation Involving Cyclic Diaryliodonium Salts: Site-Selective Synthesis of Phenanthridines and Benzocarbazoles via a Traceless Directing Group Strategy. Org. Lett. 2019, 21, 9869-9873. [CrossRef] [PubMed]

69. Mayer, L.; Kohlbecher, R.; Müller, T.J.J. Concatenating Suzuki Arylation and Buchwald-Hartwig Amination by a Sequentially Pd-Catalyzed One-Pot Process-Consecutive Three-Component Synthesis of C,N-Diarylated Heterocycles. Chem. Eur. J. 2020, 26, 15130-15134. [CrossRef]

70. Chen, H.; Yang, H.; Li, N.; Xue, X.; He, Z.; Zeng, Q. Palladium-Catalyzed C-N Cross-Coupling of NH-Heteroarenes and Quaternary Ammonium Salts via C-N Bond Cleavage. Org.Process Res. Develop. 2019, 23, 1679-1685. [CrossRef]

71. Ye, X.; Huang, J.; Deng, Z.; Yuan, J.; Peng, Y. Palladium-Catalyzed Cross-Coupling Reactions of 4-Tosyl-oxyquinazolines with Indoles: An Efficient Approach to 4-(1H-Indol-1-yl)quinazolines. Synthesis 2021, 53, 383-390.

72. Choy, P.Y.; Chung, K.H.; Yang, Q.; So, C.M.; Sun, R.W.-Y.; Kwong, F.Y. A General Palladium-Phosphine Complex to Explore Aryl Tosylates in the N-Arylation of Amines: Scope and Limitations. Chem. Asian J. 2018, 13, 2465-2474. [CrossRef] [PubMed]

73. Chen, X.; Yang, Z.; Chen, X.; Liang, W.; Zhu, Z.; Xie, F.; Li, Y. Hydrogen-Transfer-Mediated N-Arylation of Naphthols Using Indolines as Hydrogen Donors. J. Org. Chem. 2020, 85, 508-514. [CrossRef] [PubMed]

74. Monguchi, Y.; Marumoto, T.; Takamatsu, H.; Sawama, Y.; Sajiki, H. Palladium on Carbon-Catalyzed One-Pot N-Arylindole Synthesis: Intramolecular Aromatic Amination, Aromatization, and Intermolecular Aromatic Amination. Adv. Synth. Catal. 2014, 356, 1866-1872. [CrossRef]

75. Crawford, S.M.; Lavery, C.B.; Stradiotto, M. BippyPhos: A Single Ligand With Unprecedented Scope in the Buchwald-Hartwig Amination of (Hetero)aryl Chlorides. Chem. Eur. J. 2013, 19, 16760-16771. [CrossRef] [PubMed]

76. Ghorbani-Vaghei, R.; Hemmati, S.; Hamelian, M.; Veisi, H. An Efficient, Mild and Selective Ullmann-Type N-Arylation of Indoles Catalysed by Pd Immobilized on Amidoxime-Functionalized Mesoporous SBA-15 as Heterogeneous and Recyclable Nanocatalyst. Appl. Organomet. Chem. 2015, 29, 195-199. [CrossRef]

77. Veisi, H.; Poor Heravi, M.R.; Hamelian, M. SBA-15-Functionalized Melamine-Pyridine Group-Supported Palladium(0) as an Efficient Heterogeneous and Recyclable Nanocatalyst for $\mathrm{N}$-Arylation of Indoles through Ullmann-Type Coupling Reactions. Appl. Organomet. Chem. 2015, 29, 334-337. [CrossRef] 
78. Veisi, H.; Morakabati, N. Palladium Nanoparticles Supported on Modified Single-Walled Carbon Nanotubes: A Heterogeneous and Reusable Catalyst in the Ullmann-Type N-Arylation of Imidazoles and Indoles. New J. Chem. 2015, 39, 2901-2907. [CrossRef]

79. Ghorbani-Vaghei, R.; Hemmati, S.; Hekmati, M. Pd Immobilized on Modified Magnetic $\mathrm{Fe}_{3} \mathrm{O}_{4}$ Nanoparticles: Magnetically Recoverable and Reusable Pd Nanocatalyst for Suzuki-Miyaura Coupling Reactions and Ullmann-Type N-Arylation of Indoles. J. Chem. Sci. 2016, 128, 1157-1162. [CrossRef]

80. Boyd, E.M.; Sperry, J. Total Synthesis of (-)-Aspergilazine A. Org. Lett. 2014, 16, 5056-5059. [CrossRef]

81. Hajipour, A.R.; Dordahan, F.; Rafiee, F. Synthesis of Tertiary Aryl Amines of Various Aryl Halides and Secondary Amines using Ortho-Palladated Complex of Tribenzylamine. Appl. Organomet. Chem. 2013, 27, 704-706. [CrossRef]

82. Monti, A.; Rama, R.J.; Gómez, B.; Maya, C.; Álvarez, E.; Carmona, E.; Nicasio, M.C. N-Substituted Aminobiphenyl Palladacycles Stabilized by Dialkylterphenyl Phosphanes: Preparation and Applications in CN Cross-Coupling Reactions. Inorg. Chim. Acta 2021, 518, 120214. [CrossRef]

83. Wagner, P.; Bollenbach, M.; Doebelin, C.; Bihel, F.; Bourguignon, J.-J.; Salomé, C.; Schmitt, M. t-BuXPhos: A Highly Efficient Ligand for Buchwald-Hartwig Coupling in Water. Green Chem. 2014, 16, 4170-4178. [CrossRef]

84. Izquierdo, J.; Jain, A.D.; Abdulkadir, S.A.; Schiltz, G.E. Palladium-Catalyzed Coupling Reactions on Functionalized 2Trifluoromethyl-4-chromenone Scaffolds: Synthesis of Highly Functionalized Trifluoromethyl Heterocycles. Synthesis 2019, 51, 1342-1352. [CrossRef] [PubMed]

85. Grimm, J.B.; Lavis, L.D. Synthesis of Rhodamines from Fluoresceins Using Pd-Catalyzed C-N Cross-Coupling. Org. Lett. 2011, 13, 6354-6357. [CrossRef]

86. Shimizu, K.; Minami, Y.; Goto, O.; Ikehira, H.; Hiyama, T. Silicon-based C-N Cross-coupling Reaction. Chem. Lett. 2014, 43, 438-440. [CrossRef]

87. Minami, Y.; Komiyama, T.; Shimizu, K.; Hiyama, T.; Goto, O.; Ikehira, H. Catalytic Carbon-Nitrogen Bond-Forming CrossCoupling Using N-Trimethylsilylamines. Bull. Chem. Soc. Japan 2015, 88, 1437-1446. [CrossRef]

88. Hosseini-Sarvari, M.; Razmi, Z. Highly Active Recyclable Heterogeneous Pd/ZnO Nanoparticle Catalyst: Sustainable Developments for the $\mathrm{C}-\mathrm{O}$ and $\mathrm{C}-\mathrm{N}$ Bond Cross-Coupling Reactions of Aryl Halides under Ligand-Free Conditions. RSC Adv. 2014, 4, 44105-44116. [CrossRef]

89. Fareghi-Alamdari, R.; Haqiqi, M.G.; Zekri, N. Immobilized Pd(0) Nanoparticles on Phosphine-Functionalized Graphene as a Highly Active Catalyst for Heck, Suzuki and N-Arylation Reactions. New J. Chem. 2016, 40, 1287-1296. [CrossRef]

90. Panahi, F.; Daneshgar, F.; Haghighi, F.; Khalafi-Nezhad, A. Immobilized Pd Nanoparticles on Silica-Starch Substrate (PNP-SSS): Efficient Heterogeneous Catalyst in Buchwald-Hartwig C-N Cross-Coupling Reaction. J. Organomet. Chem. 2017, 851, $210-217$. [CrossRef]

91. Yong, F.-F.; Teo, Y.-C.; Tay, S.-H.; Tan, B.Y.-H.; Lim, K.-H. A Ligand-Free Copper(I) Oxide Catalyzed Strategy for the N-Arylation of Azoles in Water. Tetrahedron Lett. 2011, 52, 1161-1164. [CrossRef]

92. Liu, L.; Wu, F.; Liu, Y.; Xie, J.; Dai, B.; Zhou, Z. Copper-Catalysed N-Arylation of Pyrrole with Aryl Iodides Under Ligand-Free Conditions. J. Chem. Res. 2019, 38, 180-182. [CrossRef]

93. Khalil, A.; Fihri, A.; Jouiad, M.; Hashaikeh, R. Electrospun Copper Oxide Nanoparticles as an Efficient Heterogeneous Catalyst for N-Arylation of Indole. Tetrahedron Lett. 2014, 55, 5973-5975. [CrossRef]

94. Amadine, O.; Maati, H.; Abdelouhadi, K.; Fihri, A.; El Kazzouli, S.; Len, C.; El Bouari, A.; Solhy, A. Ceria-Supported Copper Nanoparticles: A Highly Efficient and Recyclable Catalyst for N-Arylation of Indole. J. Mol. Cat. A-Chem. 2014, 395, 409-419. [CrossRef]

95. Chaudhary, K.; Subodh; Prakash, K.; Mogha, N.K.; Masram, D.T. Fruit Waste (Pulp) Decorated CuO NFs as Promising Platform for Enhanced Catalytic Response and Its Peroxidase Mimics Evaluation. Arab. J. Chem. 2020, 13, 4869-4881. [CrossRef]

96. Hemmati, S.; Mehrazin, L.; Hekmati, M.; Izadi, M.; Veisi, H. Biosynthesis of CuO Nanoparticles Using Rosa Canina Fruit Extract as a Recyclable and Heterogeneous Nanocatalyst for C-N Ullmann Coupling Reactions. Mater. Chem. Phys. 2018, 214, 527-532. [CrossRef]

97. Lim, J.; Kim, J.D.; Choi, H.C.; Lee, S. CNT-CuO Catalyzed C-N Bond Formation for N-Arylation of 2-Phenylindoles. J. Organomet. Chem. 2019, 902, 120970. [CrossRef]

98. Pai, G.; Chattopadhyay, A.P. Ligand-Free Copper Nanoparticle Promoted N-Arylation of Azoles with Aryl and Heteroaryl Iodides. Tetrahedron Lett. 2014, 55, 941-944. [CrossRef]

99. Suramwar, N.V.; Thakare, S.R.; Karade, N.N.; Khaty, N.T. Green Synthesis of Predominant (111) Facet CuO Nanoparticles: Heterogeneous and Recyclable Catalyst for N-Arylation of Indoles. J. Mol. Catal. A-Chem. 2012, 359, 28-34. [CrossRef]

100. Talukdar, D.; Das, G.; Thakur, S.; Karak, N.; Thakur, A.J. Copper Nanoparticle Decorated Organically Modified Montmorillonite (OMMT): An Efficient Catalyst for the N-Arylation of Indoles and Similar Heterocycles. Catal. Commun. 2015, 59, 238-243. [CrossRef]

101. Reddy, K.H.V.; Satish, G.; Ramesh, K.; Karnakar, K.; Nageswar, Y.V.D. An Efficient Synthesis of N-Substituted Indoles from Indoline/Indoline Carboxylic Acid via Aromatization Followed by $\mathrm{C}-\mathrm{N}$ Cross-Coupling Reaction by Using Nano Copper Oxide as a Recyclable Catalyst. Tetrahedron Lett. 2012, 53, 3061-3065. [CrossRef]

102. Patil, P.H.; Nallasivam, J.L.; Fernandes, R.A. Unimolecular 4-Hydroxypiperidines: New Ligands for Copper-Catalyzed NArylation. Asian J. Org. Chem. 2015, 4, 552-559. [CrossRef] 
103. Yang, X.; Xing, H.; Zhang, Y.; Lai, Y.; Zhang, Y.; Jiang, Y.; Ma, D. CuI/8-Hydroxyquinalidine Promoted N-Arylation of Indole and Azoles. Chin. J. Chem. 2012, 30, 875-880. [CrossRef]

104. Elliott, E.-C.; Maggs, J.L.; Park, B.K.; O’Neill, P.M.; Stachulski, A.V. Convenient Syntheses of Halo-dibenz[b,f]azepines and Carbamazepine Analogues via N-Arylindoles. Org. Biomol. Chem. 2013, 11, 8426-8434. [CrossRef] [PubMed]

105. Vaidya, G.N.; Khan, A.; Verma, H.; Kumar, S.; Kumar, D. Structure Ligation Relationship of Amino Acids for the Amination Cross-Coupling Reactions. J. Org. Chem. 2019, 84, 3004-3010. [CrossRef] [PubMed]

106. Chen, H.; Lei, M.; Hu, L. Synthesis of 1-Aryl Indoles via Coupling Reaction of Indoles and Aryl Halides Catalyzed by $\mathrm{CuI} /$ metformin. Tetrahedron 2014, 70, 5626-5631. [CrossRef]

107. Balalaie, S.; Bararjanian, M.; Hosseinzadeh, S.; Rominger, F.; Bijanzadeh, H.R.; Wolf, E. Designing a Sequential Ugi/Ullmann Type Reaction for the Synthesis of Indolo[1,2-a]quinoxalinones Catalyzed by CuI/1-Proline. Tetrahedron 2011, 67, 7294-7300. [CrossRef]

108. Zhang, L.; Zhao, F.; Zheng, M.; Zhai, Y.; Liu, H. Rapid and Selective Access to Three Distinct Sets of Indole-Based Heterocycles from a Single Set of Ugi-Adducts under Microwave Heating. Chem. Commun. 2013, 49, 2894-2896. [CrossRef]

109. Zhang, L.; Zheng, M.; Zhao, F.; Zhai, Y.; Liu, H. Rapid Generation of Privileged Substructure-Based Compound Libraries with Structural Diversity and Drug-Likeness. ACS Comb. Sci. 2014, 16, 184-191. [CrossRef] [PubMed]

110. Lee, J.; Choi, J.H.; Shin, S.; Heo, J.-N.; Lim, H.J. N-Arylation of Sterically Hindered NH-Nucleophiles: Copper-Mediated Syntheses of Diverse $\mathrm{N}$-Arylindole-2-carboxylates. Synthesis 2015, 47, 3301-3308. [CrossRef]

111. Lee, J.-H.; Kim, H.; Kim, T.; Song, J.H.; Kim, W.-S.; Ham, J. Functionalization of Organotrifluoroborates via Cu-Catalyzed C-N Coupling Reaction. Bull. KoreanChem. Soc. 2013, 34, 42-48. [CrossRef]

112. Liu, W.; Han, L.-Y.; Liu, R.-L.; Xu, L.-G.; Bi, Y.-L. Copper-Catalyzed N-Arylation of 2-Arylindoles with Aryl Halides. Chin. Chem. Lett. 2014, 25, 1240-1243. [CrossRef]

113. Rodrigues, M.B.; Feitosa, S.C.; Wiethan, C.W.; Rosa, W.C.; da Silveira, C.H.; Pagliari, A.B.; Martins, M.A.P.; Zanatta, N.; Iglesias, B.A.; Bonacorso, H.G. Ullmann-Type Copper-Catalyzed Coupling Amination, Photophysical and DNA/HSA-Binding Properties of New 4-(Trifluoromethyl)quinoline Derivatives. J. Fluor. Chem. 2019, 221, 84-90. [CrossRef]

114. Ghobrial, M.; Mihovilovic, M.D.; Schnurch, M. Exploration of C-H and N-H-Bond Functionalization Towards 1-(1,2-Diarylindol3-yl)tetrahydroisoquinolines. Beilstein J. Org. Chem. 2014, 10, 2186-2199. [CrossRef]

115. Yadav, D.K.T.; Rajak, S.S.; Bhanage, B.M. N-Arylation of Indoles with Aryl Halides Using Copper/Glycerol as a Mild and Highly Efficient Recyclable Catalytic System. Tetrahedron Lett. 2014, 55, 931-935. [CrossRef]

116. Wei, J.J.; Song, W.B.; Zhu, Y.F.; Wei, B.L.; Xuan, L.J. N,N-Dimethyl-d-glucosamine as an Efficient Ligand for Copper-Catalyzed Ullmann-Type Coupling of N-H Heterocycles with Aryl Halides. Tetrahedron 2018, 74, 19-27. [CrossRef]

117. Chen, Y.; Du, F.; Chen, F.; Zhou, Q.; Chen, G. Methyl- $\alpha$-d-glucopyranoside as Green Ligand for Selective Copper-Catalyzed N-Arylation. Synthesis 2019, 51, 4590-4600. [CrossRef]

118. Ge, X.; Zhang, S.; Chen, X.; Liu, X.; Qian, C. A Designed Bi-Functional Sugar-Based Surfactant: Micellar Catalysis for C-X Coupling Reaction in Water. Green Chem. 2019, 21, 2771-2776. [CrossRef]

119. Yuan, C.; Zhao, Y.; Zheng, L. $\alpha$-d-Galacturonic Acid as Natural Ligand for Selective Copper-Catalyzed N-Arylation of NContaining Heterocycles. Synlett 2019, 30, 2173-2180. [CrossRef]

120. Zhou, Q.; Du, F.; Chen, Y.; Fu, Y.; Sun, W.; Wu, Y.; Chen, G. L-(-)-Quebrachitol as a Ligand for Selective Copper(0)-Catalyzed $\mathrm{N}$-Arylation of Nitrogen-Containing Heterocycles. J. Org. Chem. 2019, 84, 8160-8167. [CrossRef]

121. Bollenbach, M.; Aquino, P.G.V.; de Araújo-Júnior, J.X.; Bourguignon, J.-J.; Bihel, F.; Salomé, C.; Wagner, P.; Schmitt, M. Efficient and Mild Ullmann-Type N-Arylation of Amides, Carbamates, and Azoles in Water. Chem. Eur. J. 2017, 23, 13676-13683. [CrossRef] [PubMed]

122. Liu, S.; Zhou, J. Aqueous Copper-Catalyzed N-Arylation of Indoles: The Surfactant Strategy. New J. Chem. 2013, 37, 2537-2540. [CrossRef]

123. Malavade, V.; Patil, M.; Patil, M. Scope, Kinetics, and Mechanism of "On Water" Cu Catalysis in the C-N Cross-Coupling Reactions of Indole Derivatives. Eur. J. Org. Chem. 2020, 561-569. [CrossRef]

124. Molaei, H.; Ghanbari, M.M. Practical Copper-Catalyzed N-Arylation of Amines with 20\% Aqueous Solution of $n$-Bu $\mathrm{HOH}_{4} \mathrm{Chin}$. Chem. Lett. 2012, 23, 301-304. [CrossRef]

125. Abele, E.; Abele, R. KOH/Adogen 464/Proline System for Highly Effective Cu-Catalyzed “On-Water" N-H Arylation of Heteroaromatic Compounds. Chem. Heterocycl. Com. 2013, 49, 1384-1386. [CrossRef]

126. Engel-Andreasen, J.; Shimpukade, B.; Ulven, T. Selective Copper Catalysed Aromatic N-Arylation in Water. Green Chem. 2013, 15, 336-340. [CrossRef]

127. Mukhopadhyay, C.; Tapaswi, P.K. Highly Efficient and Simple Catalytic System for the N-Arylation of Some Hindered AzaHeterocycles in Water. Synth. Commun. 2012, 42, 2217-2228. [CrossRef]

128. Salomé, C.; Wagner, P.; Bollenbach, M.; Bihel, F.; Bourguignon, J.-J.; Schmitt, M. Buchwald-Hartwig Reactions in Water Using Surfactants. Tetrahedron 2014, 70, 3413-3421. [CrossRef]

129. Teo, Y.-C.; Yong, F.-F.; Lim, G.S. A Manganese/Copper Bimetallic Catalyst for C-N Coupling Reactions under Mild Conditions in Water. Tetrahedron Lett. 2011, 52, 7171-7174. [CrossRef]

130. Zhou, G.; Chen, W.; Zhang, S.; Liu, X.; Yang, Z.; Ge, X.; Fan, H.-J. A Newly Designed Carbohydrate-Derived Alkylamine Promotes Ullmann Type C-N Coupling Catalyzed by Copper in Water. Synlett 2019, 30, 193-198. 
131. Zhou, Q.; Du, F.; Chen, Y.; Fu, Y.; Chen, G. “On Water” Promoted N-Arylation Reactions Using Cu (0)/Myo-inositol Catalytic System. Tetrahedron Lett. 2019, 60, 1938-1941. [CrossRef]

132. Damkaci, F.; Alawaed, A.; Vik, E. N-Picolinamides as Ligands for Ullmann-type CN Coupling Reactions. Tetrahedron Lett. 2016, 57, 2197-2200. [CrossRef]

133. Su, J.; Qiu, Y.; Jiang, S.; Zhang, D. New Ligands for Copper-Catalyzed C-N Coupling Reactions at Gentle Temperature. Chin. J. Chem. 2014, 32, 685-688. [CrossRef]

134. Yang, K.; Qiu, Y.; Li, Z.; Wang, Z.; Jiang, S. Ligands for Copper-Catalyzed C-N Bond Forming Reactions with 1 Mol\% CuBr as Catalyst. J. Org. Chem. 2011, 76, 3151-3159. [CrossRef]

135. Wang, Y.; Zhang, Y.; Yang, B.; Zhang, A.; Yao, Q. N-(1-Oxy-2-picolyl)oxalamic Acids as a New Type of $O, O-L i g a n d s$ for the Cu-Catalyzed N-Arylation of Azoles with Aryl Halides in Water or Organic solvent. Org. Biomol. Chem. 2015, 13, 4101-4114. [CrossRef]

136. Taywade, A.; Chavan, S.; Ulhe, A.; Berad, B. Unique CuI-Pyridine Based Ligands Catalytic Systems for N-Arylation of Indoles and Other Heterocycles. Synth. Commun. 2018, 48, 1443-1453. [CrossRef]

137. Echeverry-Gonzalez, C.A.; Ortiz Villamizar, M.C.; Kouznetsov, V.V. The Remarkable Selectivity of the 2-Arylquinoline-Based Acyl Hydrazones Toward Copper Salts: Exploration of Their Catalytic Applications in the Copper Catalysed N-Arylation of Indole Derivatives and C1-Alkynylation of Tetrahydroisoquinolines via the A3 Reaction. New J. Chem. 2021, 45, 243-250.

138. Abe, T.; Takahashi, Y.; Matsubara, Y.; Yamada, K. An Ullmann N-Arylation/2-Amidation Cascade by Self-Relay Copper Catalysis: One-Pot Synthesis of Indolo[1,2-a]quinazolinones. Org. Chem. Front. 2017, 4, 2124-2127. [CrossRef]

139. Ghosh, T.; Maity, P.; Ranu, B.C. Cobalt-Copper Catalyzed C(sp2)—N Cross Coupling of Amides or Nitrogenated Heterocycles with Styrenyl or Aryl Halides. ChemistrySelect 2018, 3, 4406-4412. [CrossRef]

140. Mostafa, M.A.B.; Calder, E.D.D.; Racys, D.T.; Sutherland, A. Intermolecular Aryl C-H Amination through Sequential Iron and Copper Catalysis. Chem. Eur. J. 2017, 23, 1044-1047. [CrossRef] [PubMed]

141. Sadhu, P.; Punniyamurthy, T. Copper(ii)-Mediated Regioselective N-Arylation of Pyrroles, Indoles, Pyrazoles and Carbazole via Dehydrogenative Coupling. Chem. Commun. 2016, 52, 2803-2806. [CrossRef] [PubMed]

142. Pradhan, S.; De, P.B.; Punniyamurthy, T. Copper(II)-Mediated Chelation-Assisted Regioselective N-Naphthylation of Indoles, Pyrazoles and Pyrrole through Dehydrogenative Cross-Coupling. J. Org. Chem. 2017, 82, 4883-4890. [CrossRef] [PubMed]

143. Zhang, Y.; Hu, Z.-Y.; Li, X.-C.; Guo, X.-X. Copper-Catalyzed Decarboxylative N-Arylation of Indole-2-carboxylic Acids. Synthesis 2019, 51, 1803-1808. [CrossRef]

144. Petiot, P.; Dansereau, J.; Gagnon, A. Copper-Catalyzed N-Arylation of Azoles and Diazoles Using Highly Functionalized Trivalent Organobismuth Reagents. RSC Adv. 2014, 4, 22255-22259. [CrossRef]

145. Hébert, M.; Petiot, P.; Benoit, E.; Dansereau, J.; Ahmad, T.; Le Roch, A.; Ottenwaelder, X.; Gagnon, A. Synthesis of Highly Functionalized Triarylbismuthines by Functional Group Manipulation and Use in Palladium- and Copper-Catalyzed Arylation Reactions. J. Org. Chem. 2016, 81, 5401-5416. [CrossRef]

146. Jadhav, B.D.; Pardeshi, S.K. A Facile and Practical Copper Diacetate Mediated, Ligand Free C-N Cross Coupling of Trivalent Organobismuth Compounds with Amines and N-heteroarenes. RSC Adv. 2016, 6, 14531-14537. [CrossRef]

147. Le Roch, A.; Hébert, M.; Gagnon, A. Copper-Promoted O-Arylation of the Phenol Side Chain of Tyrosine Using Triarylbismuthines. Eur. J. Org. Chem. 2020, 5363-5367. [CrossRef]

148. Le Roch, A.; Chan, H.-C.; Gagnon, A. Copper-Promoted N-Arylation of the Indole Side Chain of Tryptophan Using Triarylbismuthines. Eur. J. Org. Chem. 2020, 5815-5819. [CrossRef]

149. Alonso, I.; Alvarez, R.; de Lera, Á.R. Indole-Indole Ullmann Cross-Coupling for $\mathrm{C}_{\mathrm{Ar}}-\mathrm{N}$ Bond Formation: Total Synthesis of (-)-Aspergilazine A. Eur. J. Org. Chem. 2017, 4948-4954. [CrossRef]

150. Modha, S.G.; Greaney, M.F. Atom-Economical Transformation of Diaryliodonium Salts: Tandem C-H and N-H Arylation of Indoles. J. Am. Chem. Soc. 2015, 137, 1416-1419. [CrossRef]

151. Ziegler, D.T.; Choi, J.; Muñoz-Molina, J.M.; Bissember, A.C.; Peters, J.C.; Fu, G.C. A Versatile Approach to Ullmann C-N Couplings at Room Temperature: New Families of Nucleophiles and Electrophiles for Photoinduced, Copper-Catalyzed Processes. J. Am. Chem. Soc. 2013, 135, 13107-13112. [CrossRef]

152. Guo, S.; Liu, Y.; Zhang, X.; Fan, X. Iridium-Catalyzed Oxidative Annulation of 2-Arylindoles with Benzoquinone Leading to Indolo[1,2-f]phenanthridin-6-ols. Adv. Synth. Catal. 2020, 362, 3011-3020. [CrossRef]

153. Kong, L.; Sun, Y.; Zheng, Z.; Tang, R.; Wang, M.; Li, Y. Chemoselective N-H or C-2 Arylation of Indole-2-carboxamides: Controllable Synthesis of Indolo[1,2-a]quinoxalin-6-ones and 2,3'-Spirobi[indolin]-2'-ones. Org. Lett. 2018, 20, 5251-5255. [CrossRef]

154. Liu, X.; Cao, Z.; Huang, H.; Liu, X.; Tan, Y.; Chen, H.; Pei, Y.; Tan, S. Novel D-D- $\pi$-A Organic Dyes Based on Triphenylamine and Indole-Derivatives for High Performance Dye-Sensitized Solar Cells. J. Power Sources 2014, 248, 400-406. [CrossRef]

155. Keruckas, J.; Grazulevicius, J.V.; Volyniuk, D.; Cherpak, V.; Stakhira, P. 3,6-Bis(indol-1-yl)-9-phenylcarbazoles as Electroactive Materials for Electrophosphorescent Diodes. Dye. Pigment. 2014, 100, 66-72. [CrossRef]

156. Hussain, F.; Wang, X.; Wang, S. Impact of Bidentate N,C-Chelate Ligands on the Performance of Phosphorescent Pt(II) Complexes as Oxygen Sensors. J. Organomet. Chem. 2019, 880, 300-311. [CrossRef]

157. Xiang, N.; Gao, Z.; Tian, G.; Chen, Y.; Liang, W.; Huang, J.; Dong, Q.; Wong, W.-Y.; Su, J. Novel Fluorene/Indole-Based Hole Transport Materials with High Thermal Stability for Efficient OLEDs. Dye. Pigment. 2017, 137, 36-42. [CrossRef] 
158. Jia, B.; Lian, H.; Chen, Z.; Chen, Y.; Huang, J.; Dong, Q. Novel Carbazole/Indole/Thiazole-Based Host Materials with High Thermal Stability for Efficient Phosphorescent Organic Light-Emitting Diodes. Dye. Pigment. 2017, 147, 552-559. [CrossRef]

159. Selvam, R.; Subramanian, K. Benzimidazole-Indole-Chalcone Connected Methacrylate-Based Side Chain D- $\pi$-A Polymer and Its Application in Organic Photovoltaics. J. Polym. Sci. A Polym. Chem. 2017, 55, 997-1007. [CrossRef]

160. Chen, Y.; Xie, J.; Wang, Z.; Cao, J.; Chen, H.; Huang, J.; Zhang, J.; Su, J. Highly Efficient Bipolar Host Material Based-on Indole and Triazine Moiety for Red Phosphorescent Light-Emitting Diodes. Dye. Pigment. 2016, 124, 188-195. [CrossRef]

161. Crocetti, L.; Schepetkin, I.A.; Ciciani, G.; Giovannoni, M.P.; Guerrini, G.; Iacovone, A.; Khlebnikov, A.I.; Kirpotina, L.N.; Quinn, M.T.; Vergelli, C. Synthesis and Pharmacological Evaluation of Indole Derivatives as Deaza Analogues of Potent Human Neutrophil Elastase Inhibitors. Drug Develop. Res. 2016, 77, 285-299. [CrossRef]

162. Hirayama, T.; Okaniwa, M.; Imada, T.; Ohashi, A.; Ohori, M.; Iwai, K.; Mori, K.; Kawamoto, T.; Yokota, A.; Tanaka, T.; et al. Synthetic Studies of Centromere-Associated Protein-E (CENP-E) Inhibitors: 1. Exploration of Fused Bicyclic Core Scaffolds Using Electrostatic Potential Map. Bioorg. Med. Chem. 2013, 21, 5488-5502. [CrossRef]

163. Alonso, J.A.; Andrés, M.; Bravo, M.; Buil, M.A.; Calbet, M.; Castro, J.; Eastwood, P.R.; Eichhorn, P.; Esteve, C.; Gómez, E.; et al Structure-Activity Relationships (SAR) and Structure-Kinetic Relationships (SKR) of Bicyclic Heteroaromatic Acetic Acids as Potent CRTh2 Antagonists I. Bioorg. Med. Chem. Lett. 2014, 24, 5118-5122. [CrossRef] [PubMed]

164. Bzeih, T.; Lamaa, D.; Frison, G.; Hachem, A.; Jaber, N.; Bignon, J.; Retailleau, P.; Alami, M.; Hamze, A. Csp2-Csp2 and Csp2-N Bond Formation in a One-Pot Reaction between $N$-Tosylhydrazones and Bromonitrobenzenes: An Unexpected Cyclization to Substituted Indole Derivatives. Org. Lett. 2017, 19, 6700-6703. [CrossRef]

165. Zhang, Q.; Zhong, Y.; Yan, L.-N.; Sun, X.; Gong, T.; Zhang, Z.-R. Synthesis and Preliminary Evaluation of Curcumin Analogues as Cytotoxic Agents. Bioorg. Med. Chem. Lett. 2011, 21, 1010-1014. [CrossRef]

166. Bao, X.; Zhu, W.; Yuan, W.; Zhu, X.; Yan, Y.; Tang, H.; Chen, Z. Design, Synthesis and Evaluation of Novel Potent Angiotensin II Receptor 1 Antagonists. Eur. J. Med. Chem. 2016, 123, 115-127. [CrossRef] [PubMed]

167. Wu, Z.; Anh, N.T.P.; Yan, Y.-J.; Xia, M.-B.; Wang, Y.-H.; Qiu, Y.; Chen, Z.-L. Design, Synthesis and Biological Evaluation of AT1 Receptor Blockers Derived from 6-Substituted Aminocarbonyl Benzimidazoles. Eur. J. Med. Chem. 2019, 181, 111553. [CrossRef] [PubMed]

168. Zhu, W.; Bao, X.; Ren, H.; Da, Y.; Wu, D.; Li, F.; Yan, Y.; Wang, L.; Chen, Z. N-Phenyl Indole Derivatives as AT1 Antagonists with Anti-Hypertension Activities: Design, Synthesis and Biological Evaluation. Eur. J. Med. Chem. 2016, 115, 161-178. [CrossRef]

169. Zhu, W.; Bao, X.; Ren, H.; Liao, P.; Zhu, W.; Yan, Y.; Wang, L.; Chen, Z. Design, Synthesis, and Pharmacological Evaluation of 5-oxo-1,2,4-oxadiazole Derivatives as AT1 Antagonists with Antihypertension Activities. Clin. Exp. Hypertens. 2016, 38, 435-442. [CrossRef]

170. Zhu, W.; Da, Y.; Wu, D.; Zheng, H.; Zhu, L.; Wang, L.; Yan, Y.; Chen, Z. Design, Synthesis and Biological Evaluation of New 5-Nitro Benzimidazole Derivatives as AT1 Antagonists with Anti-Hypertension Activities. Bioorg. Med. Chem. 2014, 22, $2294-2302$. [CrossRef]

171. Thiyagamurthy, P.; Teja, C.; Naresh, K.; Gomathi, K.; Nawaz Khan, F.-R. Design, Synthesis and in Silico Evaluation of Benzoxazepino(7,6-b)quinolines as Potential Antidiabetic Agents. Med. Chem. Res. 2020, 29, 1882-1901. [CrossRef]

172. Nandwana, N.K.; Singh, R.P.; Patel, O.P.S.; Dhiman, S.; Saini, H.K.; Jha, P.N.; Kumar, A. Design and Synthesis of Imidazo/Benzimidazo[1,2-c]quinazoline Derivatives and Evaluation of Their Antimicrobial Activity. ACS Omega 2018, 3, 16338-16346. [CrossRef]

173. Miller, L.M.; Keune, W.-J.; Castagna, D.; Young, L.C.; Duffy, E.L.; Potjewyd, F.; Salgado-Polo, F.; Engel García, P.; Semaan, D.; Pritchard, J.M.; et al. Structure-Activity Relationships of Small Molecule Autotaxin Inhibitors with a Discrete Binding Mode. J. Med. Chem. 2017, 60, 722-748. [CrossRef]

174. Xu, G.; Liu, T.; Zhou, Y.; Yang, X.; Fang, H. 1-Phenyl-1H-indole Derivatives as a New Class of Bcl-2/Mcl-1 Dual Inhibitors: Design, Synthesis, and Preliminary Biological Evaluation. Bioorg. Med. Chem. 2017, 25, 5548-5556. [CrossRef]

175. Fox, B.M.; Beck, H.P.; Roveto, P.M.; Kayser, F.; Cheng, Q.; Dou, H.; Williamson, T.; Treanor, J.; Liu, H.; Jin, L.; et al. A Selective Prostaglandin E2 Receptor Subtype 2 (EP2) Antagonist Increases the Macrophage-Mediated Clearance of Amyloid-Beta Plaques. J. Med. Chem. 2015, 58, 5256-5273. [CrossRef] [PubMed]

176. Quirit, J.G.; Lavrenov, S.N.; Poindexter, K.; Xu, J.; Kyauk, C.; Durkin, K.A.; Aronchik, I.; Tomasiak, T.; Solomatin, Y.A.; Preobrazhenskaya, M.N.; et al. Indole-3-carbinol (I3C) Analogues are Potent Small Molecule Inhibitors of NEDD4-1 Ubiquitin Ligase Activity that Disrupt Proliferation of Human Melanoma Cells. Biochem. Pharmacol. 2017, 127, 13-27. [CrossRef]

177. Giordanetto, F.; Knerr, L.; Nordberg, P.; Pettersen, D.; Selmi, N.; Beisel, H.-G.; de la Motte, H.; Månsson, Å.; Dahlström, M.; Broddefalk, J.; et al. Design of Selective sPLA2-X Inhibitor (-)-2-\{2-[Carbamoyl-6-(trifluoromethoxy)-1H-indol-1-yl]pyridine-2yl\}propanoic Acid. ACS Med. Chem. Lett. 2018, 9, 600-605. [CrossRef] [PubMed]

178. Knerr, L.; Giordanetto, F.; Nordberg, P.; Pettersen, D.; Selmi, N.; Beisel, H.-G.; de la Motte, H.; Olsson, T.; Perkins, T.D.J.; Herslöf, M.; et al. Discovery of a Series of Indole-2-Carboxamides as Selective Secreted Phospholipase A2 Type X (sPLA2-X) Inhibitors. ACS Med. Chem. Lett. 2018, 9, 594-599. [CrossRef] [PubMed]

179. Abate, C.; Pati, M.L.; Contino, M.; Colabufo, N.A.; Perrone, R.; Niso, M.; Berardi, F. From Mixed Sigma-2 Receptor/P-Glycoprotein Targeting Agents to Selective P-Glycoprotein Modulators: Small Structural Changes Address the Mechanism of Interaction at the Efflux Pump. Eur. J. Med. Chem. 2015, 89, 606-615. [CrossRef] [PubMed] 
180. Pati, M.L.; Abate, C.; Contino, M.; Ferorelli, S.; Luisi, R.; Carroccia, L.; Niso, M.; Berardi, F. Deconstruction of 6,7-Dimethoxy1,2,3,4-tetrahydroisoquinoline Moiety to Separate P-Glycoprotein (P-gp) Activity from $\sigma 2$ Receptor Affinity in Mixed P-gp/ $\sigma 2$ Receptor Agents. Eur. J. Med. Chem. 2015, 89, 691-700. [CrossRef] [PubMed]

181. Tomoo, T.; Nakatsuka, T.; Katayama, T.; Hayashi, Y.; Fujieda, Y.; Terakawa, M.; Nagahira, K. Design, Synthesis, and Biological Evaluation of 3-(1-Aryl-1H-indol-5-yl)propanoic Acids as New Indole-Based Cytosolic Phospholipase A2 $\alpha$ Inhibitors. J. Med. Chem 2014, 57, 7244-7262. [CrossRef]

182. Uno, T.; Kawai, Y.; Yamashita, S.; Oshiumi, H.; Yoshimura, C.; Mizutani, T.; Suzuki, T.; Chong, K.T.; Shigeno, K.; Ohkubo, M.; et al. Discovery of 3-Ethyl-4-(3-isopropyl-4-(4-(1-methyl-1H-pyrazol-4-yl)-1H-imidazol-1-yl)-1H-pyrazolo[3,4-b]pyridin-1yl)benzamide (TAS-116) as a Potent, Selective, and Orally Available HSP90 Inhibitor. J. Med. Chem. 2019, 62, 531-551. [CrossRef] [PubMed] 